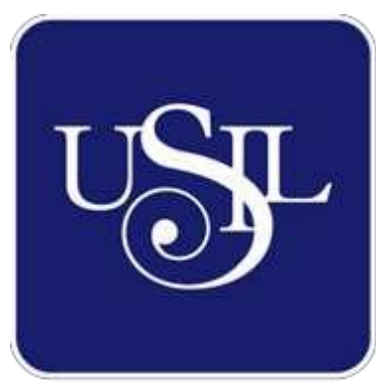

UNIVERSIDAD

SAN IGNACIO

DE LOYOLA

ESCUELA DE POSTGRADO DE LA

UNIVERSIDAD SAN IGNACIO DE LOYOLA

Maestría en Gestión de Negocios de Nutrición

\title{
PLAN DE NEGOCIOS DE COMIDA RÁPIDA SALUDABLE EN LIMA METROPOLITANA 2016
}

Tesis para optar el Grado de Maestro en Gestión de Negocios de Nutrición

GIANINA PAMELA CABRERA SIPIRAN IVANNA NANCY PISFIL DÍAZ

Asesor:

María Teresa Blanco de Alvarado - Ortiz

Lima - Perú

2018 


\section{PLAN DE NEGOCIOS DE}

COMIDA RÁPIDA SALUDABLE EN

LIMA METROPOLITANA 2016 


\section{RESUMEN EJECUTIVO}

La propuesta de fast food saludable, ofrece al consumidor en Lima Moderna una alternativa de tener rápido acceso a consumir bebidas y platos agradables teniendo conocimiento del valor calórico y nutricional que estos aportan y a un precio acorde al mercado, favoreciendo la salud y necesidades del consumidor.

Se ofrecerá una carta elaborada por la o el nutricionista y la o el chef, la cual tiene una variedad y nuevas opciones de bebidas y platos agradables, atractivos y sobre todo saludables y se caracterizan por el contenido de nutrientes a base de alimentos $100 \%$ naturales, orgánicos y productos elaborados libres de gluten y/o azúcares refinados como las verduras, hortalizas, frutas frescas, zumos, alimentos de origen animal y/o vegetal, entre otros. Adicional a la carta, se ofrecerá postres veganos, integrales y orgánicos, de Vegánimo, empresa socia y comprometida con la salud y el medio ambiente.

Para la implementación del negocio se requiere una inversión total de 157 632,80 soles; del cual el 35,6\% (56 174,80 soles) será financiado por una entidad financiera y el 64,4\% restante (101 458 soles) es la inversión económica. Se contará con un equipo capacitado para realizar sus respectivas funciones y que vivan un estilo wellnes para transmitir los principios de Healthy Corner. 


\section{ÍNDICE}

INTRODUCCIÓN

CAPÍTULO I: GENERALIDADES.............................................................................. 16

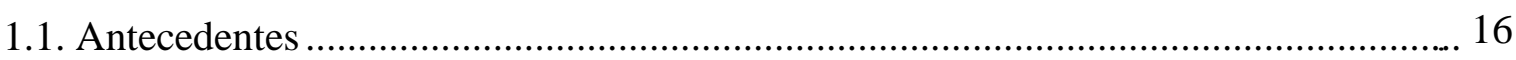

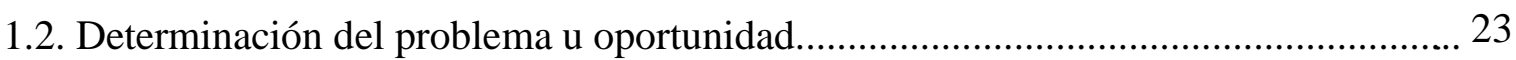

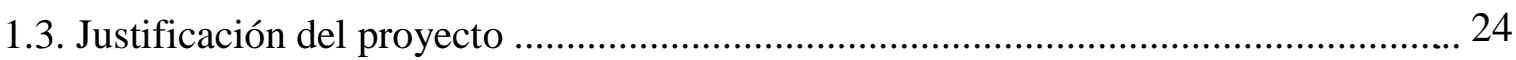

1.4. Objetivos generales y específicos .................................................. 25

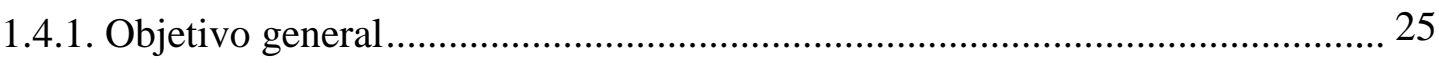

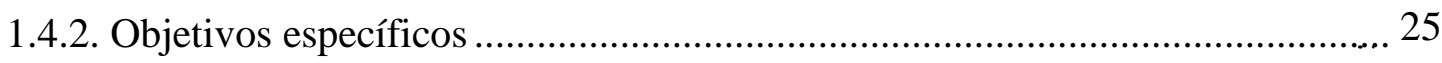

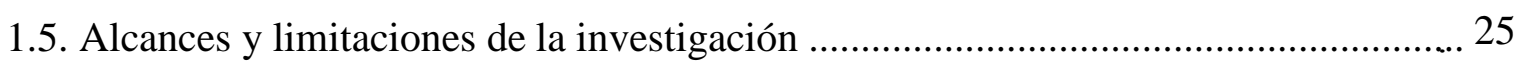

CAPÍTULO II: ANÁLISIS DEL ENTORNO ...................................... 26

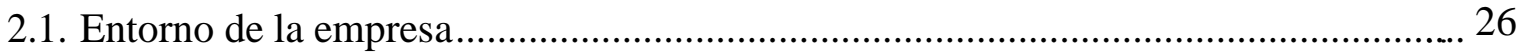

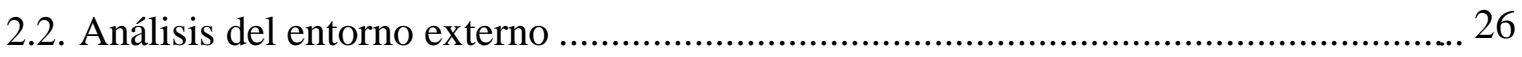

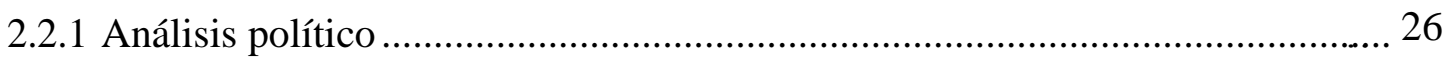

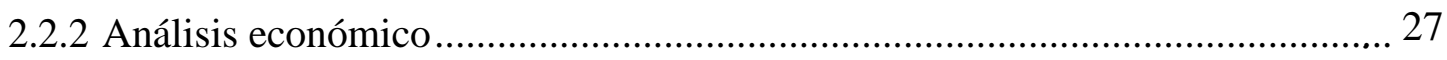

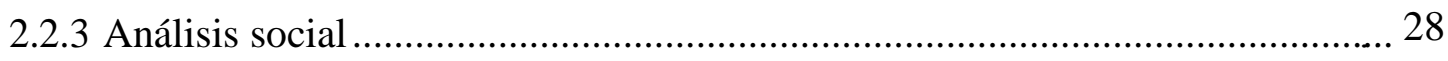

2.2.4 Análisis tecnológico .................................................... 28

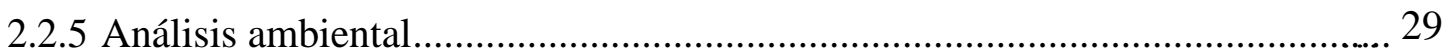

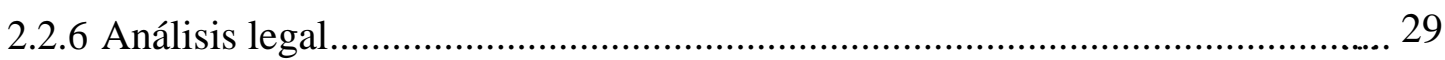

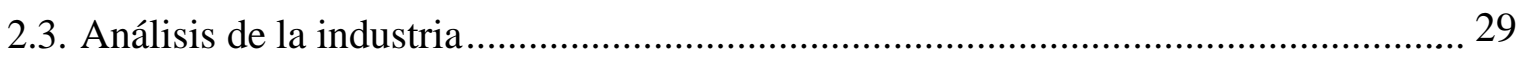

2.3.1 Poder de negociación de los proveedores ....................................................... 30

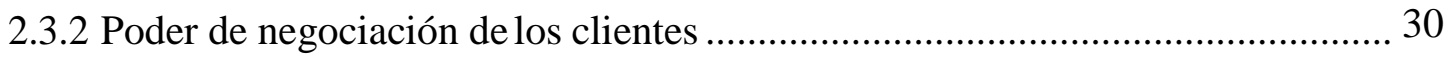

2.3.3 Amenazas de competidores potenciales ………………............................. 31

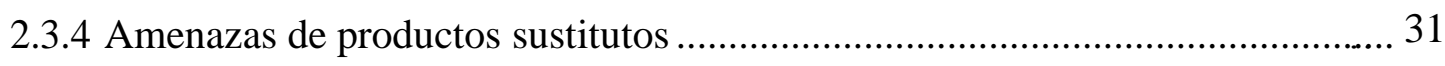


2.3.5 Rivalidad entre competidores actuales

31

2.4. Tendencias de la industria (crecimiento, inversiones, consumidores) 33

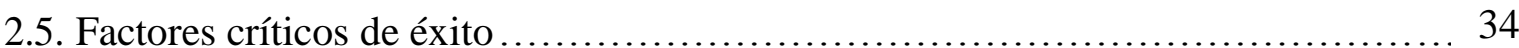

2.6. Análisis de la competencia ........................................... 35

2.6.1. Empresas que ofrecen el mismo producto o servicio, indicando las semejanzas y diferencias que tienen con el proyecto de empresa............ 36

2.6.2. Matriz de perfil competitivo ........................................... 39

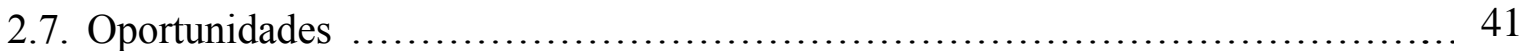

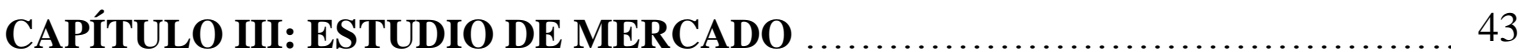

3.1. Descripción del servicio o producto ..................................... 43

3.2. Selección del segmento de mercado ......................................... 47

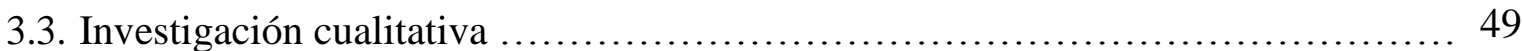

3.3.1. Selección del método de indagación ....................................... 49

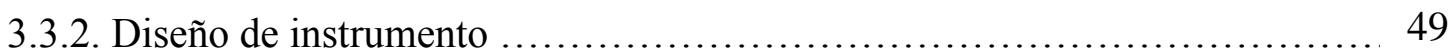

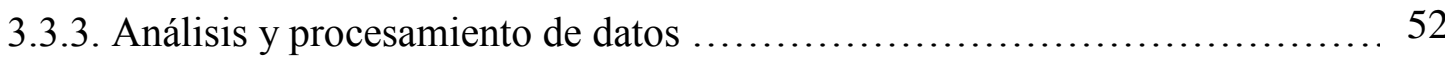

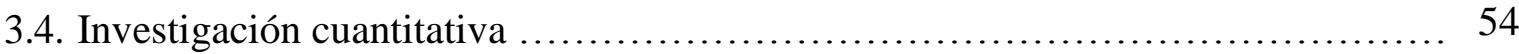

3.4.1. Proceso de muestreo.................................................. 54

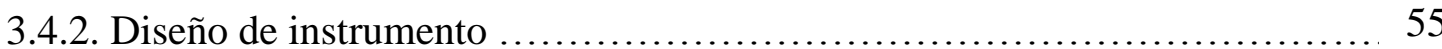

3.4.3. Análisis y procesamiento de datos ..................................... 55

3.5. Conclusiones y recomendaciones del estudio cualitativo y cuantitativo ............. 65

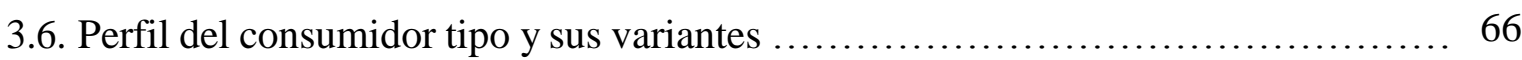

CAPÍTULO IV: PROYECCIÓN DEL MERCADO OBJETIVO .................. 68

4.1. El ámbito de la proyección ................................................ 68

4.2. Selección del método de proyección ...................................... 68 
4.2.1. Mercado potencial ............................................... 68

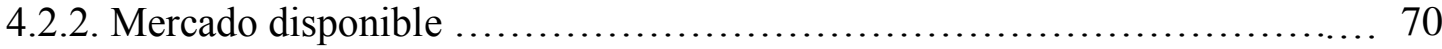

4.2.3. Mercado efectivo ................................................. 70

4.2.4. Mercado objetivo .............................................. 71

4.3. Pronóstico de ventas ................................................... 71

4.4. Aspectos críticos que impactan el pronóstico de ventas ........................ 72

CAPÍTULO V: INGENIERÍA DEL PROYECTO ............................. 73

5.1. Estudio de ingeniería .................................................. 73

5.1.1. Modelamiento y selección de procesos productivos .................... 73

5.1.2. Selección del equipamiento ................................... 77

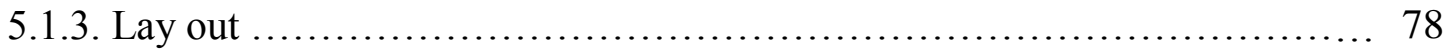

5.1.4. Distribución de equipos y maquinarias ............................... 80

5.2. Determinación del tamaño ............................................... 80

5.2.1. Proyección de crecimiento ..................................... 80

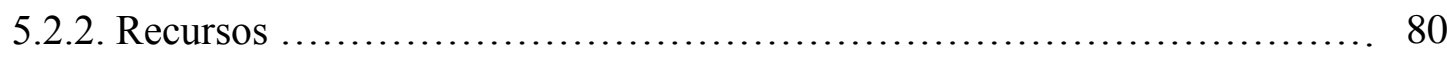

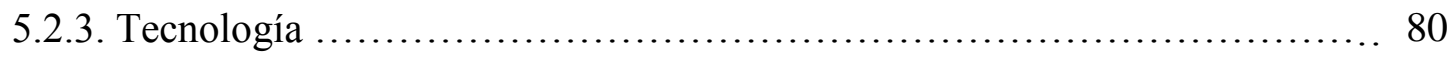

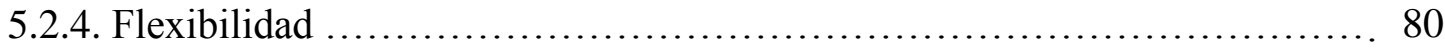

5.2.5. Selección del tamaño ideal .......................................... 81

5.3. Estudio de localización ............................................... 81

5.3.1. Definición de factores locacionales ............................... 81

5.3.2. Consideraciones legales ...................................... 82

5.3.2.1. Identificación del marco legal ................................ 82

5.3.2.2. Ordenamiento jurídico de la empresa ......................... 82

5.4. Determinación de la localización óptima $\ldots \ldots \ldots \ldots \ldots \ldots \ldots \ldots \ldots \ldots \ldots \ldots \ldots \ldots, 84$ 
CAPÍTULO VI: ASPECTOS ORGANIZACIONALES ............................................... 86

6.1. Caracterización de la cultura organizacional deseada ............................................... 86

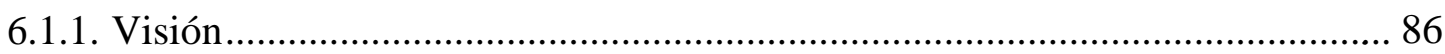

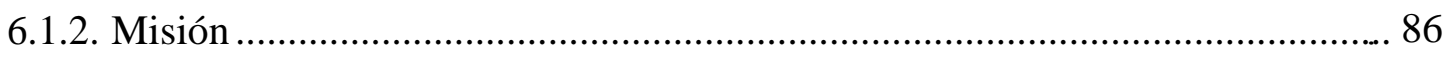

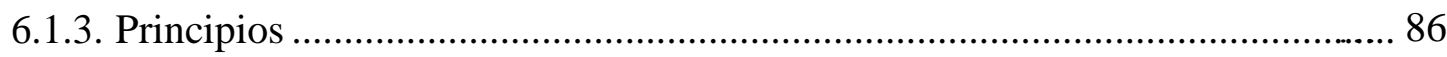

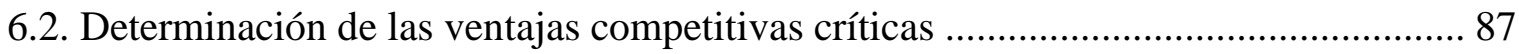

6.3. Diseño de la estructura organizacional deseada.................................................... 87

6.4. Diseño de los perfiles de puestos clave .................................. 88

6.5. Remuneraciones, compensaciones e incentivos .............................................. 92

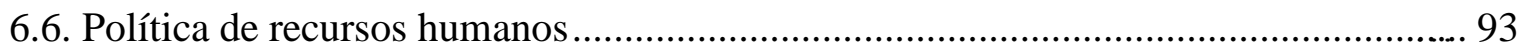

CAPÍTULO VII: PLAN DE MARKETING ................................................................. 94

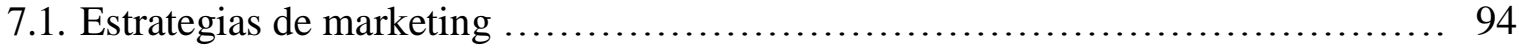

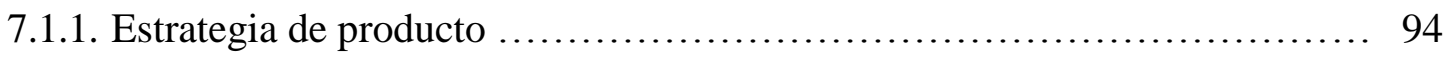

7.1.2. Estrategia de precio .......................................... 96

7.1.3. Estrategia de distribución ........................................ 98

7.1.4. Estrategia de promoción y publicidad ............................ 98

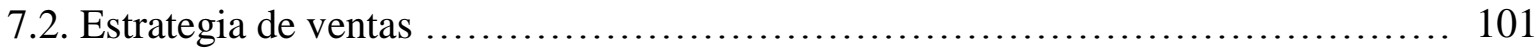

7.2.1. Plan de ventas .................................................... 102

7.2.2. Políticas de servicios y garantías ................................. 102

CAPÍTULO VIII: PLANIFICACIÓN FINANCIERA ....................... 103

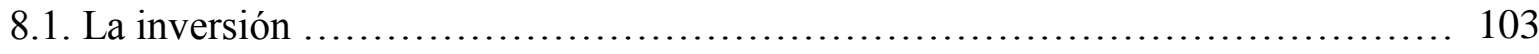

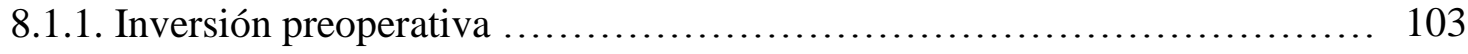

8.1.2. Inversión en capital de trabajo ...................................... 104

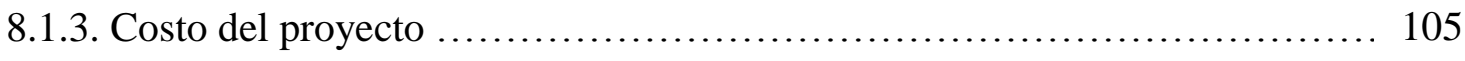

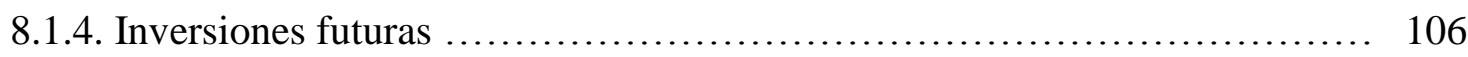


8.2. Financiamiento ...................................................... 106

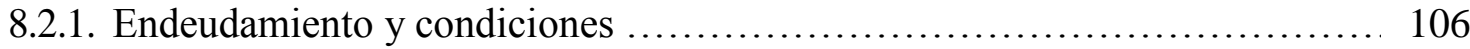

8.2.2. Capital y costo de oportunidad ...................................... 106

8.2.3. Costo de capital promedio ponderado ............................... 107

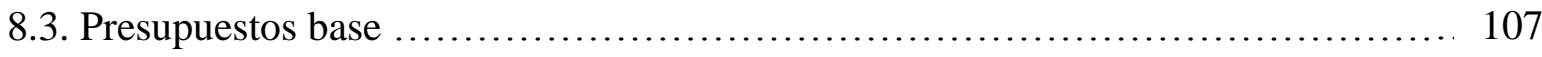

8.3.1. Presupuesto de ventas ........................................... 107

8.3.2. Presupuesto de costos de producción $\ldots \ldots \ldots \ldots \ldots \ldots \ldots \ldots \ldots \ldots \ldots \ldots \ldots \ldots . \ldots \ldots$

8.3.3. Presupuesto de compras ............................................ 108

8.3.4. Presupuesto de costo de ventas .................................... 109

8.3.5. Presupuesto de gastos administrativos ............................. 109

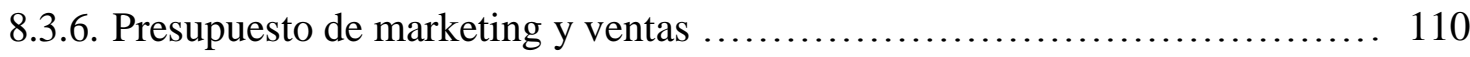

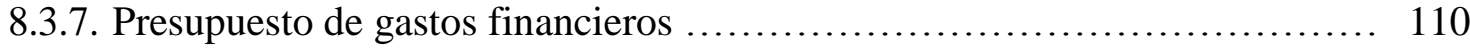

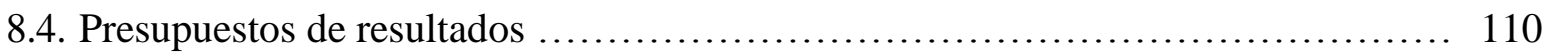

8.4.1. Estado de ganancias y pérdidas proyectado ........................... 111

8.4.2. Balance proyectado .......................................... 112

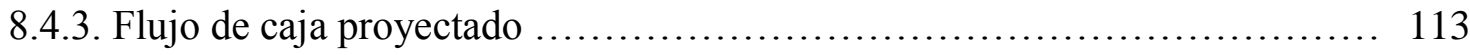

CAPÍTULO IX: EVALUACIÓN ECONÓMICO FINANCIERA ................ 114

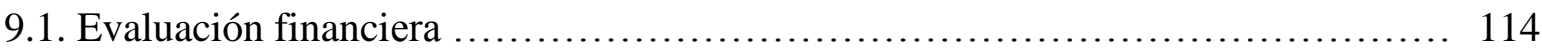

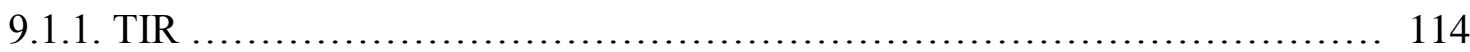

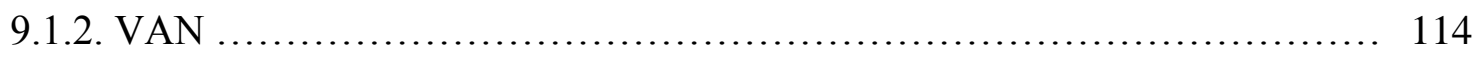

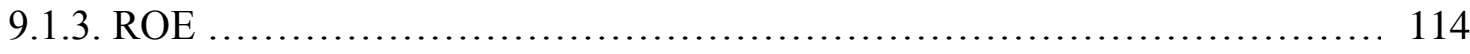

9.1.4. Ratios ........................................................ 115

9.2. Análisis de riesgo ..................................................... 115

9.2.1. Análisis de punto de equilibrio ................................... 115

9.2.2. Análisis de sensibilidad ........................................ 116 
9.2.3. Análisis de escenarios

10.1. Definición del modelo de negocio Canvas

10.2. Componentes del modelo de negocio Canvas

10.2.1. Segmentos de clientes

10.2.2. Propuesta de valor

10.2.3. Canales

10.2.4. Relaciones con el cliente

10.2.5. Fuentes de ingresos

10.2.6. Recursos clave

10.2.7. Actividades clave

10.2.8. Socios clave

10.2.9. Estructura de costos 122

10.3. Esquematización del modelo de negocio 123

\section{CONCLUSIONES Y RECOMENDACIONES}

Conclusiones 124

Recomendaciones 125

\section{ÍNDICE DE GRÁFICOS}

Gráfico 1: Análisis de las cinco fuerzas de Porter 32

Gráfico 2: Proceso productivo del servicio del fast food "Healthy Corner" 73

Gráfico 3: Flujograma de fast food "Healthy Corner" 76

Gráfico 4: Estructura organizacional de "Healthy Corner" 88

Gráfico 5: Modelo de negocio CANVAS 123 


\section{ÍNDICE DE FIGURAS}

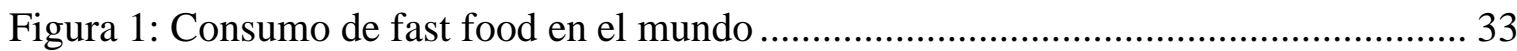

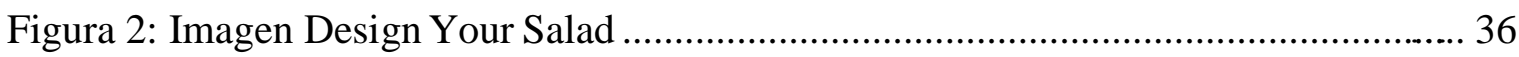

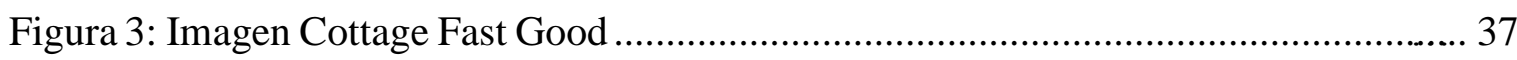

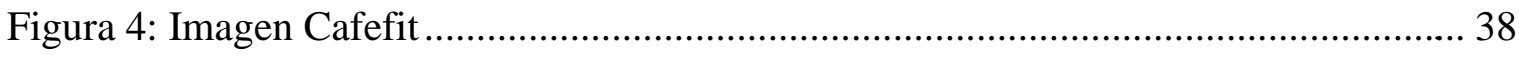

Figura 5: Carta de bebidas y platos elaborados del fast food "Healthy Corner" .........44

Figura 6: Imagen del tablero de fast food "Healthy Corner" .......................................... 45

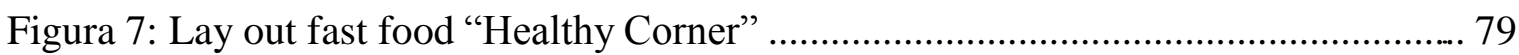

Figura 8: Mapa de ubicación del centro comercial Jockey Plaza .................................... 84

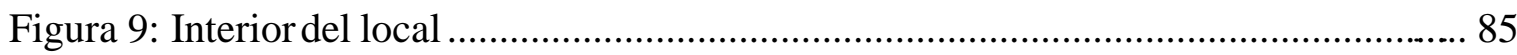

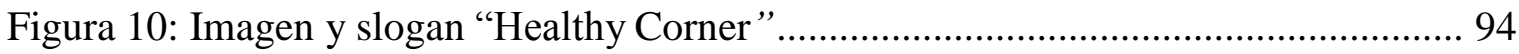

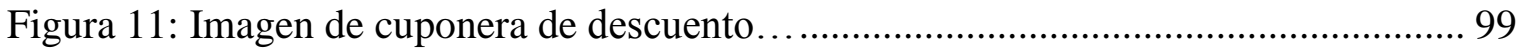

Figura 12: Medio de publicidad blog y Facebook ............................. 99

Figura 13: Panel publicitario ............................................ 100

Figura 14: Medio de difusión radial ........................................ 100

\section{ÍNDICE DE TABLAS}

Tabla 1: Tabla comparativa de las competencias directas de "Healthy Corner" ........ 38

Tabla 2: Matriz de Perfil Competitivo ....................................... 39

Tabla 3: Valor energético y nutricional de los productos de "Healthy Corner" ................ 46

Tabla 4: Número de personas según género .................................................................. 55

Tabla 5: Número de personas procedentes de los distritos de Lima Moderna .......... 56

Tabla 6: Número de personas del nivel socioeconómico B y C ...................................... 56

Tabla 7: Número de personas según su rango de edad ............................................... 57

Tabla 8: Número de personas según motivo de consumo en fast food............................ 57 
Tabla 9: Número de personas según frecuencia al patio de comidas de centro comerciales 58

Tabla 10: Número de personas según atributos importantes para consumir en un fast food 58

Tabla 11: Número de personas según frecuencia de consumo en fast food tradicional ...59

Tabla 12: Número de personas según idea de concepto de "fast food saludable" ......60

Tabla 13: Número de personas según conocimiento de fast food saludable 60

Tabla 14: Número de personas según intención de compra de la prueba de concepto ... 61

Tabla 15: Número de personas según frecuencia de consumo de la prueba de concepto 61

Tabla 16: Número de personas según el horario de asistencia a la prueba de concepto . 62

Tabla 17: Número de personas según preferencia de consumo 62

Tabla 18: Número de personas según la modalidad de pago 63

Tabla 19: Número de personas según monto a pagar por consumo personal 63

Tabla 20: Número de personas según las opciones de nombres para la empresa 64

Tabla 21: Número de personas según preferencia de difusión en medio de comunicación 64

Tabla 22: Tabla comparativa del estudio cualitativo y cuantitativo de Healthy Corner 76

Tabla 23: Mercado potencial de "Healthy Corner" .69

Tabla 24: Mercado efectivo de "Healthy Corner" 70

Tabla 25: Mercado objetivo de "Healthy Corner" 71

Tabla 26: Proyección de ventas anual del año 2017 al 2021 ......................................... 72

Tabla 27: Proyección de ventas anual sin IGV del año 2017 al 2021 72

Tabla 28: Artículo de equipamiento del área de cocina y despacho "Healthy Corner" ...77

Tabla 29: Artículo de equipamiento del área administrativa de "Healthy Corner" ....78

Tabla 30: Artículo descartable de "Healthy Corner" 78 
Tabla 31: Remuneración del personal ........................................ 92

Tabla 32: Lista de productos de fast food saludable "Healthy Corner" ............... 95

Tabla 33: Lista de precios de venta de "Healthy Corner" .......................... 96

Tabla 34: Lista de costos de productos "Healthy Corner" ......................... 97

Tabla 35: Presupuesto para la estrategia de promoción $\ldots \ldots \ldots \ldots \ldots \ldots \ldots \ldots \ldots \ldots \ldots . \ldots 8$

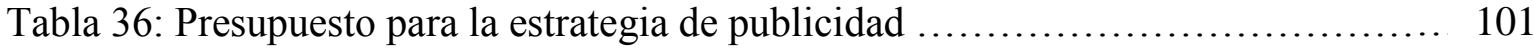

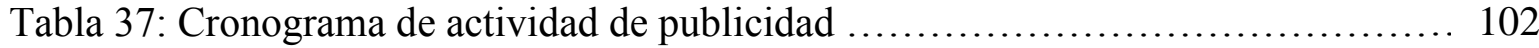

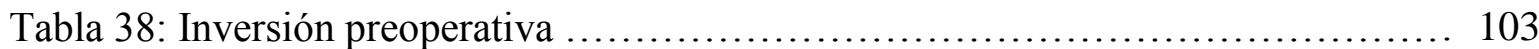

Tabla 39: Inversión en capital de trabajo ...................................... 104

Tabla 40: Costo del proyecto ............................................... 105

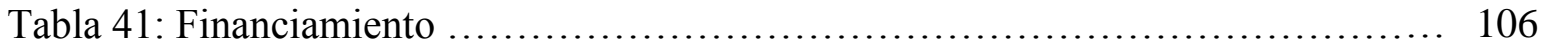

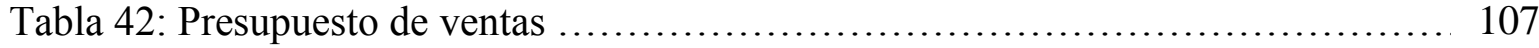

Tabla 43: Presupuesto de gastos de ventas ..................................... 108

Tabla 44: Presupuesto de compras .......................................... 108

Tabla 45: Presupuesto de costos de ventas .................................. 109

Tabla 46: Presupuesto de gastos administrativos $\ldots \ldots \ldots \ldots \ldots \ldots \ldots \ldots \ldots \ldots \ldots \ldots \ldots \ldots \ldots$

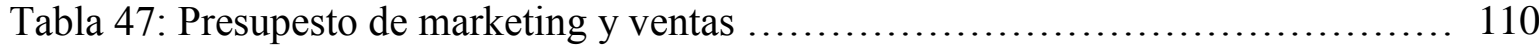

Tabla 48: Estado de ganancias y pérdidas proyectados ............................ 111

Tabla 49: Balance proyectado .......................................... 112

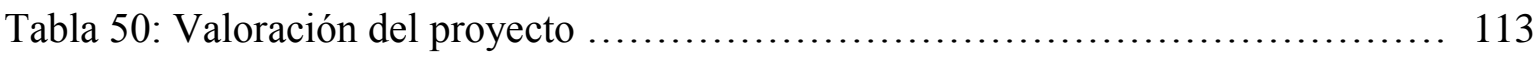

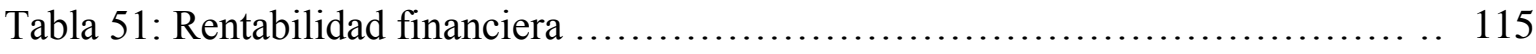

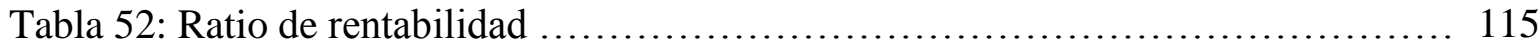

Tabla 53: Ratio de endeudamiento ........................................... 115

Tabla 54: Estado de resultados integrales ................................... 116

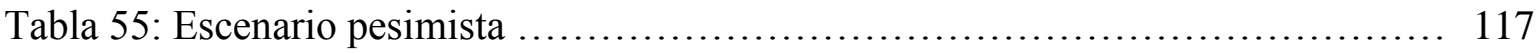


Tabla 56: Escenario optimista

\section{ANEXOS}

Anexo 1: Valor nutricional de productos fast food 126

Anexo 2: Ley de la Alimentación saludable (Ley N 30021)

Anexo 3: Transcripción del Focus Group 01 130

Anexo 4: Transcripción del Focus Group 02 138

Anexo 5: Evidencia fotográfica de los Focus Group 146

Anexo 6: Ficha de Nivel socioeconómico 147

Anexo 7: Encuesta 149

BIBLIOGRAFÍA 152 REFERENCIAS ELECTRÓNICAS 153 


\section{INTRODUCCIÓN}

En la actualidad a nivel mundial se está viviendo una época de grandes cambios, principalmente se observa esto en los mercados y las tendencias de los consumidores en casi todas las industrias. Particularmente la industria de la comida rápida está teniendo un proceso de transformación gracias a cambios en los hábitos de consumo.

En el Perú el estilo de vida está definida por la tendencia consumista del mercado y el crecimiento económico, por ello el ritmo de vida de las personas es mucho más rápido y para muchas personas asistir a centros de fast food es más sencillo que elaborar sus propios platos en casa.

En la Capital de Perú, Lima, se encuentra diferentes opciones de comida, según las preferencias, comodidad y accesibilidad por costos. Hoy el fast food es uno de los negocios de mayor expansión y año tras año sigue creciendo en el país. Por ello cabe resaltar que en el Perú ha aumentado el consumo de fast food en un $260 \%$ en los últimos 10 años, consolidándose como el caso más crítico en América Latina según la Organización Mundial de la Salud (OMS). Según el Documento "Perú: Enfermedades No Trasmisibles y Trasmisibles, 2015 del Instituto Nacional de Estadística e Informática (INEI) informa que hay una tasa de 53,2\% de peruanos de 15 años a más con sobrepeso y obesidad.

La obesidad es un problema que avanza vertiginosamente en el Perú y una de las principales causas es la mala alimentación. Partiendo de lo mencionado en el párrafo anterior los fast food serían una de las principales causales de esta condición; considerando el aporte de alta densidad energética, alto contenido de grasas saturadas, hidratos de carbono y sodio.

El Estado Peruano viene tomando medidas preventivas por la alarmante cifra de obesidad y enfermedades asociadas como la hipertensión arterial, dislipidemias mixtas, diabetes y 
enfermedades cardiovasculares; mediante la Ley de Promoción de la Alimentación Saludable (Ley $N^{\circ}$ 30021), aunque la ley no involucra bebidas alcohólicas.

Ante lo expuesto, surge la idea de un plan de negocios de comida rápida saludable en Lima Metropolitana, 2016, que tiene como objetivo principal demostrar su viabilidad por ser una alternativa saludable que es base fundamental para una mejor calidad de vida.

El desarrollo de la propuesta tendrá los siguientes contenidos: El primer capítulo describe las generalidades del plan de negocios de fast food saludable, en el que explica los antecedentes, el problema, justificación, objetivos que se pretende alcanzar, así como el alcance y limitaciones.

El segundo capítulo, se basa en el análisis del entorno de la empresa, el análisis de la industria de fast food, las tendencias, factores críticos de éxitos, análisis de la competencia y oportunidades para llevar a cabo con éxito el negocio de fast food saludable.

En el tercer capítulo, se desarrollará el estudio de mercado en el cual se hace la descripción del servicio, selección del segmento de mercado, investigación cualitativa mediante un focus group que servirá para diseñar el instrumento en la investigación cuantitativa. La encuesta definirá al perfil del consumidor.

El cuarto capítulo, abarcará la proyección del mercado objetivo, considerando el ámbito de proyección, mercado potencial, disponible, efectivo y objetivo. Así como el pronóstico de ventas y sus aspectos críticos del mismo.

En el quinto capítulo, se basa en la ingeniería del proyecto, determinación del tamaño, estudio de localización del negocio. Seguidamente del sexto capítulo, en el que se explicará aspectos fundamentales para establecer la misión, visión y principios de negocios, así como las estrategias, ventajas competitivas, diseño de estructura organizacional que funcione adecuadamente al servicio. Y el séptimo capítulo, plantea las estrategias para el plan de marketing y de ventas. 
En el octavo capítulo, se elaborará la planificación financiera, explicando la inversión total del proyecto, financiamiento, así como presupuestos base y de resultados. El noveno capítulo, constará de la evaluación económica financiera en base a la metodología del VAN, y análisis de riesgo de diferentes escenarios.

Por último, en el décimo capítulo se diseñará el modelo de negocios Canvas, describiendo cada uno de sus nueve componentes y su esquematización.

Este plan de negocios finaliza con las conclusiones y recomendaciones obtenidas una vez analizado el mercado y resultados económicos para la creación de este fast food saludable ubicado en Lima Metropolitana. 


\section{CAPÍTULO I: GENERALIDADES}

\subsection{Antecedentes}

Según el documento "El consumo de comida rápida, Situación en el mundo y acercamiento autonómico, USA 2011, EAE Business School” La comida rápida es un tipo de comida económica, como su mismo nombre indica, de rápida preparación y consumo. Dichas características que en nuestra sociedad se convierten en ventajas para los consumidores; desde adolescentes de bajo poder adquisitivo hasta trabajadores que carecen de tiempo para almorzar por sus exigentes jornadas laborales. (16)

Respecto a su aporte nutricional, este tipo de comidas tienen alto valor calórico, alto contenido en grasas saturadas, colesterol e hidratos de carbono, su contenido de fibra, vitaminas y minerales es deficiente, aunque en el caso del sodio es todo lo contrario. (Ver Anexo 1) (8)

La comida rápida o fast food llegó al Perú en la década de los 1980s, etapa que el país se encontraba en crisis debido al gobierno militar de Juan Velasco Alvarado. El pollo frito de Kentucky Fried Chicken (KFC) aparece en el mercado peruano cuando ninguna otra empresa se atrevía a invertir en este negocio, sin embargo, Raúl Diez Canseco Terry pudo conseguir junto a dos inversionistas, el único negocio estadounidense que operó desde 1981 bajo el modelo de franquicia. Al año siguiente, a Diez Canseco le ofrecieron la franquicia de Pizza Hut; a estas se sumaron Burger King, Chili’s, Starbucks Perú, entre otros a la actualidad. (5)

Hoy la comida rápida es uno de los negocios de mayor expansión y año tras año sigue creciendo a nivel mundial. Actualmente se está viviendo en una época de grandes cambios, principalmente si se observa los mercados y las tendencias de los consumidores en casi todas las industrias. Particularmente, la industria de la comida rápida está teniendo un proceso de transformación debido a cambios en los hábitos de consumo. Los peruanos han 
vivido estos cambios acelerados, el estilo de vida apresurado ha modificado los hábitos de consumo y han surgido nuevas necesidades que antes no existían. Sin embargo, ha traído consigo una problemática de salud pública, la obesidad, la cual avanza vertiginosamente en el Perú, especialmente entre las mujeres, ya que el porcentaje de casos en este sector aumentó en 5\% durante el último año. (1)

El Instituto Nacional de Estadística e Informática (INEI) presentó el documento "Perú: Enfermedades No Transmisibles y Transmisibles, 2014" elaborado por la recopilación de datos de la Encuesta Demográfica y de Salud Familiar, revela que una de cada cuatro peruanas padece de exceso de peso. En el 2013 se registró una población con exceso de peso de $20,9 \%$, cifra que aumentó a 40,1\% para el año 2014. (6)

Según el último documento "Perú: Enfermedades No Transmisibles y Transmisibles, 2015”; el 53,2 \% de la población de 15 y más años padece de exceso de peso. (17)

A continuación, se brinda más información sobre el mercado de comida rápida:

a) Análisis prospectivo del sector comida rápida en Lima: 2014 - 2030, Arbaiza L,

Cánepa M, Cortez O y Lévano G., Universidad ESAN- Lima, Perú. $2014_{(1)}$

Resumen: Estudio prospectivo que tiene como objetivo evaluar el mercado de comida rápida en Lima con el fin de determinar el escenario más probable en Lima al año 2030. Concluye: En términos económicos el Perú tiene una amplia oportunidad de expansión y crecimiento en el negocio de la comida rápida. Desde el 2012 el consumidor peruano no sólo lo ve como un espacio de consumo sino como un lugar de entretenimiento familiar. Para el 2030 con seguridad habrá un crecimiento sostenible de este sector por la alta probabilidad de que cambien los hábitos de consumo locales como producto de las tendencias mundiales orientadas al consumo de comidas más saludables, desarrollo de tecnología, que permitan la disminución de precios y la calidad de los alimentos y auge de desarrollo de urbano con zonas comerciales para el ingreso de negocios. 
b) Plan de negocios para una red de locales de comida rápida saludable en Guadalajara, Jalisco, México. Carrillo, Luis M. Santiago de Chile, 2014 (2)

Resumen: La investigación tiene como objetivo evaluar técnica y financieramente la factibilidad de apertura de una cadena de comida rápida saludable en México, por lo pronto sólo se realizaría la apertura en Jalisco en el Nivel socioeconómico (NSE) A y $\mathrm{B}$, y en un futuro el C y D. Ofreciendo preparaciones como tortillas y panes propios de la zona, pero a la vez que sean saludables para los consumidores, también ofrece el servicio delivery.

c) Plan de negocios para la puesta en marcha de un fast food saludable en la ciudad de Piura, Castillo Sandoval, Laura Franchesca, Universidad de Piura - Piura, 2014. (3) Resumen: La investigación tiene como objetivo diseñar el plan de negocios para la puesta en marcha de un fast food saludable en la ciudad de Piura. Es decir, ofrecer variedad de platos preparados a base de verduras, frutas, carnes magras al vapor o a la parrilla; con el fin de promover el consumo de alimentos sanos de una manera rápiday por lo tanto mejorar a largo plazo la calidad de vida y el bienestar físico de las personas. La oferta está dirigida a hombres y mujeres entre 25 y 65 años pertenecientes a los niveles socioeconómicos $\mathrm{A} / \mathrm{B}$ y $\mathrm{C}$, porque presentan mayor poder adquisitivo y se preocupan por los cuidados en la salud y la preservación de enfermedades no trasmisibles a largo plazo. La investigación contempla la idea del negocio y los objetivos a alcanzar con la puesta en marcha de este proyecto en el corto y largo plazo. Además, incluye investigación y análisis del mercado, capacidad, diseño y distribución física de la planta y procesos productivos. También se contempla el plan de marketing del servicio, enfocado a las llamadas "4 $\mathrm{P}$ del marketing". Esta tesis finaliza con las conclusiones obtenidas una vez analizado el mercado y resultados económicos para la creación de este fast food saludable en Piura. 
d) Are fast food restaurants an environmental risk factor of obesity? Jeffery, Robert W; Baxter, Judy; McGuire, Maureen; Linde, Jennifer, International Journal of Behavioral Nutrition \& Activit Físical; 2006, vol. 3, p1. (6)

Resumen: La concurrencia a los restaurantes de "comida rápida" ha aumentado y esta se relacionado a la obesidad. Este estudio examinó que vivir y/o trabajar cerca de los restaurantes de "comida rápida" se asocia con el exceso de peso corporal; es decir la prevalencia de tener un IMC superior a 30 , se debe a una dieta alta en grasas. $\mathrm{Su}$ consumo es mayor por la proximidad que tienen los fast food a los centros de trabajo, estudio, casa, ya que se les encuentra en todos lados.

Concluye: No se demostró una estrecha relación entre obesidad y el consumo de fast food; esto puede deberse a errores en la metodología del estudio, considerando que la muestra no era significativa.

e) Repercusiones de la comida rápida en la sociedad, M $^{a}$ Dolores Moliní Cabrera, Sevilla - España, 2007. (8)

Resumen: La comida rápida es muy consumida gracias a sus intensos sabores, su palatabilidad y su facilidad para adquirirla. Si este tipo de comida conlleva una serie de características nutricionales, que hacen que no sea aconsejable su consumo habitual. Entre estas características destaca su abundancia en grasas saturadas y colesterol. Su excesivo consumo conlleva a diversas enfermedades como dislipidemias, enfermedades cardiovasculares, obesidad, etc. Podemos ver a través de diversos documentos queeste tipo de comida es tan aceptada y consumida en nuestra sociedad, por ello se hace las recomendaciones acerca de su consumo muy moderada.

Concluye: Cuando acudamos a restaurantes de comida rápida, debemos procurar evitar las porciones mayores, optando por las de menor tamaño y hay que procurar no consumir fast food más de una o dos veces al mes. 
f) Effects of fast food branding on young children's taste preferences, Robinson, T.N., Dina, L. G., Borzekowski, EdD., Matheson, D.M. y Kraemer H.C, Arch. Pediatric Adolescent Med, 2007, 161: 792-797 (9)

Resumen: Se quiere examinar los efectos de la marca, marketing y exposiciones del mundo real acumulativos en los niños pequeños mediante pruebas de la influencia de la marca de una fuente fuertemente comercializada en las preferencias gustativas. Se trata de un estudio experimental. Los niños degustaron cinco pares de alimentos y bebidas en envases idénticos de McDonald y acertaron, pero los envases sin marca y se les pidió que indicaran si sabía lo mismo o si uno tenía mejor sabor.

Concluye: La marca de alimentos y bebidas influye en la percepción del gusto de los niños pequeños. Los resultados son consistentes con las recomendaciones para regular la comercialización a los niños pequeños y también sugieren que la marca puede ser una estrategia útil para mejorar los comportamientos alimenticios de los niños.

\section{g) Conocimientos en nutrición}

"Las necesidades energéticas se definen como la ingesta de energía en la dieta necesaria para el crecimiento o el mantenimiento de una persona de una edad, sexo, peso, altura y nivel de actividad física definidos". (Krause, 2013, p.19). (7)

En el texto de Krause se menciona que:

a) Una dieta apropiada ha de ser idónea y equilibrada, y debe considerar características como edad y fase de desarrollo, preferencias y hábitos alimentarios. Asimismo, depende de la disponibilidad de alimentos, las condiciones socioeconómicas, las prácticas culturales y tradiciones familiares, los medios de preparación y conservación y la aptitud en la preparación de los alimentos. Incluye la energía y todos los nutrientes en cantidades apropiadas y en proporciones idóneas entre sí. La presencia o 
ausencia de un nutriente esencial puede afectar a la disponibilidad, la absorción, el metabolismo o las necesidades dietéticas de otros. (p. 274)

b) Son diversos los patrones que se emplean como guía para la planificación y la evaluación del aporte alimentario para individuos y grupos de población. La Organización para la Alimentación y la Agricultura (FAO) y la Organización Mundial de la Salud (OMS), integradas ambas en las Naciones Unidas, han establecido estándares internacionales en diversas áreas relacionadas con la calidad y la seguridad de los alimentos, así como las correspondientes recomendaciones sobre dieta y nutrientes.

En EE. UU., el Food and Nutrition Board (FNB) del Institute of Medicine (IOM) ha venido impartiendo recomendaciones nutricionales desde los años cuarenta. A partir de mediados de los años noventa, las recomendaciones nutricionales del FNB son utilizadas en EE. UU. y Canadá. El U.S. Department of Agriculture (USDA) y el U.S. Department of Health and Human Services (USDHHS) mantienen responsabilidad compartida en lo que respecta al establecimiento de recomendaciones dietéticas, recopilación y análisis de datos sobre la composición de los alimentos y formulación de normativas sobre información nutricional referida a los productos alimentarios.

Health Canada es el organismo responsable de las recomendaciones nutricionales en Canadá, mientras que, en Australia, la responsabilidad corresponde al National Health and Medical Research Council.

La Asociación Dietética de Japón actualiza sus directrices cada 4 años, siendo la última versión de las mismas una de las bases de actuación del Ministerio de Salud, Trabajo y Bienestar. 
Análogamente, muchos otros países han establecido directrices apropiadas para las circunstancias y las necesidades de sus poblaciones.

c) Ingestas dietéticas diarias estimadas seguras y adecuadas: Se sabe que numerosos nutrientes son esenciales para el mantenimiento de la vida y la salud, aunque los datos para algunos de ellos son insuficientes para establecer una ingesta recomendada. Los valores para esos nutrientes son las ingestas dietéticas diarias estimadas seguras y adecuadas (IDDESA). La mayor parte de ellas se expresan en forma de intervalo, para indicar que no se trata de recomendaciones específicas, sino que se deben observar dentro de un rango comprendido entre límites máximos y mínimos.

d) Componentes de las IDR: El modelo de las IDR constituye una ampliación de las CDR, que se centran exclusivamente en los niveles de nutrientes para la prevención de enfermedades carenciales en poblaciones sanas. Para responder a los avances científicos en el marco de la dieta y la salud a lo largo del ciclo vital, el actual modelo de IDR incorpora cuatro elementos de referencia: ingesta adecuada (IA), necesidades medias estimadas (NME), CDR e ingesta máxima tolerada (IMT).

- La ingesta adecuada (IA) es una recomendación de nutrientes basada en la aproximación observada o determinada experimentalmente de la ingesta de nutrientes en un grupo (o grupos) de personas sanas, cuando no hay suficientes datos científicos que permitan calcular la CDR o los NME. Algunos nutrientes esenciales, como el calcio, se expresan en forma de IA.

- Las necesidades medias estimadas (NME) corresponden a las necesidades medias de un nutriente para personas sanas. En este 
ámbito se ha realizado una valoración funcional o clínica con las correspondientes mediciones de idoneidad. Las NME son la cantidad de un nutriente con la que aproximadamente la mitad de los individuos ven cubiertas sus necesidades y la mitad restante no. Las NME se emplean para evaluar la idoneidad de los nutrientes en poblaciones, pero no en personas.

- Las cantidades diarias recomendadas (CDR) corresponden a la cantidad de un nutriente necesario para satisfacer las necesidades de casi todas (97 o 98\%) las personas sanas de la población de referencia. Las CDR de un nutriente sirven como objetivo de ingesta para personas, no como referencia para la idoneidad de la ingesta en poblaciones.

- Por último, se estableció la ingesta máxima tolerada (IMT) para numerosos nutrientes, con el fin de reducir el riesgo de efectos adversos o tóxicos por consumo de nutrientes de forma concentrada, solos o combinados con otros (no en los alimentos) o en procesos de enriquecimiento o fortalecimiento. La IMT corresponde al nivel máximo de ingesta diaria del nutriente que no es probable que induzca efectos adversos para la salud en casi todos los miembros de la población general. (p.275)

\subsection{Determinación del problema y oportunidad}

Existe cierta incertidumbre respecto de lo que ocurrirá en los próximos años en el Perú, porque se puede observar las acciones del Estado por palear los índices de malnutrición mediante programas nacionales, asimismo promulgando la Ley de la Alimentación, entre 
otras actividades, en defensa de la salud de los peruanos, principalmente de los niños. (14) (Ver Anexo 2)

Por otro lado, tenemos a un Perú abierto a la globalización y con ello hay nuevas tendencias y por ende cambios en el estilo de vida del consumidor.

Ante esta realidad y la recopilación de antecedentes mencionados, el fast food saludable sería una oportunidad de negocio propicio, ya que se contribuiría a la mejora de hábitos alimentarios, asimismo la disminución en el índice de exceso de peso en nuestro país. Teniendo en cuenta que está enfocada en las personas que trabajan y jóvenes que no tienen suficiente tiempo para buscar opciones saludables en el mercado de Lima Metropolitana, Perú. (2)

\subsection{Justificación del proyecto}

El crecimiento sostenible de este sector económico ha generado una problemática, ya que el consumo desmedido de este tipo de comidas denominada "comida rápida" ha generado a largo plazo un incremento en la tasa de morbimortalidad por enfermedades crónicas no trasmisibles (ECNT) como la diabetes, hipertensión arterial, hipercolesterolemia y obesidad; constituyendo un problema de salud pública como lo manifiesta la OMS, por ello es necesario plantear y ejecutar acciones para mejorar los hábitos alimentarios del consumidor peruano.

Según INEI (2015) en el Departamento Lima Metropolitana, para el caso de personas mayores de 15 años, el 11,3\% padece de hipertensión, el 4,5\% han sido diagnosticado con diabetes, 53,2\% tiene exceso de peso. La tasa de sobrepeso y obesidad ha ido en aumento en los últimos años de manera paulatina, por lo que ante lo mencionado se da la propuesta de negocio "fast food de comida saludable" con el fin de proponer mediante esta alternativa 
nuevos hábitos saludables y agradables, con nuevas propuestas culinarias y de costos asequibles al consumidor.

\subsection{Objetivos generales y específicos}

\subsubsection{Objetivo General}

Demostrar la viabilidad de implementar un fast food de comida saludable para personas que desean buscar una alternativa saludable en el distrito de Surco en Lima Metropolitana, 2016.

\subsubsection{Objetivos específicos}

- Analizar los niveles de consumo y satisfacción que presentan con respecto a los centros de comida rápida en Lima.

- Estudiar los hábitos del consumidor con respecto a su asistencia a salir a comer fuera del hogar.

- Sondear el mercado y medir la intención de compra y asistencia para la creación de un fast food saludable.

- Evaluar el rendimiento económico de la puesta en marcha de dicho formato.

\subsection{Alcances y limitaciones de la investigación}

La comida rápida saludable es un proyecto novedoso en el negocio de comida rápida a un sector de la población no atendida con el formato "fast food". El cual estará al alcance de las personas que requieran un servicio de comida rápida con una alternativa diferente optimizando el tipo de comida para mantener una alimentación balanceada y saludable. La limitación que tiene la propuesta de comida rápida saludable es que no va a competir directamente con las grandes franquicias de fast food que hay en el Perú y específicamente en Lima, que es la población objetivo. Por otro lado, no se realizará servicio delivery. 


\section{CAPÍTULO II: ANÁLISIS DEL ENTORNO}

\subsection{Entorno de la empresa}

En el presente capítulo se evaluó el análisis del entorno de la ciudad de Lima, Perú para identificar las oportunidades y amenazas del plan de negocios de comida rápida saludable. Se inició analizando el entorno externo, utilizando la herramienta PESTAL (técnica del marketing para analizar los factores Político, Económico, Social, Tecnológico, Ambiental y Legal); el análisis de la industria (entorno interno), utilizando la herramienta de las cinco fuerzas de Porter; así como la tendencia en la industria, la evaluación de los factores claves para el éxito versus los competidores y sustitutos y finalmente las identificar las oportunidades de la viabilidad del negocio.

\subsection{Análisis del entorno externo}

El plan de negocios requiere un análisis del entorno externo para evaluar la viabilidad del negocio, mediante la herramienta PESTAL que identifica y analiza cada uno de los factores externos para asegurar el éxito del negocio.

\subsubsection{Análisis político}

El gobierno del ex presidente del Perú, Ollanta Humala (2011 - 2016) se caracterizó por mejorar la nutrición, salud y educación. Implementó nuevos programas nacionales como QALI WARMA, CUNA MÁS, etc. En el año 2013 el Congreso de la República del Perú, aprobó la implementación de la Ley de Promoción de la Alimentación Saludable (Ley $\mathrm{N}^{\circ}$ 30021), la cual beneficia a la política de este gobierno y se aplica a todas las personas naturales y jurídicas que comercialicen, importen, suministren y fabriquen alimentos fabricados. (14)

Según el plan de gobierno del presidente Pedro Pablo Kuczynski (2016-2021), manifiesta que atenderá los principales problemas de salud, como disminuir los 
indicadores de mortalidad y morbilidad, siendo la mala alimentación una de las principales causas de las enfermedades crónicas no transmisibles; mantendrá, mejorará la eficiencia y cobertura de los programas sociales que en el anterior gobierno se inició. (24)

\subsubsection{Análisis económico}

Según el Informe Técnico de Producción Nacional del mes de febrero del 2016 del Instituto Nacional de Estadística e Informática (INEI), el primer bimestre del 2016 registró que la actividad económica acumuló un crecimiento de 4,72\%, durante el último año (marzo 2015 a febrero 2016) hubo un crecimiento de 3,79\%. Específicamente en el sector alojamiento y restaurantes el incremento total es de $3,08 \%$; y el subsector restaurantes presentó un aumento de 2,83\% por los establecimientos de comida rápida, entre otros. (19)

Según Perfiles Zonales de IPSOS 2015 menciona que Lima Moderna representa el 12,9\% de la población total de Lima Metropolitana, se registra 378 mil hogares y el ingreso promedio mensual del hogar es S/. 6319, de los cuales S/. 1370 (28\%) representa el gasto en alimentos y bebidas. (20)

Alfredo Ferrero, de Análisis \& Opinión manifestó que las elecciones presidenciales y congresales del 2016 hacen que el Perú presente un periodo de inestabilidad y desconfianza para la decisión de inversión y, conviene dar gobernabilidad al país, ya que la economía y la política van de la mano. (10)

El gobierno saliente ha incrementado el "sueldo mínimo" a ochocientos cincuenta (850) soles, lo cual puede haber afectado a la empresa al pago de las remuneraciones al personal, debido a los incrementos y/o cambios que hace el gobierno. Por otro lado, el actual gobierno de Pedro Pablo Kuczynski apunta a un crecimiento 
económico, brindando su apoyo a las nuevas empresas dando licencias, reduciendo el IGV, impuesto a la Renta, etc.

\subsubsection{Análisis social}

El estudio Thinkfit de Kantar Worldpanel Latam - 2010 / 2011 reveló que los consumidores peruanos pagan hasta $123 \%$ más en la compra de productos saludables, versus otras opciones no saludables. El Gerente General de Kantar Worldpanel, explicó que en Lima se paga 48 \% más. Este costo elevado se debe a que la mayoría de estos productos, entre ellos los light, son importados, ademásque existe aún poca oferta en nuestro país, indicó que el mercado peruano de productos saludables se encuentra en desarrollo y presenta un gran potencial por explotar. El $35 \%$ de los peruanos consumen principalmente productos light con el fin de tener una alimentación sana y cuidar su peso. (1)

\subsubsection{Análisis tecnológico}

En la actualidad la tecnología es un factor imprescindible en cuanto a procesos se trata y, lo es más cuando están relacionados con temas de salud pública. La diferencia entre comida saludable y no saludable, más allá del nivel de grasa y de otros componentes, es el tratamiento en la cocción. (26)

La industria de alimentos o de la comida rápida saludable requiere inversiones en tecnología, diseño de productos, para su producción y comercialización. La tecnología necesaria para la producción o entrega de servicios de alimentos se puede encontrar con proveedores con costos competitivos.

Se implementará el equipamiento necesario para brindar un soporte tecnológico para llevar un control interno de ventas mediante un software; por otro lado, y no menos importante es optimizar los procesos de producción, conservación y envasado 
contando con cámaras frigoríficas, conservadoras, hornos eléctricos, parrillas, cocinas de inducción, envases de alta calidad etc. (26)

\subsubsection{Análisis ambiental}

Se considera propicio que se implemente en el sector de comida rápida, un negocio novedoso que ofrezca una alternativa "saludable" y, esta debe estar ligada a normas que optimice y garantice un medio ambiente más saludable, teniendo en cuenta las recomendaciones del Departamento de Salud Pública y Medio Ambiente de la OMS. Por ello, se utilizarán vasos biodegradables de papel cartón para las bebidas y envases de plástico polietilén tereftalato (PET) para los alimentos.

\subsubsection{Análisis legal}

Es un gran respaldo contar con la Ley de Promoción de la Alimentación Saludable (Ley N³0021), promulgada por el Congreso de la República del Perú. La directora general de la OMS, Margaret Chan, ha calificado esta ley como un paso necesario para prevenir y hacer frente al incremento de enfermedades no trasmisibles. Tiene por objetivos, promover el derecho a la salud pública y el desarrollo adecuado de las personas, y reducir las enfermedades vinculadas al sobrepeso y la obesidad; propone lograr estos objetivos a través de la educación nutricional, el fomento de la actividad física, la implementación de quioscos y comedores saludables en las instituciones de educación básica, así como también de la regulación de la publicidad e información relacionada con alimentos y bebidas. (14)

\subsection{Análisis de la industria}

El plan de negocios requiere un análisis de la industria que identifique cuáles serán las oportunidades y amenazas del fast food saludable, mediante el modelo estratégico de las cinco fuerzas de Porter (Ver Gráfico 1). 


\subsubsection{Poder de negociación de los proveedores}

Los insumos son la principal fuente de trabajo y por ello es de suma importancia elegir al detalle los proveedores que cumplan los estándares de calidad, principalmente los proveedores de alimentos cárnicos, lácteos, frutas y verduras, etc., que se requieran para cubrir nuestra variedad de menús.

Los negocios ubicados en el Gran Mercado Mayorista de Lima serán proveedores que nos abastecerá insumos perecibles como verduras y frutas al por mayor según la estación y costos de los mismos. El proveedor de aves será REDONDOS, el de carnes rojas INPELSA, el de carne de soya y productos veganos MADRE NATURA, se adquirirá enlatados y otros alimentos no perecibles en MAKRO, se comprará empaques y envases desechables de plástico en BEZALEEL E.I.R.L. El fast food saludable tendrá dentro de su carta postres libres de azúcar contando con la presencia de nuestro proveedor VEGANIMO.

Por otro lado, EQUIPAMIENTO DE COCINA SAC implementará el servicio de cocina con equipos y mobiliario de acero inoxidable y los utensilios de cocina, FACUSA.

Los proveedores tienen un bajo poder de negociación puesto que hay una gran gama de competencia en los rubros que se requieren.

\subsubsection{Poder de negociación de los clientes}

Las personas naturales son el cliente potencial de fast food saludable, la importancia que se le da al cliente es pieza clave para el éxito del negocio; sin embargo, estos tienen bajo poder de negociación, son llamados precio-aceptantes, también conocida como competencia perfecta, ya que el cliente acepta el precio establecido como un dato externo a ellos, una realidad que no pueden cambiar y a la que deben adecuar sus comportamientos. 


\subsubsection{Amenazas de competidores potenciales}

Actualmente en Lima Metropolitana existen grandes cadenas de centros comerciales, donde se brinda la mejor oferta comercial para poder ofrecer entretenimiento y diversión. (3) En dichos centros comerciales encontramos lugares de comida rápida tradicionales. La propuesta plantea la creación de un fast food de comida saludable, para el cual se ha analizado dos tipos de competencia: por giro de negocio, la cual es la competencia directa ofreciendo menús similares al negocio propuesto; por ejemplo, Design your salad, Cottage y Cafefit; y por actividad

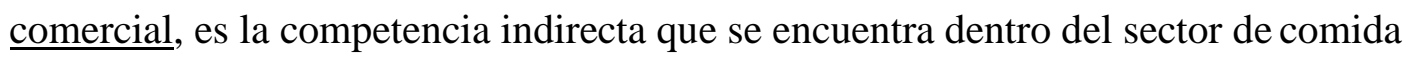
rápida como KFC y Pizza Hut.

La rivalidad entre las cadenas de comida rápida es muy alta ya que compiten por ganar clientes ya sea mediante el precio, promociones, atención rápida, entre otros; si bien es cierto ellos no ofrecen los mismos productos, pero si la necesidad de satisfacción; por ello tienen un alto poder de negociación.

\subsubsection{Amenazas de productos sustitutos}

En la actualidad hay muchos sustitutos del fast food saludable, los posibles reemplazantes de mayor demanda y de gran amenaza son las ya conocidas cadenas de fast food como KFC, BEMBOS y MC DONALD’S, que han puesto al mercado productos con menor aporte calórico. AL PLATO, comida al peso y productos listos al consumo que se encuentra en el patio de comidas de los diversos supermercados en Lima Metropolitana. Por ello, estos son la gran amenaza.

\subsubsection{Rivalidad entre competidores actuales}

En el Perú el negocio de los fast food se inició en el año 1980 y actualmente en Lima Metropolitana existe un gran número de franquicias de fast food, así como en varias 
provincias. La competencia entre ellas es muy fuerte, y la diferencia entre las mismas son el precio y el producto final, es decir el tipo de menús que ofrecen al consumidor. Existe sólo en Lima una reciente e innovadora lista de restaurantes de comida saludable (temática en algunos casos), cafeterías y quioscos saludables en las municipalidades de San Isidro y Miraflores.

Ante lo mencionado, la tendencia por lo saludable ha generado muchos competidores para el negocio propuesto, siendo esta gran amenaza.

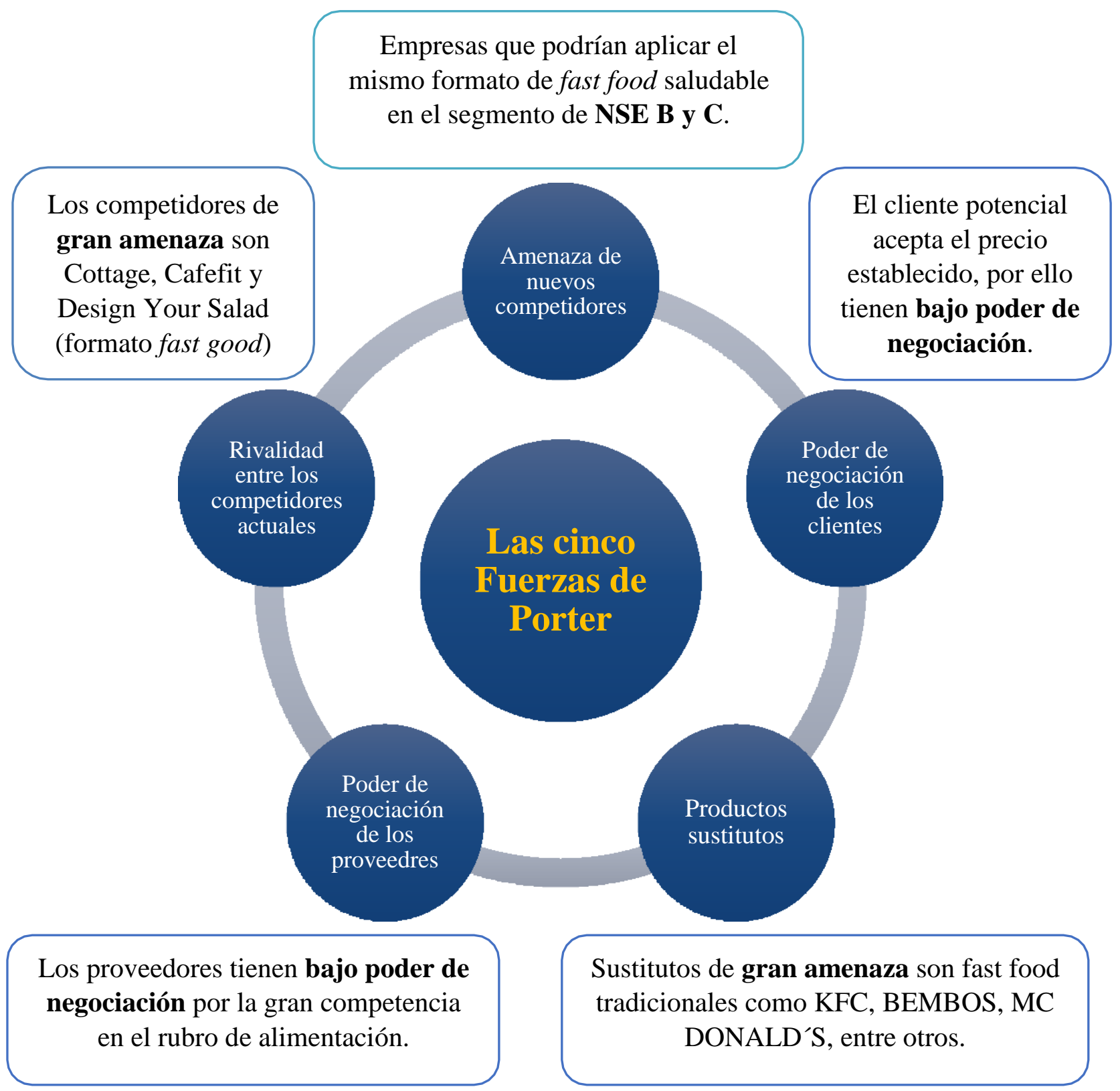

Gráfico 1: Análisis de las cinco fuerzas de Porter. Elaboración propia 


\subsection{Tendencias de la industria (crecimiento, inversiones, consumidores)}

El fast food tiene un antecedente desde la época de la Antigua Roma, sin embargo, el concepto de comida rápida se consolida en Europa durante la Guerra de Napoleónicas en el siglo XIX. (23)

Posteriormente se crearon los ya conocidas fast food Mc Donald's, KFC, Pizza Hut, Burger King, entre otras, que han ido creciendo y actualmente tienen franquicias en todo el mundo. A fines de la década de los 70’s Raúl Diez Canseco Terry conoció el fast food KFC en Guayaquil, Ecuador y tuvo la idea de traer la franquicia al Perú, pudo concretar dicho sueño en el año 1980 y posteriormente inauguró también en Lima la franquicia PizzaHut, sabiendo que este negocio tenía una gran ganancia a futuro. (5)

En el año 2009, el sector de comida rápida en América Latina tuvo una ganancia de 144 600 millones de euros, cuya ganancia incremento al año 2014 en un 19\% con 172500 millones de euros. El continente América registra un gasto importante en consumo de comida rápida con un $47 \%$ del consumo a nivel mundial. (1)

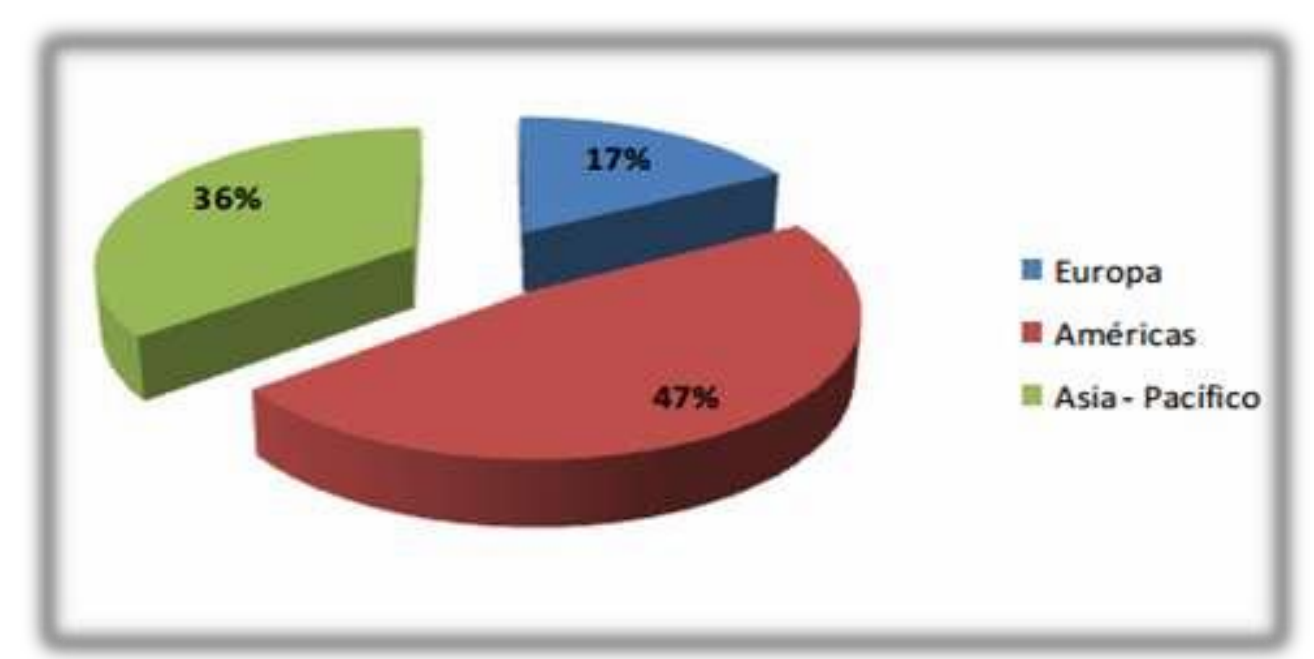

Figura 1: Consumo de fast food en el mundo. Fuente: Datamonitor 
Por otro lado, la tendencia por el cuidado a la salud ha generado que se cree otras corrientes de comida rápida, un estilo de alimentación por la comida lenta o también llamado "Slow food"; comida inteligente, "Smart food" y la comida rápida saludable, "Fast good". (1)

La corriente "Slow food" es un movimiento con alcance internacional. Fue fundada por Carlos Petrini en 1986, quien define al movimiento como la unión del placer de la comida con la responsabilidad y armonía con la naturaleza, protegiendo la biodiversidad alimentaria y establece vínculos entre consumidores y productores. (1)

Por otro lado, se define a "Smart food" como alimentos inteligentes, ya que estos son beneficiosos para el organismo conteniendo un adecuado aporte nutricional (vitaminas y minerales) previniendo enfermedades. (1)

Finalmente, la conocida "Fast good" fue creada por el chef Ferran Adriá ofreciendo una cocina gastronómica sencilla e innovadora, un ejemplo de esta son las juguerías. Como se mencionó en el párrafo anterior estas corrientes han hecho que los fast food incorporen nuevos platos saludables como es el caso de McDonald's París que inauguró su primer establecimiento con un menú que no incluye hamburguesas, siendo reemplazadas por ensaladas y otros platillos saludables. Este tipo de negocio tendrá permanencia en el mercado, para ello es necesario que se ajuste a las necesidades del consumidor. (1)

\subsection{Factores críticos de éxito}

Los factores críticos de éxito se refieren a aquello que generará mayor interés acerca del fast food de comida saludable. Entre ellos tenemos:

- Localización: La ubicación del fast food saludable es fundamental para alcanzar el éxito, este debe encontrarse entre los seis distritos de Lima Moderna que han sido previamente evaluados (La Molina, Miraflores, Santiago de Surco, San Borja, San Isidro y San Miguel). La ubicación objetiva del fast food saludable será aledaño a los 
fast food tradicionales o en los conocidos patio de comidas de centros comerciales o también llamados food courts.

- Las redes sociales: Actualmente la tecnología es parte de nuestra vida diaria, el $98 \%$ de la población de Lima Moderna entre los 8 y 70 años utiliza las redes sociales principalmente la aplicación Facebook, este será de gran utilidad como medio de publicidad para que el negocio muestre el servicio, la carta, ofertas y ubicación de locales. Esta red busca obtener la mayor cantidad de seguidores, siendo estos los que recomiendan a nuevos clientes de vivir la nueva experiencia del fast food saludable. (17)

- El menú: Se considera el factor de éxito más importante de todos, garantizando la asistencia y preferencia de los clientes, brindando calidad y variedad de platos y combos a ofrecer. La carta es la herramienta para captar el interés de nuestro cliente objetivo.

- El precio del menú: Es oscilante, ya que el precio del menú depende del efecto de la inflación anticipada. Sin embargo, se debe tener en cuenta que los precios deben ir acorde al mercado y la competencia de los fast food saludables y tradicionales.

- Servicio al cliente: El cliente es lo más importante, por ello la atención del personal hacia el cliente debe ser amable y servicial. Se tendrá un protocolo de atención al cliente respecto al saludo, sugerencia de menús, hacer el pedido correctamente, etc.

\subsection{Análisis de la Competencia}

Para el análisis de los competidores se usará información recabada con fuentes secundarias y primarias (focus group y encuestas). Los competidores que serán objeto de estudio son aquellos más conocidos dentro de la industria de la comida rápida saludable en Lima Metropolitana, entre los cuales están: (a) Design Your Salad, (b) Cottage Fast Good y (c) Cafefit. 
2.6.1. Empresas que ofrecen el mismo producto o servicio, indicando las semejanzas y diferencias que tienen con el proyecto de empresa

Se presentará tres cadenas de fast food saludables de competencia con el negocio propuesto.

\section{a) Design Your Salad:}

Es una empresa dedicada al consumo de alimentos saludables, donde dan la libertad a sus clientes de escoger los ingredientes para armar sus ensaladas, también tienen wraps, lasañas, sándwich con cárnicos, sándwich vegano, bebidas, postres, sopas y cremas.

- Semejanzas: Locales ubicados en Lima Moderna (Miraflores y Santiago de Surco) con los mismos horarios de atención. El fast food ofrece alimentación saludable con los servicios diseña tu ensalada, combos y platos a la carta, cuentan con fan page.

- Diferencias: Design Your Salad ofrece servicio delivery a distritos cercanos a sus dos locales. No cuentan con postres sin azúcar dentro de su menú.

\section{- Logo y slogan:}

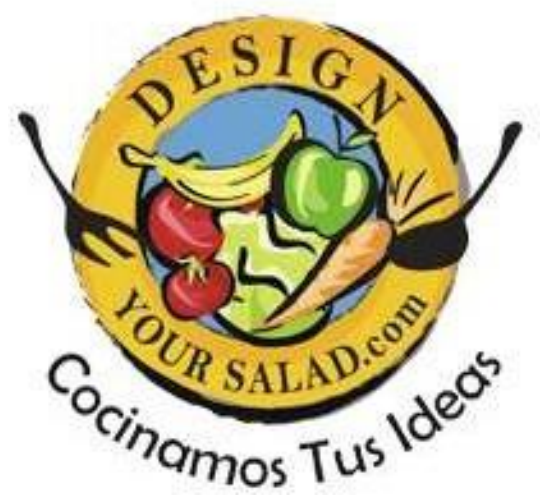

Figura 2: Imagen Design Your Salad. Tomada de red social Facebook. 


\section{b) Cottage fast good:}

Es una empresa peruana de comida rápida saludable, que brinda productos nutritivos. Fue creada por especialistas en nutrición y gastronomía.

- $\quad$ Semejanzas: locales ubicados en Lima Moderna. El fast food ofrece alimentación saludable con los servicios combos y platos a la carta, cuentan con fan page.

- Diferencias: No ofrecen alimentación para clientes veganos y que no consuman azúcar en su menú. Cuenta con tres locales en C.C. Salaverry, Jockey Plaza y Mall Santa Anita.

- $\quad$ Logo y slogan:

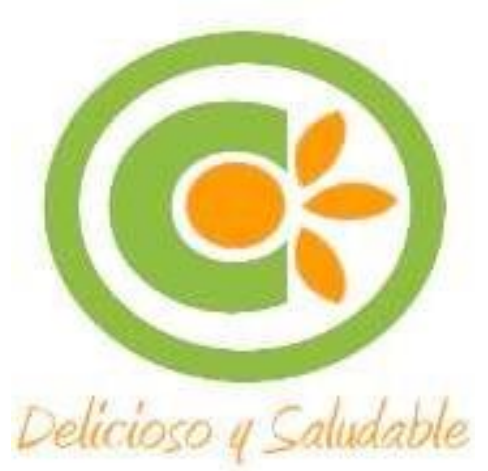

Figura 3: Imagen Cottage Fast Good. Tomada de red social Facebook.

\section{c) Cafefit:}

Es una empresa que ofrece alimentación saludable y cuenta con una carta elaborada por nutricionistas especialistas en deportivos, que la han separado en 3 grupos de acuerdo con el contenido calórico, proteico y de carbohidratos; ofrecen ensaladas, sándwich, wraps, jugos y batidos y otros.

- Semejanzas: Brinda una amplia carta de alimentación saludable. Cuenta con fan page.

- Diferencias: Cuenta con cinco locales en Lima Metropolitana y tres de ellos en Lima Moderna tanto en Centro Comerciales como en Gimnasios, con 
horario más amplio, dos de sus locales realizan delivery para zonas aledañas.

Su carta se encuentra separada en tres líneas (actívate, refuérzate y cuídate) y en cada uno de sus platos se encuentra su aporte calórico, así como la cantidad de gramos de carbohidratos y proteínas. No cuentan con alimentación para personas veganas y postres sin azúcar en su carta.

- Logo y slogan:

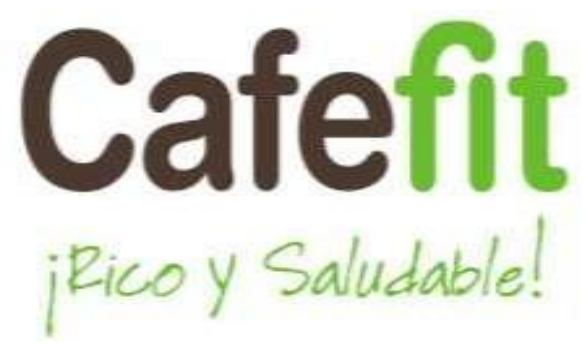

Figura 4: Imagen Cafefit. Tomada de sitio web.

Tabla 1

Tabla comparativa de las competencias directas de Healthy Corner

\begin{tabular}{|c|c|c|c|c|c|c|}
\hline \multirow{2}{*}{ EMPRESAS } & \multicolumn{4}{|c|}{ SEMEJANZAS } & \multicolumn{2}{|c|}{ DIFERENCIAS } \\
\hline & Servicio & Horario & $N^{\circ}$ Locales & Publicidad & Delivery & Productos \\
\hline & Carta variada & $\begin{array}{l}\text { Lunes a } \\
\text { domingo }\end{array}$ & $\begin{array}{c}2 \text { / } 2 \text { locales } \\
\text { en Lima Moderna }\end{array}$ & Fanpage & $\mathrm{Si}$ & $\begin{array}{l}\text { No tienen } \\
\text { postres sin } \\
\text { azúcar }\end{array}$ \\
\hline 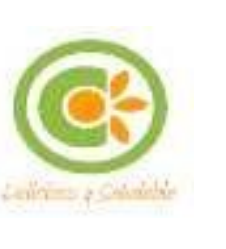 & $\begin{array}{l}\text { Carta variada } \\
\text { con aporte } \\
\text { calórico y } \\
\text { gramaje de } \\
\text { carbohidratos } \\
\text { y proteínas }\end{array}$ & $\begin{array}{l}\text { Lunes a } \\
\text { domingo }\end{array}$ & $\begin{array}{c}2 \text { / } 4 \text { locales } \\
\text { en Lima Moderna }\end{array}$ & Fanpage & No & $\begin{array}{c}\text { No } \\
\text { productos } \\
\text { para veganos } \\
\text { ni postres } \\
\text { sin azúcar }\end{array}$ \\
\hline Cafefit & $\begin{array}{l}\text { Carta variada } \\
\text { con aporte } \\
\text { calórico y } \\
\text { gramaje de } \\
\text { carbohidratos } \\
\text { y proteínas }\end{array}$ & $\begin{array}{l}\text { Lunes a } \\
\text { domingo }\end{array}$ & $\begin{array}{c}3 \text { / } 4 \text { locales } \\
\text { en Lima Moderna } \\
\text { (Centros Comerciales } \\
\text { y gimnasios) }\end{array}$ & Fanpage & $\mathrm{Si}$ & $\begin{array}{l}\text { No tienen } \\
\text { postres sin } \\
\text { azúcar }\end{array}$ \\
\hline
\end{tabular}

Fuente: Elaboración propia. 


\subsubsection{Matriz del perfil competitivo}

La finalidad de realizar la matriz del perfil competitivo es analizar las competencias y debilidades según los factores críticos de éxito del plan de negocio del fast food saludable.

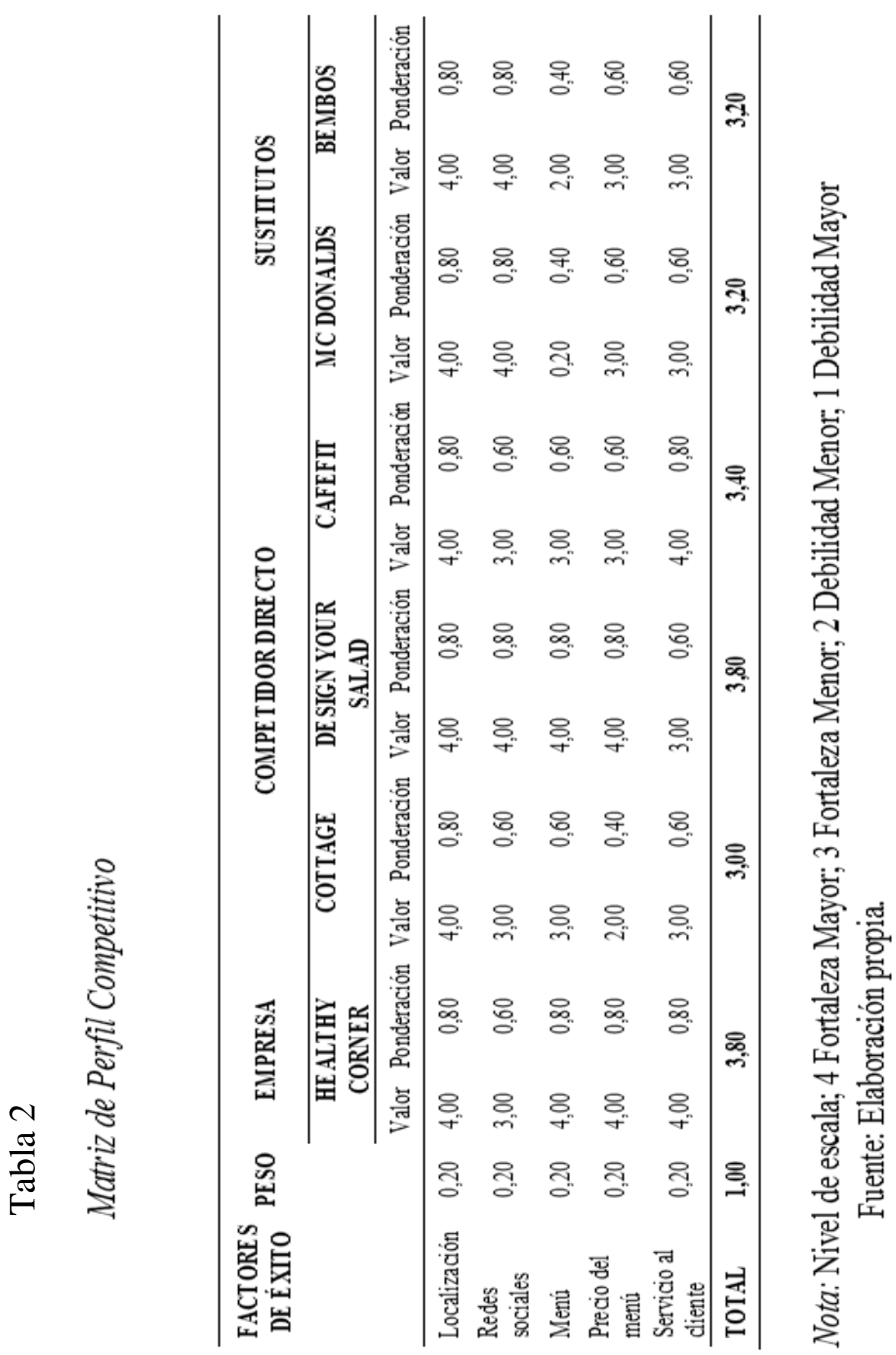


En la Tabla 2 se puede apreciar que los factores de éxito son localización del fast food saludable, las redes sociales como medio de marketing, el menú por su calidad y variedad de producto a ofrecer al cliente, el precio del menú debe encontrarse acorde al mercado y servicio al cliente. Los cuáles serán comparados con Healthy Corner mediante la puntuación acorde en cada uno de los factores de éxito.

Considerando el primer factor de éxito, la localización de los tres competidores tiene un alto puntaje, ya que cada uno de ellos tienen locales establecidos en los distritos de Lima Moderna.

En la actualidad la exposición de servicios y productos en las redes sociales es un factor de éxito, los tres competidores manejan el marketing mediante aplicación de celular (App), Facebook y/o página web; resaltando entre ellos Design Your Salad.

Considerando la calidad y variedad del menú un factor de éxito, los competidores tienen base nutricional, pensando en brindar un servicio y producto inocuo, apto para diversos estilos de alimentación (incluyendo algunos productos veganos, libres de azúcar y de gluten) para desarrollar su carta de menú. Entre los que destacan Design Your Salad.

El precio de menú es determinante para obtener clientes, por ello comparando los precios de los tres competidores, Design Your Salad tiene el precio más elevado, esto podría deberse a que cuenta con una carta más amplia y productos/ insumos con mayores costos.

Finalmente, el servicio al cliente es tan importante como los factores antes mencionado, en el cual destaca Cafefit por tener personal entrenado y capacitado para la atención al cliente. 
En conclusión, Healthy Corner promete ser un competidor que reúne la puntuación más alta al igual que Design Your Salad con 3,80, el cual los ubica como los competidores con prevalencia a Fortalezas Mayores en cada uno de los factores de éxito; frente a los sustitutos "fast food tradicional" que presentan la menor puntuación con 3,20.

\subsection{Oportunidades}

La oportunidad de negocio de un fast food saludable en Lima Metropolitana es propicia, ya que tiene múltiples razones para ser un negocio rentable. A continuación, se detallan:

- El perfil del consumidor peruano es variable, particularmente en la industria de los alimentos actualmente hay un fuerte movimiento fitness y wellness, por ello se encuentra en auge el consumo de productos saludables llamados también productos light, de costos similares a productos tradicionales (no light), esto se debe a que el consumidor "valora" mejorar su condición de vida, salud e imagen personal, practicidad, soluciones modernas, entre otras. (12)

- En la actualidad el número de mujeres que trabaja fuera del hogar ha incrementado en 23,2\% en los últimos 10 años, lo que representa a 6,9 millones de mujeres, creando así una necesidad de consumir alimentos fuera de casa y se encuentran en la búsqueda de un lugar donde cuenten con una alimentación saludable y nutritiva. (13)

- $\quad$ El 53,2\% de la población de 15 años a más padece de exceso de peso, principalmente es causado por una mala alimentación, siendo este último uno de los factores de riesgo para desarrollar enfermedades crónicas no transmisibles, por ejemplo, hipertensión, diabetes, dislipidemias, obesidad y enfermedades cardiovasculares. Por ello este problema de salud pública es una oportunidad de negocio como alternativa para el 
cliente que busca alimentos saludables y en la cantidad adecuada con un aporte calórico y nutricional. (17)

- El primer bimestre del año 2016, la industria de comida rápida tiene un crecimiento económico sostenido, en el cual se obtuvo un incremento de 2,83\%. (19)

- El 45\% de la población de Lima Moderna, entre las edades de 21 a 35 años visita ocasionalmente los fast food. (20)

El 98\% de la población de Lima Moderna entre las edades 8 y 70 años, tiene la red social Facebook, la cual es una de las principales formas de comunicación, promoción y difusión de servicios y productos. (22)

- La Remuneración Mínima Vital (RMV) de los trabajadores asciende a 850 soles, este incremento de sueldo principalmente tiene mayor beneficio en el sector de alimentos, ya que, según el Informe del Perfil del Consumidor Peruano de la Universidad de Piura, si hubiese un incremento de $25 \%$ en el presupuesto, el $27,1 \%$ de los encuestados mejorarían su presupuesto de alimentación. Por otro lado, el 54\% de los peruanos prefiere acudir a fast food. (24). 


\section{CAPÍTULO III: ESTUDIO DE MERCADO}

\subsection{Descripción del servicio}

La propuesta de fast food saludable, ofrece al consumidor en Lima Moderna una alternativa de tener rápido acceso a consumir bebidas y platos agradables teniendo conocimiento del valor calórico y nutricional que estos aportan y a un precio acorde al mercado, favoreciendo la salud y necesidades del consumidor.

El único local estará estratégicamente ubicado en el patio de comidas del Centro Comercial Jockey Plaza en el distrito de Santiago de Surco perteneciente a Lima Moderna. El diseño de interiores del local irá acorde a la tendencia mundial por lo natural y orgánico, el fast food saludable tendrá un ambiente acogedor. (Ver Figura 9)

Se ofrecerá una carta elaborada por la o el nutricionista y la o el chef, la cual tiene una variedad y nuevas opciones de bebidas y platos agradables, atractivos y sobre todo saludables en la modalidad de raciones unitarias y por combos personales, teniendo en cuenta el tamaño adecuado y el valor calórico estándar (Ver Figura 5) y nutricional de los platos. (Ver Figura 6)

Las bebidas y platos a ofrecer se caracterizan por el contenido de nutrientes a base de alimentos $100 \%$ naturales, orgánicos y productos elaborados libres de gluten y/o azúcares refinados como las verduras, hortalizas, frutas frescas, zumos, alimentos de origen animal y/o vegetal, entre otros. Adicional a la carta, se ofrecerá postres veganos, integrales y orgánicos, de Vegánimo, empresa socia y comprometida con la salud y el medio ambiente. El horario de atención al público será de lunes a domingo desde las 10:00 horas hasta las 23:00 horas. 


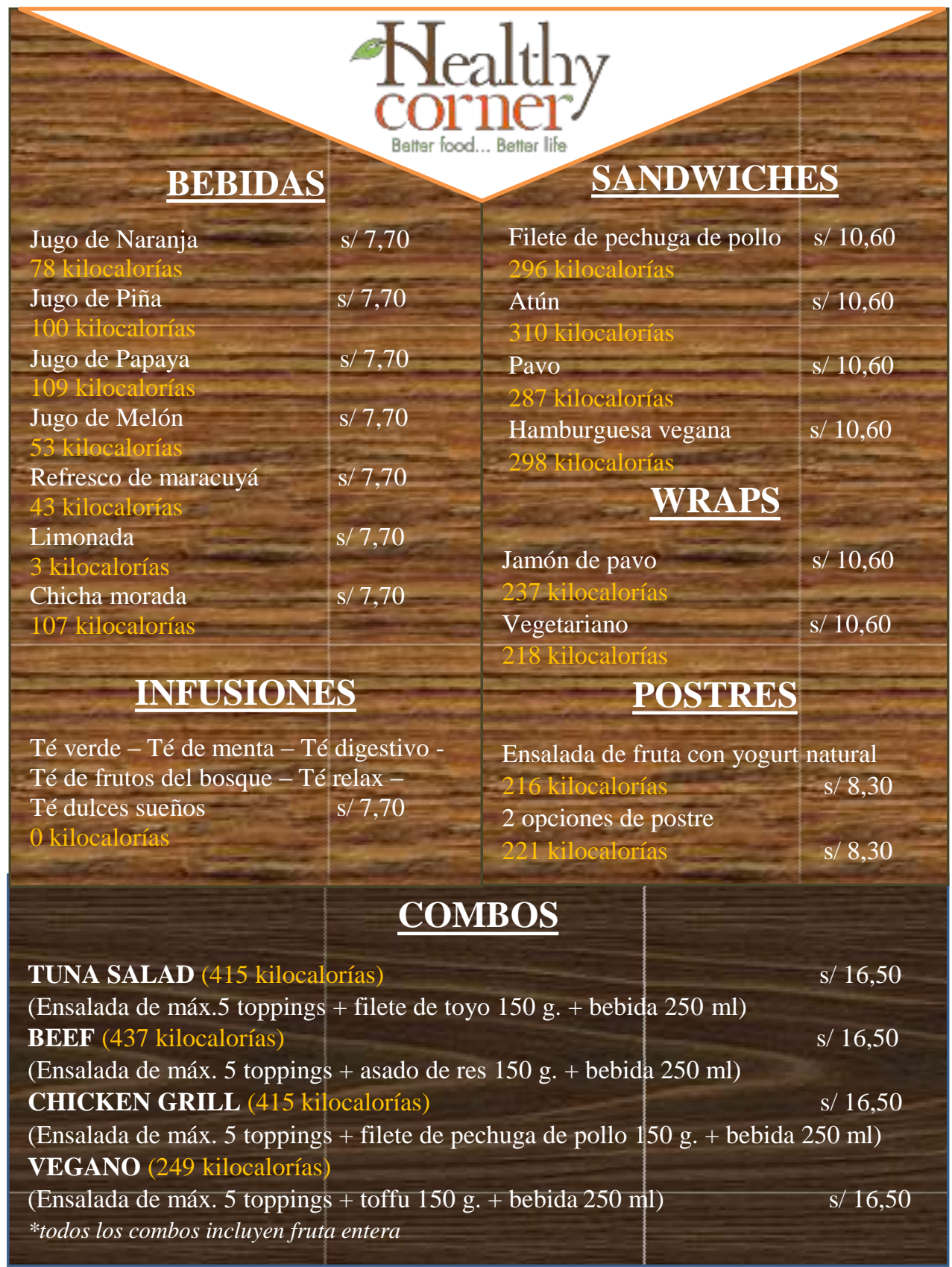

Figura 5: Carta de bebidas y platos elaborados del fast food Healthy Corner.

Elaboración propia 
Los tableros o paneles del fast food promocionarán los productos y su valor energético y nutricional.

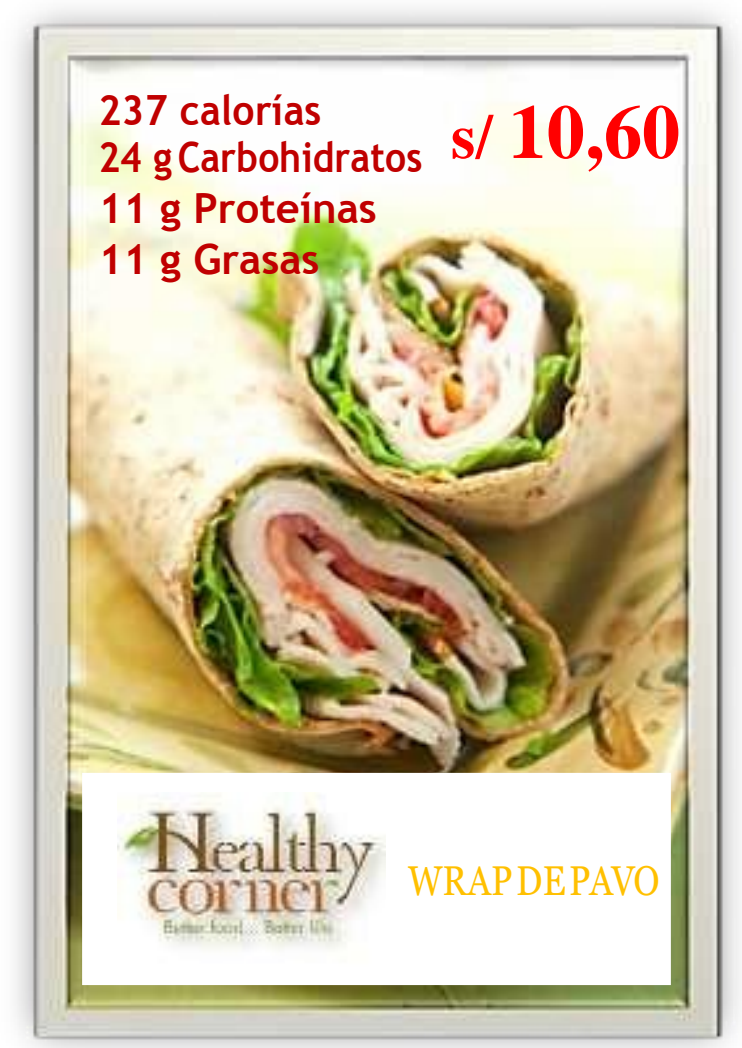

Figura 6: Imagen del tablero de fast food Healthy Corner.

Elaboración propia 
Tabla 3

Valor energético y nutricional de los productos de "Healthy Corner"

\begin{tabular}{|c|c|c|c|c|}
\hline \multirow{2}{*}{$\begin{array}{l}\text { Producto } \\
\text { Jugos e Infusiones }\end{array}$} & \multicolumn{4}{|c|}{ Valor Nutricional } \\
\hline & ENER & PROT & CHO & LIP \\
\hline & kcal. & $\mathrm{g}$ & $\mathrm{g}$ & $\mathrm{g}$ \\
\hline Jugo de Naranja & 78,0 & 1,8 & 17,3 & 0,2 \\
\hline Jugo de Piña & 100,0 & 1,0 & 23,9 & 0,3 \\
\hline Jugo de Papaya & 109,0 & 0,4 & 27,9 & 0,4 \\
\hline Jugo de Melón & 53,0 & 1,9 & 12,6 & 0,4 \\
\hline Refresco de Maracuyá & 43,0 & 0,3 & 6,9 & 0 \\
\hline Limonada & 2,9 & 0,1 & 0,9 & 0 \\
\hline Chicha morada & 107,0 & 0,7 & 27,7 & 0,4 \\
\hline Té Verde & 0 & 0 & 0 & 0 \\
\hline Té de Menta & 0 & 0 & 0,1 & 0 \\
\hline Té de frutos del bosque (mora, arándanos, frambuesa) & 0 & 0 & 0,2 & 0 \\
\hline $\begin{array}{l}\text { Té digestivo (Manzanilla, muña, boldo, anís, cedrón, } \\
\text { menta) }\end{array}$ & 0 & 0 & 0,2 & 0 \\
\hline $\begin{array}{l}\text { Té Relax (valeriana, menta, romero, hierba luisa, } \\
\text { manzanilla) }\end{array}$ & 0 & 0 & 0,2 & 0 \\
\hline $\begin{array}{l}\text { Té Dulces sueños (manzanilla, valeriana, naranja, menta, } \\
\text { canela, cedrón) }\end{array}$ & 0 & 0 & 0,2 & 0 \\
\hline Sándwiches & ENER & PROT & CHO & LIP \\
\hline Filete de pechuga de pollo (70g en crudo) & 296 & 20 & 35 & 2,1 \\
\hline Atún $(60 \mathrm{~g}$ escurrido) & 310 & 15 & 40 & 3 \\
\hline Pavo (70g en crudo) & 287 & 20 & 36 & 1,9 \\
\hline Hamburguesa vegana de lentejas ( $70 \mathrm{~g}$ en crudo) & 298 & 18 & 39 & 2,4 \\
\hline Wraps & ENER & PROT & CHO & LIP \\
\hline Jamón de pavo & 237 & 11 & 24 & 11 \\
\hline Vegetariano & 218 & 10 & 24 & 8 \\
\hline Postres & ENER & PROT & CHO & LIP \\
\hline Ensalada de fruta con yogurt natural y kiwicha & 216 & 2,5 & 28,9 & 3,3 \\
\hline 2 opciones de postres dulces con edulcorante y sin leche & 221,3 & 5,2 & 31,2 & 14,1 \\
\hline Combos & ENER & PROT & CHO & LIP \\
\hline $\begin{array}{l}\text { TUNA SALAD } \\
\text { (ensalada máxima 5topping+filete de toyo } 150 \mathrm{~g} \text { en crudo + bebida } 250 \mathrm{ml} \text { ) }\end{array}$ & 415,2 & 33,3 & 26,2 & 0,7 \\
\hline $\begin{array}{l}\text { BEEF } \\
\text { (ensalada máxima } 5 \text { toppings +asado de res } 150 \mathrm{~g} \text { en crudo + bebida } 250 \mathrm{ml} \text { ) }\end{array}$ & 437 & 34,1 & 27,6 & 1,2 \\
\hline $\begin{array}{l}\text { CHICKEN GRILL } \\
\text { (ensalada máxima } 5 \text { toppings +filete de pechuga de pollo } 150 \text { en crudo + bebida } 250 \mathrm{ml} \text { ) }\end{array}$ & 415,2 & 33,3 & 26,2 & 0,7 \\
\hline $\begin{array}{l}\text { VEGANO } \\
\text { (ensalada máxima } 5 \text { toppings }+ \text { toffu } 150 \mathrm{~g} \text { en crudo }+ \text { bebida } 250 \mathrm{ml} \text { ) } \\
{ }^{*} \text { Combos con postre natural incluye fruta entera }\end{array}$ & 249 & 11,4 & 29,5 & 5,5 \\
\hline
\end{tabular}

Fuente: Elaboración propia 


\subsection{Selección del segmento de mercado}

El segmento del mercado son los consumidores de fast food que tienen intención de compra de un formato saludable.

Según IPSOS APOYO 2016- Perfiles Zonales del 100\% de la población de Lima Metropolitana el 12,7\% de la población pertenece a Lima Moderna. (21)

Es importante señalar que el ingreso familiar per cápita es el factor más influyente en las decisiones de compra para el consumo de alimentos en los hogares. Tomando en cuenta lo mencionado el mercado objetivo se limita a los NSE B $(52,6 \%)$ y C $(13,2 \%)$, siendo un total de 65,8\% de la población de Lima Moderna.

Según IPSOS en Lima Moderna el 45\% de la población entre las edades de 21 a 35 años de edad, visita ocasionalmente locales de fast food y el estudio de ARELLANO MARKETING 2015, concluye que las personas mayores de 25 años de edad tienden a preocuparse por su peso y por ende en consumir una alimentación saludable, estas edades están incluidas en el rango de edad por perfiles zonales de IPSOS APOYO 2015, considerándose a las personas que se encuentran entre los 21 a 59 años, equivalente al 53,8\% de la población de Lima Moderna. (20)

Según la consultora Quality Research 2015, el 73\% de Lima Moderna acude por lo menos una vez cada 15 días a los fast food, siendo un total de 611654 hab. (11)

Según IPSOS la población entre 21 a 59 años, es el 53,8\%, siendo un total de 329070 hab. Según DATUM INTERNACIONAL 2013, el 40\% de limeños se preocupan en tener una alimentación saludable, siendo un total de 131628 hab. (21) 
Resumen:

A. Población de Lima Moderna (IPSOS APOYO 2016):

1273377 hab.

B. Nivel socioeconómico en Lima Moderna al 100\% (IPSOS APOYO 2016):

- $\quad$ NSE A $\rightarrow 32,2 \%$

- NSE B $\rightarrow 52,6 \%$

- $\quad \mathrm{NSE} \mathrm{C} \rightarrow 13,2 \%$ $65,8 \%=837882$ hab.

- $\quad$ NSE D $\rightarrow 1,5 \%$

- $\quad \mathrm{NSE} \mathrm{E} \rightarrow 0,5 \%$

C. Población de Lima Moderna que acude quincenalmente a los fast food (CONSULTORA QUALITY RESEARCH 2015):

$$
73 \%=611654 \text { hab. }
$$

D. Grupo etario entre los 21 a 59 años de edad (IPSOS APOYO 2016):

$$
53.8 \%=329070 \text { hab. }
$$

E. Población de Lima que se preocupa por su alimentación saludable (DATUM INTERNACIONAL 2013):

$40 \%=131628$ hab.

Entonces:

Tamaño del Universo: 131628

Heterogeneidad: $50 \%$

Margen de error: 5,5

Nivel de confianza: 95

El tamaño de la muestra 317 hab. 


\subsection{Investigación cualitativa}

La investigación cualitativa se llevó a cabo mediante la técnica del Focus Group.

\subsubsection{Selección del método de indagación}

La finalidad del Focus Group es obtener la mayor cantidad de información veraz para sostener este estudio y la viabilidad del proyecto.

Los Objetivos del Focus Group son:

- Analizar los hábitos alimenticios de los consumidores de comida rápida.

- Conocer la percepción de los consumidores acerca de comida rápida y comida saludable.

- Comportamiento de compra de consumidores frente a la comida saludable.

- Conocer el grado de satisfacción de los consumidores de fast food ante la Comida saludable.

- Sondear la idea del negocio.

Se realizaron dos grupos:

- Grupo 1: Ocho personas del nivel socioeconómico B de Lima Moderna. Entre21 a 59 años, que han consumido fast food en los últimos 30 días.

- Grupo 2: Ocho personas del nivel socioeconómico C de Lima Moderna. Entre 21 a 59 años, que han consumido fast food en los últimos 30 días.

\subsubsection{Diseño de instrumento}

A continuación, se presenta el instrumento "Guía de indagación” diseñado con el fin de aplicarlo en los Focus Group.

(Ver Anexo 3 Transcripción del focus group 01)

(Ver Anexo 4 Transcripción del focus group 02)

(Ver Anexo 5 Evidencia fotográfica de focus group) 


\section{GUÍA DE INDAGACIÓN}

\section{a. Introducción:}

Buenos días, mi nombre es .... La finalidad de esta reunión es para tratar algunos temas de interés en la cual cada uno puede expresar libremente sus opiniones. Les informo que serán grabados sólo para la facilidad del recojo de información, y recuerden que ninguna de sus respuestas estará equivocada sino al contrario todas sus opiniones serán válidas y de gran ayuda para el propósito de la investigación. A continuación, me gustaría que se presente, brindando su nombre y ocupación.

\section{b. Calentamiento:}

Empecemos hablando de las tres comidas diarias, desayuno, almuerzo y cena:

- ¿Suele consumir las tres comidas?

- ¿En dónde suele consumir sus comidas, en casa o fuera de casa?

- Si es en casa ¿Qué suele consumir?

- Si es fuera de casa ¿A qué sitios suele acudir? ¿Qué ordena? ¿Con qué frecuencia?

- ¿Ha acudido a algún fast food en los últimos 30 días?

\section{c. Preguntas de profundidad:}

- ¿Qué entiende por fast food o comida rápida?

- ¿Cuál es su opinión con respecto a la comida rápida o fast food?

- ¿Qué fast food conoce?

- ¿Cuál es su preferido o a cuál acude la mayoría de las veces? ¿Por qué? ¿Influye el precio?

- ¿En qué momento del día acude a un fast food?

- ¿Con quiénes suele acudir a estos centros de comida rápida, solos, con la familia, con los amigos? 
- ¿Entre comer en casa e ir a un fast food, cuál prefiere? ¿Qué diferencias encuentra? ¿Cree que la comida rápida puede afectar su salud? ¿Por qué?

- ¿Qué entiende usted por “comida saludable”?

\section{d. Prueba de concepto:}

A continuación, les explicaré un concepto para que me den su opinión.

La propuesta de fast food saludable, ofrece al consumidor en Lima Moderna una alternativa de tener rápido acceso a consumir bebidas y platos agradables teniendo conocimiento del valor calórico y nutricional que estos aportan y a un precio acorde al mercado, favoreciendo la salud y necesidades del consumidor.

El único local estará estratégicamente ubicado en el patio de comidas del Centro Comercial Jockey Plaza en el distrito de Santiago de Surco. El horario de atención al público será de lunes a domingo desde las 10:00 horas hasta las 23:00 horas.

Se ofrecerá una carta elaborada por la o el nutricionista y la o el chef, la cual tiene una variedad y nuevas opciones de bebidas y platos agradables, atractivos y sobre todo saludables, ya que son productos a base de alimentos $100 \%$ naturales, orgánicos y productos elaborados libres de gluten y/o azúcares refinados como las verduras, hortalizas, frutas frescas, zumos, alimentos de origen animal y/o vegetal, entre otros. Adicional a la carta, se ofrecerá postres veganos, integrales y orgánicos, de Vegánimo, empresa socia y comprometida con la salud y el medio ambiente.

- ¿Qué opina/piensa de este concepto que les acabo de describir?

- ¿Es bueno, malo?

- ¿Qué le gusta, que no le gusta? ¿Por qué?

- ¿Ha escuchado algún concepto como éste? 
- ¿Usted asistiría a un sitio como este? ¿Por qué?

- ¿Con quiénes asistiría?

- ¿En qué horario asistiría, desayuno, almuerzo o cena?

- ¿Le gustaría que en este servicio que les acabo de describir, hubiese servicio de delivery?

- ¿Usted lo tomaría como una opción entre sus alternativas de fast food?

- ¿Cuánto pagaría por una ración personal?

- ¿Con qué frecuencia asistiría?

- ¿Les gusta el nombre HEALTHY CORNER o preferiría otro nombre para el establecimiento? ¿Preferiría que el nombre sea en inglés o en español?

- ¿Dónde le gustaría que se promocione el concepto?

\section{e. Finalización:}

Muchas gracias por su tiempo. Se les pide que se acerquen al coffe break.

\subsubsection{Análisis y procesamiento de datos}

El focus group estuvo conformado por dos grupos de ocho personas cada uno, según su NSE B y C de Lima Moderna, que tienen entre los 21 a 59 años de edad. Ambas reuniones tuvieron una duración de 60 minutos y fueron grabadas y filmadas con el fin de recopilar todas las opiniones de cada uno de ellos.

Al inicio se hizo referencia a la introducción realizando la presentación y el motivo del Focus Group, requiriendo sus datos personales para identificarlos.

Luego se inició las preguntas de calentamiento y se obtuvo las siguientes opiniones: La mayoría de los participantes consume las tres comidas (desayuno, almuerzo y cena), ya que suelen prepararlos en casa; sin embargo, hay cinco participantes que no cumplen con estos tiempos de alimentación, ya que se encuentran fuera de casa. 
Todos los participantes consumen comida criolla, solo uno especificó que también consumía comida vegetariana. La mayoría de los participantes suelen acudir preferentemente a KFC, pollerías y Chifa cuando desean consumir sus alimentos fuera de casa. Todos han acudido a un fast food en los últimos 30 días.

En las preguntas a profundidad se obtuvieron las siguientes opiniones:

Los participantes entienden por "fast food" un lugar donde venden comida exprés y perjudicial para la salud; opinan que esta es rica, poco saludable y contiene grasa saturada.

Todos coinciden que el precio influye en el consumo de los fast food, entre los que conocen y prefieren son KFC, Pizza Hut y Bembos, debido a que le gusta a toda la familia, hay variedad, son económicos y tienen promociones. De menor preferencia son Pollerías y Otto Grill. La mayoría acude a los fast food en horarios de almuerzo y cena. Suelen acudir con la familia y amigos.

Coinciden que el consumo de fast food puede afectar a su salud, por ello prefieren consumir sus alimentos en casa, debido a que son más saludable y ricos, utilizan poco condimento y conocen quien lo prepara.

Asimismo, entienden por "comida saludable" a aquella comida que es balanceada, contiene nutrientes, y contiene poco condimento y grasa saturada.

Luego de exponer la prueba de concepto se obtuvo las siguientes opiniones:

Los participantes opinan que la propuesta de un "fast food saludable" es interesante y una buena opción de consumo; les gusta el concepto porque es comida saludable y al paso, sobre todo porque la carta es elaborada por chef y nutricionista.

La mayoría ha escuchado un concepto similar y todos asistirían con sus familias y amigos en los horarios de almuerzo y cena. Les gustaría que hubiese servicio delivery. 
Los participantes lo consideran una opción entre las alternativas de fast food, estarían dispuestos a pagar 12 soles por un desayuno y hasta 20 soles por almuerzo y cena; la mayoría optó por considerar ir diariamente y 2 veces a la semana.

A la mayoría de los participantes le gusta el nombre Healthy Corner, sin embargo, prefieren el nombre en español.

Les gustaría que promocionen el concepto en las redes sociales; paneles publicitarios cerca de Universidades, oficinas, hospitales, supermercados, centros comerciales y gimnasios; televisión; radio; folletos; boletines y periódico.

\subsection{Investigación cuantitativa}

Con la finalidad de fundamentar una adecuada investigación de mercado se realizó el modelo de Encuesta referente al fast food saludable, con el fin de obtener la mayor cantidad de información veraz para sostener este estudio y la viabilidad del proyecto.

\subsubsection{Proceso de muestreo}

Es un estudio de muestreo no probabilístico, por conveniencia, para la recolección de datos.

El tamaño de la muestra es de 317 individuos. La Encuesta fue aplicada a los transeúntes de las inmediaciones del patio de comidas de los Centros Comerciales Open Plaza Angamos, Real Plaza Primavera, Jockey plaza, Real plaza Salaverry, Plaza San Miguel y el food courts de las Begonias-San Isidro. 


\subsubsection{Diseño de instrumento}

La encuesta se desarrolló a partir de las opiniones de los participantes del Focus Group; se pretende respaldar la viabilidad de la propuesta de fast food saludable, así como conocer el perfil, hábitos y costumbres del consumidor.

Se implementó la Ficha de NSE (Ver Anexo 6), el cual corrobora que los encuestados pertenecen al NSE B y C. Luego se procede a aplicar La encuesta que consta en dos partes: preguntas filtro y las preguntas de prueba de concepto (Ver Anexo 7). Los resultados se obtendrán en base de 317 encuestados, cuya información será ingresada al programa IBM SPSS STATISTICS 22.

\subsubsection{Análisis y procesamiento de datos}

\section{Pregunta $N^{\circ}$ 1: ¿Cuál es tu género?}

Tabla 4

Número de personas según género

\begin{tabular}{clcc}
\hline & & Frecuencia & $\begin{array}{c}\text { Porcentaje } \\
\text { válido }\end{array}$ \\
\hline \multirow{3}{*}{ Válido } & FEMENINO & 158 & 49,8 \\
& MASCULINO & 159 & 50,2 \\
& Total & 317 & 100,0 \\
\hline
\end{tabular}

Fuente: Elaboración propia.

Conclusión: Analizando el total de respuestas obtenidas, hay un porcentaje mayor de género masculino $(50,2 \%)$. 
Pregunta $\mathrm{N}^{\circ}$ 2: ¿Cuál es tú distrito de procedencia?

Tabla 5

Número de personas procedentes de los distritos de Lima Moderna

\begin{tabular}{llcc}
\hline & Frecuencia & $\begin{array}{c}\text { Porcentaje } \\
\text { válido }\end{array}$ \\
\hline BARRANCO & 30 & 9,5 \\
JESÚS MARÍA & 17 & 5,4 \\
LA MOLINA & 30 & 9,5 \\
LINCE & 21 & 6,6 \\
Válido & 26 & 8,2 \\
MAGDALENA DEL MAR & 23 & 7,3 \\
PUEBLO LIBRE & 34 & 10,7 \\
SAN BORJA & 19 & 6,0 \\
SAN ISIDRO & 24 & 7,6 \\
SAN MIGUEL & 71 & 22,4 \\
SANTIAGO DE SURCO & 22 & 6,9 \\
SURQUILLO & 317 & 100,0 \\
\hline
\end{tabular}

Fuente: Elaboración propia.

Conclusión: En la tabla se observa que la mayoría de encuestados procede de Santiago de Surco con un 22,9\%; le sigue San Borja, 10,7\% y con menor porcentaje se encuentra el distrito Jesús María con 5,4\%.

\section{Pregunta N$^{\circ}$ : ¿Cuál es tú nivel socioeconómico?}

Tabla 6

Número de personas del Nivel Socioeconómico B y C

\begin{tabular}{cccc}
\hline & & Frecuencia & $\begin{array}{c}\text { Porcentaje } \\
\text { válido }\end{array}$ \\
\hline \multirow{3}{*}{ Válido } & B & 200 & 63,1 \\
& C & 117 & 36,9 \\
& Total & 317 & 100,0 \\
\hline
\end{tabular}

Fuente: Elaboración propia.

Conclusión: El nivel socioeconómico de mayor porcentaje es el "B" con un $63,1 \%$. 
Pregunta $\mathrm{N}^{\circ}$ 4: ¿Cuál es tú rango de edad?

Tabla 7

Número de personas según su rango de edad

\begin{tabular}{cccc}
\hline & Frecuencia & $\begin{array}{c}\text { Porcentaje } \\
\text { válido }\end{array}$ \\
\hline \multirow{3}{*}{ Válido } & 21 A 35 AÑOS & 207 & 65,3 \\
& 36 A 59 AÑOS & 110 & 34,7 \\
& Total & 317 & 100,0 \\
\hline
\end{tabular}

Fuente: Elaboración propia.

Conclusión: El 65,3\% pertenecía al rango de edad de 21 a 35 años, 67

participantes fueron retirados por el filtro de edad ( $<20$ y $>60$ años).

Pregunta $\mathrm{N}^{\circ}$ 5: ¿Cuál es el motivo por el cual usted come en un fast food?

Tabla 8

Número de personas según motivo de consumo en fast food

\begin{tabular}{llcccc}
\hline & Frecuencia & Porcentaje & $\begin{array}{c}\text { Porcentaje } \\
\text { válido }\end{array}$ & $\begin{array}{c}\text { Porcentaje } \\
\text { acumulado }\end{array}$ \\
\hline \multirow{2}{*}{ Válido } & POR GUSTO & 181 & 57,1 & 57,1 & 57,1 \\
& POR FALTA DE TIEMPO & 136 & 42,9 & 42,9 & 100,0 \\
& Total & 317 & 100,0 & 100,0 & \\
\hline
\end{tabular}

Fuente: Elaboración propia.

Conclusión: La principal causa por la cual los encuestados comen en un fast food es por gusto, obteniendo un 57,1\% lo cual indica que la mayoría de las personas prefiere disfrutar fuera de casa. 
Pregunta $\mathrm{N}^{\circ}$ 6: ¿A qué patio de comida acude con mayor frecuencia?

Tabla 9

Número de personas según frecuencia al patio de comida de centro comerciales

\begin{tabular}{llcc}
\hline & & Frecuencia & $\begin{array}{c}\text { Porcentaje } \\
\text { válido }\end{array}$ \\
\hline \multirow{6}{*}{ OPEN PLAZA ANGAMOS } & 38 & 12,0 \\
REAL PLAZA SALAVERRY & 80 & 25,2 \\
& FOOD COURT SAGA & & \\
& FALABELLA BEGONIAS & 42 & 13,2 \\
& JOCKEY PLAZA & 102 & 32,2 \\
& PLAZA SAN MIGUEL & 33 & 10,4 \\
& REAL PLAZA PRIMAVERA & 22 & 6,9 \\
& Total & 317 & 100,0 \\
\hline
\end{tabular}

Fuente: Elaboración propia.

Conclusión: El 32,2\% de los encuestados asiste con mayor frecuencia al patio de comidas del C. C. Jockey Plaza, y el menor porcentaje se encuentra el Real Plaza Primavera con un 6,9\%.

Pregunta $\mathrm{N}^{\circ} 7$ : ¿Cuáles son los atributos más importantes que usted busca para consumir en un fast food?

Tabla 10

Número de personas según atributos importantes para consumir en un fast food

\begin{tabular}{lcccc}
\hline & Si & $\begin{array}{c}\text { Porcentaje } \\
\text { válido }\end{array}$ & No & $\begin{array}{c}\text { Porcentaje } \\
\text { válido }\end{array}$ \\
\hline Valido SABOR & 189 & 59,6 & 128 & 40,4 \\
VARIEDAD & 163 & 51,4 & 154 & 48,6 \\
HORARIO & 126 & 39,7 & 191 & 60,3 \\
RAPIDEZ & 105 & 33,1 & 212 & 66,9 \\
FACILIDAD DE PAGO & 109 & 34,4 & 208 & 65,6 \\
PRECIO & 38 & 12,0 & 279 & 88,0 \\
PROMOCIONES & 18 & 5,7 & 299 & 94,3 \\
BUEN AMBIENTE & 133 & 42,0 & 184 & 58,0 \\
\hline
\end{tabular}

Fuente: Elaboración propia. 
Conclusión: El 59,6\% busca el buen sabor para acudir al fast food, seguido por la variedad de menú y el buen ambiente. Como atributo menos importante con un $5,7 \%$ son las promociones.

\section{Pregunta $\mathrm{N}^{\circ}$ 8: ¿Cuál es la frecuencia de consumo en cada fast food} mencionados?

Tabla 11

Número de personas según frecuencia de consumo en fast food tradicional

\begin{tabular}{lcccccccc}
\hline & \multicolumn{2}{c}{ Nunca } & \multicolumn{2}{c}{ Regular } & \multicolumn{2}{c}{ Poco Frecuente } & \multicolumn{2}{c}{ Muy Frecuente } \\
\cline { 2 - 8 } & Frecuencia & $\begin{array}{c}\text { Porcentaje } \\
\text { válido }\end{array}$ & Frecuencia & $\begin{array}{c}\text { Porcentaje } \\
\text { válido }\end{array}$ & Frecuencia & $\begin{array}{c}\text { Porcentaje } \\
\text { válido }\end{array}$ & Frecuencia $\begin{array}{c}\text { Porcentaje } \\
\text { válido }\end{array}$ \\
\cline { 2 - 9 } CHINA WOK & 141 & 44,5 & 62 & 19,6 & 89 & 28,1 & 25 & 7,9 \\
BEMBOS & 93 & 29,3 & 71 & 22,4 & 105 & 33,1 & 48 & 15,1 \\
PIZZA HUT & 110 & 34,7 & 63 & 19,9 & 93 & 29,3 & 51 & 16,1 \\
KFC & 71 & 22,4 & 90 & 28,4 & 66 & 20,8 & 90 & 28,4 \\
BURGER KING & 119 & 37,5 & 58 & 18,3 & 103 & 32,5 & 37 & 11,7 \\
OTTO GRILL & 152 & 48,0 & 80 & 25,2 & 62 & 19,6 & 23 & 7,3 \\
MC DONALDS & 174 & 54,9 & 67 & 21,1 & 61 & 19,2 & 15 & 4,7 \\
POPEYES & 202 & 64,0 & 75 & 23,7 & 33 & 10,4 & 7 & 2,2 \\
& & & & & & & & \\
\hline
\end{tabular}

Fuente: Elaboración propia.

Conclusión: El fast food tradicional más frecuentado es $\operatorname{KFC}(28,4 \%)$ y el de menor afluencia es China Wok. 
Pregunta N$^{\circ}$ : ¿Qué les parece la idea del fast food saludable?

Tabla 12

Número de personas según idea de concepto "fast food saludable"

\begin{tabular}{llcc}
\hline & & Frecuencia & Porcentaje \\
& & válido \\
\hline \multirow{3}{*}{ Válido } & MUY BUENO & 129 & 40,7 \\
& BUENO & 182 & 57,4 \\
& NI BUENO NI MALO & 6 & 1,9 \\
& Total & 317 & 100,0 \\
\hline
\end{tabular}

Fuente: Elaboración propia.

Conclusión: El 40,7\% de los encuestado señala que la idea del fast food saludable es muy buena como nueva alternativa de comidas rápidas.

Pregunta $\mathrm{N}^{\circ} 10$ : ¿Cuál fast food saludable conoce?

Tabla 13

Número de personas según conocimiento de fast food saludable

\begin{tabular}{lcccc}
\hline & Si & $\begin{array}{c}\text { Porcentaje } \\
\text { valido }\end{array}$ & No & $\begin{array}{c}\text { Porcentaje } \\
\text { valido }\end{array}$ \\
\hline CAFEFIT & 23 & 7,3 & 294 & 92,7 \\
COTTAGE & 44 & 13,9 & 273 & 86,1 \\
DESIGN YOUR SALAD & 18 & 5,7 & 299 & 94,3 \\
\hline
\end{tabular}

Fuente: Elaboración propia.

Conclusión: El fast food saludable más conocido es Cottage con un 44\%, sin embargo, el 38\% de personas no había escuchado antes este tipo de concepto de comida rápida. 
Pregunta $\mathrm{N}^{\circ}$ 11: ¿Cuál es la opción que más se ajusta a su intención de compra del fast food saludable?

Tabla 14

Número de personas según intención de compra de la prueba de concepto

\begin{tabular}{llcc}
\hline & Frecuencia & $\begin{array}{c}\text { Porcentaje } \\
\text { válido }\end{array}$ \\
\hline \multirow{3}{*}{ Válido } & DEFINITIVAMENTE LO COMPRARÍA & 101 & 31,9 \\
& PROBABLEMENTE LO COMPRARÍA & 202 & 63,7 \\
& DE VEZ EN CUANDO LO COMPRARÍA & 14 & 4,4 \\
& Total & 317 & 100,0 \\
\hline
\end{tabular}

Fuente: Elaboración propia.

$\underline{\text { Conclusión: }}$ El 63,7\% de los encuestados probablemente compraría en el fast food saludable y el 31,9\% definitivamente lo compraría.

\section{Pregunta $\mathrm{N}^{\circ}$ 12: ¿Con qué frecuencia acudiría a este establecimiento?}

Tabla 15

Número de personas según frecuencia de consumo de la prueba de concepto

\begin{tabular}{llcc}
\hline & Frecuencia & $\begin{array}{c}\text { Porcentaje } \\
\text { válido }\end{array}$ \\
\hline \multirow{6}{*}{ CASI DIARIAMENTE } & 39 & 12,3 \\
2 O 3 VECES A LA & 97 & 30,6 \\
& SEMANA & & \\
& UNA VEZ A LA SEMANA & 129 & 40,7 \\
& UNA VEZ CADA QUINCENA & 46 & 14,5 \\
& UNA VEZ AL MES & 6 & 1,9 \\
& Total & 317 & 100,0 \\
\hline
\end{tabular}

Fuente: Elaboración propia.

Conclusión: El 40,7\% de los encuestados refiere que una vez a la semana acudiría a consumir en el fast food saludable, el 30,6\% menciona que compraría dos o tres veces a la semana. 
Pregunta $\mathrm{N}^{\circ}$ 13: ¿En cuál horario de comida asistiría al local?

Tabla 16

Número de personas según el horario de asistencia a la prueba de concepto

\begin{tabular}{clcc}
\hline & & Frecuencia & $\begin{array}{c}\text { Porcentaje } \\
\text { válido }\end{array}$ \\
\hline \multirow{3}{*}{ Válido } & ALMUERZO & 236 & 74,4 \\
& CENA & 2 & 0,6 \\
& AMBOS & 79 & 24,9 \\
& Total & 317 & 100,0 \\
\hline
\end{tabular}

Fuente: Elaboración propia.

Concepto: El 74,4\% acudiría a consumir en el horario del almuerzo, una amplia diferencia respecto al horario de la cena.

Pregunta $\mathrm{N}^{\circ} 14:$¿Cuál es su preferencia de consumo?

Tabla 17

Número de personas según preferencia de consumo

\begin{tabular}{llcc}
\hline & & Frecuencia & $\begin{array}{c}\text { Porcentaje } \\
\text { válido }\end{array}$ \\
\hline \multirow{3}{*}{ Válido } & COMER EN EL LOCAL & 269 & 84,9 \\
& TAKE OUT (PARA LLEVAR) & 48 & 15,1 \\
& Total & 317 & 100,0 \\
\hline
\end{tabular}

Fuente: Elaboración propia.

Conclusión: El 84,9\% prefiere comer en el local y solo el 15,1\% pediría para llevar. 
Pregunta N$^{\circ}$ 15: ¿Qué modalidad de pago prefiere?

Tabla 18

Número de personas según la modalidad de pago

\begin{tabular}{llcc}
\hline & Frecuencia & $\begin{array}{c}\text { Porcentaje } \\
\text { válido }\end{array}$ \\
\hline \multirow{3}{*}{ Válido } & EFECTIVO & 81 & 25,6 \\
& TAJETA DÉBITO & 58 & 18,3 \\
& TARJETA DE CRÉDITO & 27 & 8,5 \\
& VALE O CUPONES & 151 & 47,6 \\
& Total & 317 & 100,0 \\
\hline
\end{tabular}

Fuente: Elaboración propia.

Conclusión: El 47,6\% preferiría usar vales o cupones de descuento y el 25,6\% pagaría en efectivo su consumo.

Pregunta $\mathrm{N}^{\circ}$ 16: ¿Cuál es el monto tope de consumo personal que pagaría? Tabla 19

Número de personas según el monto a pagar por consumo personal

\begin{tabular}{llcc}
\hline & & Frecuencia & $\begin{array}{c}\text { Porcentaje } \\
\text { válido }\end{array}$ \\
\hline \multirow{4}{*}{ Válido } & MENOR DE 20 SOLES & 227 & 71,6 \\
& 21 A 35 SOLES & 66 & 20,8 \\
& 35 A 50 SOLES & 21 & 6,6 \\
& MAYOR A 50 SOLES & 3 &, 9 \\
& Total & 317 & 100,0
\end{tabular}

Fuente: Elaboración propia.

Conclusión: El 71,6\% de los encuestados pagaría por consumo personal menos de 20 soles y el $20,8 \%$, 35 soles. 
Pregunta N$^{\circ}$ 17: ¿Qué nombre preferiría para este nuevo concepto?

Tabla 20

Número de personas según las opciones de nombres para la empresa

\begin{tabular}{clcc}
\hline & & Frecuencia & $\begin{array}{c}\text { Porcentaje } \\
\text { válido }\end{array}$ \\
\hline \multirow{3}{*}{ Válido } & HEALTHY CORNER & 147 & 46,4 \\
& RINCÓN SALUDABLE & 84 & 26,5 \\
& K'UCHU Q'UMARA & 86 & 27,1 \\
& Total & 317 & 100,0 \\
\hline
\end{tabular}

Fuente: Elaboración propia.

Conclusión: El 46,4\% prefirió el nombre del concepto en inglés, frente 53,6\% que prefería el nombre de concepto en español o quechua.

Pregunta $\mathrm{N}^{\circ} 18:$ ¿En qué medios de comunicación prefiere que se difunda la publicidad?

Tabla 21

Número de personas según preferencia de difusión en medios de comunicación

\begin{tabular}{llcccc}
\hline & Si & $\begin{array}{c}\text { Porcentaje } \\
\text { válido }\end{array}$ & No & $\begin{array}{c}\text { Porcentaje } \\
\text { válido }\end{array}$ \\
\hline \multirow{2}{*}{ Válido } & REDES SOCIALES & 311 & 98,1 & 6 & 1,9 \\
& PANELES PUBLICITARIOS & 190 & 59,9 & 127 & 40,1 \\
& TELEVISIÓN & 164 & 51,7 & 153 & 48,3 \\
& RADIO & 148 & 46,7 & 169 & 53,3 \\
& PERIÓDICOS & 49 & 15,5 & 268 & 84,5 \\
& REVISTAS & 41 & 12,9 & 276 & 87,1 \\
\hline
\end{tabular}

Fuente: Elaboración propia.

Conclusión: Casi el 100\% de los encuestados prefiere que la difusión de publicidad sea a través de redes sociales, y con menor preferencia se encuentran los periódicos y revistas. 


\subsection{Conclusiones y recomendaciones del estudio cualitativo y cuantitativo}

- El estudio cualitativo se llevó a cabo mediante el diseño de la Guía de indagación que fue aplicada en dos grupos de Focus Group obteniendo resultados valiosos para el diseño de la Encuesta.

- Según los resultados la mayoría de los encuestados se encuentra entre los 21 a 35 años $(32,2 \%)$, la mayoría procede de los distritos de Santiago de Surco $(22,4 \%)$ y San Borja $(10,7 \%)$ destacando del nivel socioeconómico B $(63,1 \%)$ que acude preferentemente al Centro Comercial Jockey Plaza (32,2\%).

- Principalmente los encuestados acuden a un fast food por tener buen sabor $(59,6 \%)$, variedad del menú $(51,4 \%)$ y el buen ambiente $(42 \%)$. Entre los sustitutos destacan KFC $(28,4 \%)$, Pizza Hut $(16,1 \%)$ y Bembos $(15,1 \%)$.

- El 26,9 \% de los encuestados conoce algún fast food saludable en Lima Metropolitana, de los que destaca Cottage Fast Good (13,9\%).

- Luego de conocer la prueba de concepto los encuestados acudirían con frecuencia al establecimiento $(83,6 \%)$, en el horario del almuerzo $(74,4 \%)$, desean consumir mediante vales o cupones $(47,6 \%)$, les gustaría que el concepto se llame Healthy Corner $(46,4 \%)$, los medios de difusión propicios son las redes sociales $(98,1 \%)$ y paneles publicitarios $(59,9 \%)$.

- Se ha podido demostrar con los resultados obtenidos que el perfil del público objetivo se basa en un estilo de vida saludable y moderno donde el principal motivo por el cual sale a comer fuera del hogar.

- La encuesta está formulada por preguntas cerradas, lo cual limita la respuesta de los encuestados para obtener la mayor información posible. 


\subsection{Perfil del consumidor tipo y sus variantes}

El perfil del consumidor son hombres y mujeres de 21 a 59 años, que viven en los distritos de Lima Moderna que pertenecen al nivel socioeconómico B y C.

- Nivel Socioeconómico B y C: Presentan disponibilidad económica y tienen la tendencia de consumo de productos relacionados con el cuidado de la salud.

- Distritos de Lima Moderna: Personas de este sector presentan mayor predisposición de consumo de fast food y su población mayoritariamente pertenece al NSE B y C.

- Rango de 21 a 59 años: Personas económicamente activas, que tienen decisión de compra. A partir de los 25 años tienen la tendencia por el cuidado de su salud, ya que hay mayor predisposición por las enfermedades crónicas no trasmisibles.

- Perfil de necesidades: Personas con necesidad de acudir a fast food por gusto de comer fuera de casa, por trabajo, distracción y variedad de alternativas.

- Capacidad de pago: Según la encuesta los clientes o podrían pretender pagar 20 soles como máximo por consumo personal.

- Preferencias: La frecuencia de asistencia será semanal y dos veces por semana en los horarios preferentemente de almuerzo.

- Posicionamiento: la propuesta busca ofrecer una alternativa saludable en comparación a los convencionales fast food, considerando que las personas buscan atributos como buen sabor, variedad de menú y buen ambiente.

- Publicidad: las redes sociales son su principal fuente de información y los paneles publicitarios.

A continuación; se presenta la tabla comparativa del estudio cualitativo que consiste en el focus group y el estudio cuantitativo, la encuesta final a la muestra $(\mathrm{N}=317)$. 
Tabla 22

Tabla comparativa del estudio cualitativo y cuantitativo de Healthy Corner

\begin{tabular}{|c|c|c|}
\hline Tipo de Estudio & Estudio Cualitativo & Estudio Cuantitativo \\
\hline $\begin{array}{l}\text { Nombre del proyecto } \\
\text { de investigación }\end{array}$ & $\begin{array}{l}\text { Focus group sobre centro de } \\
\text { comida rápida }\end{array}$ & $\begin{array}{c}\text { Encuesta sobre centros de } \\
\text { comida rápida }\end{array}$ \\
\hline $\begin{array}{l}\text { Fecha de realización de } \\
\text { campo }\end{array}$ & Abril del 2016 & Mayo del 2016 \\
\hline $\begin{array}{l}\text { Persona natural o } \\
\text { jurídica que la realiza }\end{array}$ & $\begin{array}{l}\text { Gianina Cabrera } \\
\text { Ivanna Pisfil }\end{array}$ & $\begin{array}{l}\text { Gianina Cabrera } \\
\text { Ivanna Pisfil }\end{array}$ \\
\hline Grupo objetivo & $\begin{array}{c}\text { Dos grupos divididos por } \\
\text { NSE B y C Hombres y } \\
\text { mujeres entre los } 21 \text { a } 59 \\
\text { años, que han acudido en los } \\
\text { últimos } 30 \text { días a un fast food. }\end{array}$ & $\begin{array}{l}\text { Hombres y mujeres entre los } \\
21 \text { a } 59 \text { años, de los NSE B } \\
\text { y C de los distritos de Lima } \\
\text { Moderna }\end{array}$ \\
\hline Diseño muestral & $\begin{array}{l}\text { Muestreo no probabilístico } \\
\text { por conveniencia. }\end{array}$ & $\begin{array}{l}\text { Muestreo no probabilístico } \\
\text { por conveniencia. }\end{array}$ \\
\hline Tamaño de muestra & $\begin{array}{l}16 \text { personas en } 2 \text { grupos } \\
\text { ( } 8 \text { cada uno })\end{array}$ & 317 encuestados \\
\hline Técnica de recolección & $\begin{array}{c}\text { Entrevista grupal. } \\
\text { Estructurada }\end{array}$ & $\begin{array}{c}\text { Encuesta personal cara a } \\
\text { cara. Estructurada }\end{array}$ \\
\hline Cobertura geográfica & Distrito Santiago de Surco & $\begin{array}{l}\text { Distrito de Lima Moderna: } \\
\text { centros comerciales }\end{array}$ \\
\hline $\begin{array}{l}\text { Tema o temas } \\
\text { concretos a los que } \\
\text { refiere }\end{array}$ & Guía de indagación & Cuestionario \\
\hline
\end{tabular}

Fuente: Elaboración propia. 


\section{CAPÍTULO IV: PROYECCIÓN DEL MERCADO OBJETIVO}

\subsection{El ámbito de la proyección}

Healthy Corner se encontrará ubicado en el Centro Comercial del Jockey Plaza en el distrito de Santiago de Surco. El concepto será parte de la oferta del food courts, el cual tiene una capacidad máxima para 1500 personas (16 establecimientos).

Este establecimiento cuenta con un tráfico mensual de 2,5 millones de visitas al mes, llegando a 30 millones al año.

El plan de negocios se proyectó en 5 años partiendo desde el año 2017 al 2021.

\subsection{Selección del método de proyección}

A continuación, se detallará el análisis del mercado: potencial, disponible, efectivo y objetivo.

\subsubsection{Mercado Potencial}

Para realizar el cálculo del mercado potencial hemos realizado la siguiente fórmula: $\boldsymbol{Q}=\boldsymbol{n p q}$ y bajo el supuesto de capacidad de 1500 entre los 16 establecimiento que existe en el patio de comidas.

Q: Demanda potencial

n: número de compradores posibles

p: precio promedio del producto

$q$ : cantidad promedio de consumo por persona 
Tabla 23

Mercado potencial de Healthy Corner

\section{Cálculo del Mercado Potencial}

Capacidad máxima en el patio de comidas

Estadía en el patio de comida

Hora de atención del Jockey Plaza

Hora punta

Hora Baja

Capacidad máxima de atención en hora punta

Capacidad máxima de atención en hora baja

Porcentaje de capacidad real en hora punta

Porcentaje de capacidad real en hora baja

Número de Capacidad Real en hora punta

Número de Capacidad Real en hora baja

\section{Capacidad Real Mensual}

Capacidad real en hora punta en 1 mes (30 días)

Capacidad real en hora baja en 1 mes (30 días)

\section{3,75}

1 hora

$10 \mathrm{~h}-23 \mathrm{~h}$

$12 \mathrm{~h}-15 \mathrm{~h}$

$10 \mathrm{~h}-12 \mathrm{~h}$

$18 \mathrm{~h}-10 \mathrm{~h}$

$15 \mathrm{~h}-18 \mathrm{~h}$

$22 \mathrm{~h}-23 \mathrm{~h}$

Total de horas 7 6

$$
(93,75 * 7)=656,25
$$

$$
\left(93,75^{*} 6\right)=\quad 562,50
$$

$70 \%$

$40 \%$

$656,25 * 70 \%=459,375$

\begin{tabular}{|c|c|c|c|c|}
\hline \multirow{4}{*}{$\begin{array}{l}\text { Mercado } \\
\text { Potencial }\end{array}$} & \multicolumn{3}{|c|}{ Veces de visitas al mes } & \multirow{2}{*}{$\begin{array}{c}\text { Visitas al mes } \\
82125\end{array}$} \\
\hline & $20=21$ & 20 & 4 & \\
\hline & & monto máx. Soles & \multicolumn{2}{|c|}{ Soles al mes } \\
\hline & 82125 & 20 & \multicolumn{2}{|c|}{1642500} \\
\hline
\end{tabular}

$562,50 * 40 \%=\quad 225$

Fuente: Elaboración propia. 
El mercado potencial según el cuadro anterior es de 20531 personas durante el mes. El precio promedio calculado es 20 soles por cada consumo y el número de veces que asistirá los consumidores es 4 veces al mes según la encuesta realizada.

\section{Mercado potencial de $Q=20531 * 20 * 4=1642500$ soles}

\subsubsection{Mercado disponible}

El mercado disponible sería las 2500000 personas que acuden mensualmente al Centro Comercial Jockey Plaza. (15)

\subsubsection{Mercado efectivo}

Se determinó como mercado efectivo el $31,9 \%$ del mercado potencial, este porcentaje es en base a la encuesta realizada en la que definitivamente compraría en Healthy Corner.

Siendo el mercado efectivo 26198 visitas al mes.

Tabla 24

Mercado efectivo de Healthy Corner

\begin{tabular}{l|ccccc}
\hline \multirow{2}{*}{$\begin{array}{l}\text { Mercado } \\
\text { Efectivo }\end{array}$} & $\begin{array}{c}\text { Veces de visitas al mes } \\
\text { (Mercado potencial) }\end{array}$ & $\begin{array}{c}\text { \% cuidan su } \\
\text { alimentación }\end{array}$ & $\begin{array}{c}\text { Visitas al } \\
\text { mes }\end{array}$ & $\begin{array}{c}\text { Monto } \\
\text { máx. Soles }\end{array}$ & $\begin{array}{c}\text { Soles al } \\
\text { mes }\end{array}$ \\
\cline { 2 - 6 } & 82125 & $31,90 \%$ & $\mathbf{2 6 1 9 8}$ & 20 & $\mathbf{5 2 3 9 6 0}$ \\
\hline
\end{tabular}

Fuente: Elaboración propia. 


\subsubsection{Mercado objetivo}

El mercado objetivo es el número de personas que el establecimiento podrá atender.

Los días de semana (5 días) se atenderán 200 transacciones diarias y 350 por el fin de semana ( 2 días), lo que hace un total de 1700 por semana y 6800 por mes.

Finalmente se proyecta que por transacción será un monto de 30 soles sumando 204000 soles al mes y 10200 personas.

Tabla 25

Mercado objetivo de Healthy Corner

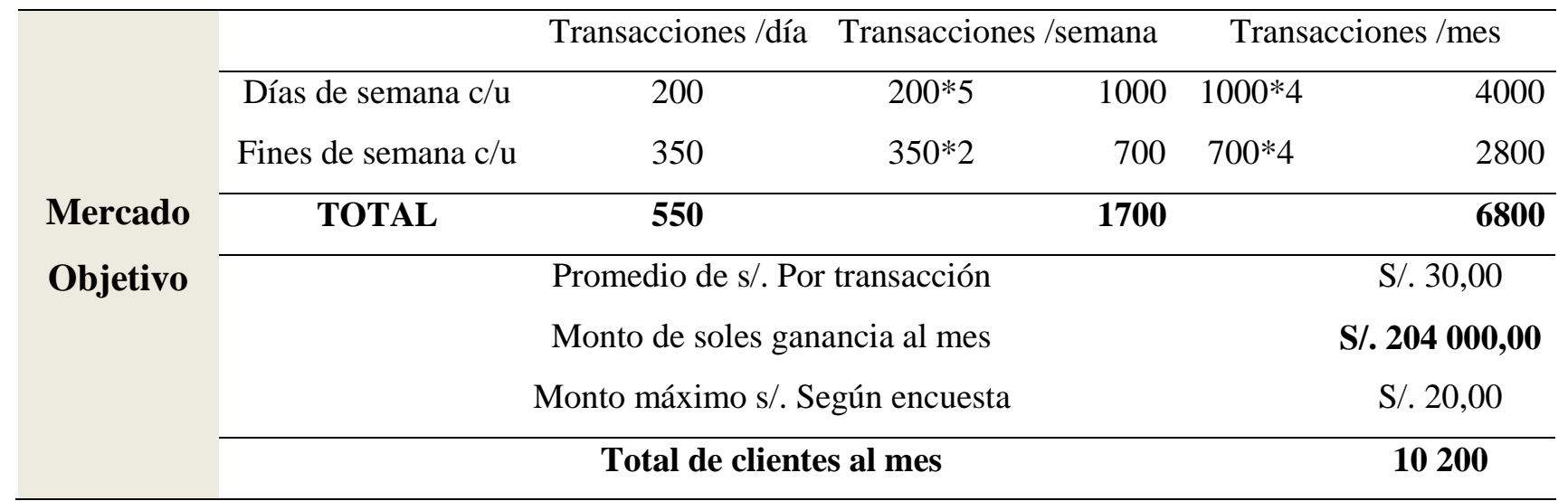

Fuente: Elaboración propia.

\subsection{Pronóstico de ventas}

El pronóstico de ventas se desarrolla en una proyección de 5 años y se utilizó los mismos supuestos y se aplicó un porcentaje de crecimiento de $0,5 \%$ considerando la diversidad de restaurantes y fast food que serían nuestros posibles competidores directos y sustitutos. Para calcular dicho pronóstico se asume que toda la producción de diferentes platos se vende según el precio de venta de cada uno de ellos. 
Tabla 26

Proyección de ventas anual del año 2017 al 2021

\section{Proyección de Ventas Anual}

\begin{tabular}{|c|c|c|c|c|c|}
\hline Años & 2017 & 2018 & 2019 & 2020 & 2021 \\
\hline $\begin{array}{l}\text { Número de visitas totales } \\
\text { al año }\end{array}$ & 323197 & 343099 & 364261 & 386728 & 410580 \\
\hline $\begin{array}{l}\text { Consumo promedio por } \\
\text { persona S/. }\end{array}$ & & & S/. 20,00 & & \\
\hline Proyección de ventas (S/.) & 6463940,00 & 6861980,0 & 285220,0 & 34560,00 & 1600,00 \\
\hline
\end{tabular}

Fuente: Elaboración propia.

Tabla 27

Proyección de ventas anual sin IGV del año 2017 al 2021

\begin{tabular}{cccccc}
\hline \multicolumn{5}{c}{ Proyección de Ventas Anual sin IGV } \\
\hline Años & $\mathbf{2 0 1 7}$ & $\mathbf{2 0 1 8}$ & $\mathbf{2 0 1 9}$ & $\mathbf{2 0 2 0}$ & $\mathbf{2 0 2 1}$ \\
\hline $\begin{array}{c}\text { Ventas sin IGV } \\
\text { (s/.) }\end{array}$ & 5300430,80 & 5626823,60 & 5973880,40 & $6,342,339.20$ & $6,733,512.00$ \\
IGV & & $18 \%$ & & \\
Costo IGV (s/.) & 1163509,20 & 1235156,40 & 1311339,60 & 1392220,80 & 1478088,00 \\
\hline $\begin{array}{c}\text { Ventas con } \\
\text { IGV (S/.) }\end{array}$ & $\mathbf{6 4 6 3 9 4 0 , 0 0}$ & $\mathbf{6 ~ 8 6 1 ~ 9 8 0 , 0 0}$ & $\mathbf{7 2 8 5 ~ 2 2 0 , 0 0}$ & $\mathbf{7 ~ 7 3 4 ~ 5 6 0 , 0 0}$ & $\mathbf{8 ~ 2 1 1 ~ 6 0 0 , 0 0}$ \\
\hline
\end{tabular}

Fuente: Elaboración propia.

\subsection{Aspectos críticos que impactan el pronóstico de ventas}

El aspecto crítico es el económico, es importante tener en cuenta el estado de la economía, si esta se encuentra en recesión o no. De haber recesión hay un incremento en la tasa de desempleo y disminución del ingreso per cápita. Ante lo mencionado el pronóstico de ventas se vería afectado. 


\section{CAPÍTULO V: INGENIERÍA DEL PROYECTO}

\subsection{Estudio de ingeniería}

La ingeniería del proyecto es fundamental para brindar un servicio de calidad y estandarizado.

\subsubsection{Modelamiento y selección de procesos productivos}

El proceso productivo de Healthy Corner constará de varias fases para garantizar la seguridad alimentaria en los productos a ofrecer; contando con una o un supervisor de calidad que realice inspección y seguimiento a las normas de calidad que son: las Buenas Prácticas de Manipulación de Alimentos (BPM), Procedimientos Operativos Estandarizados de Saneamiento (POES) y llevando el registro de los Puntos Críticos de Control (PCC).

A continuación, se presenta el gráfico del proceso productivo y posteriormente se detalla cada fase.

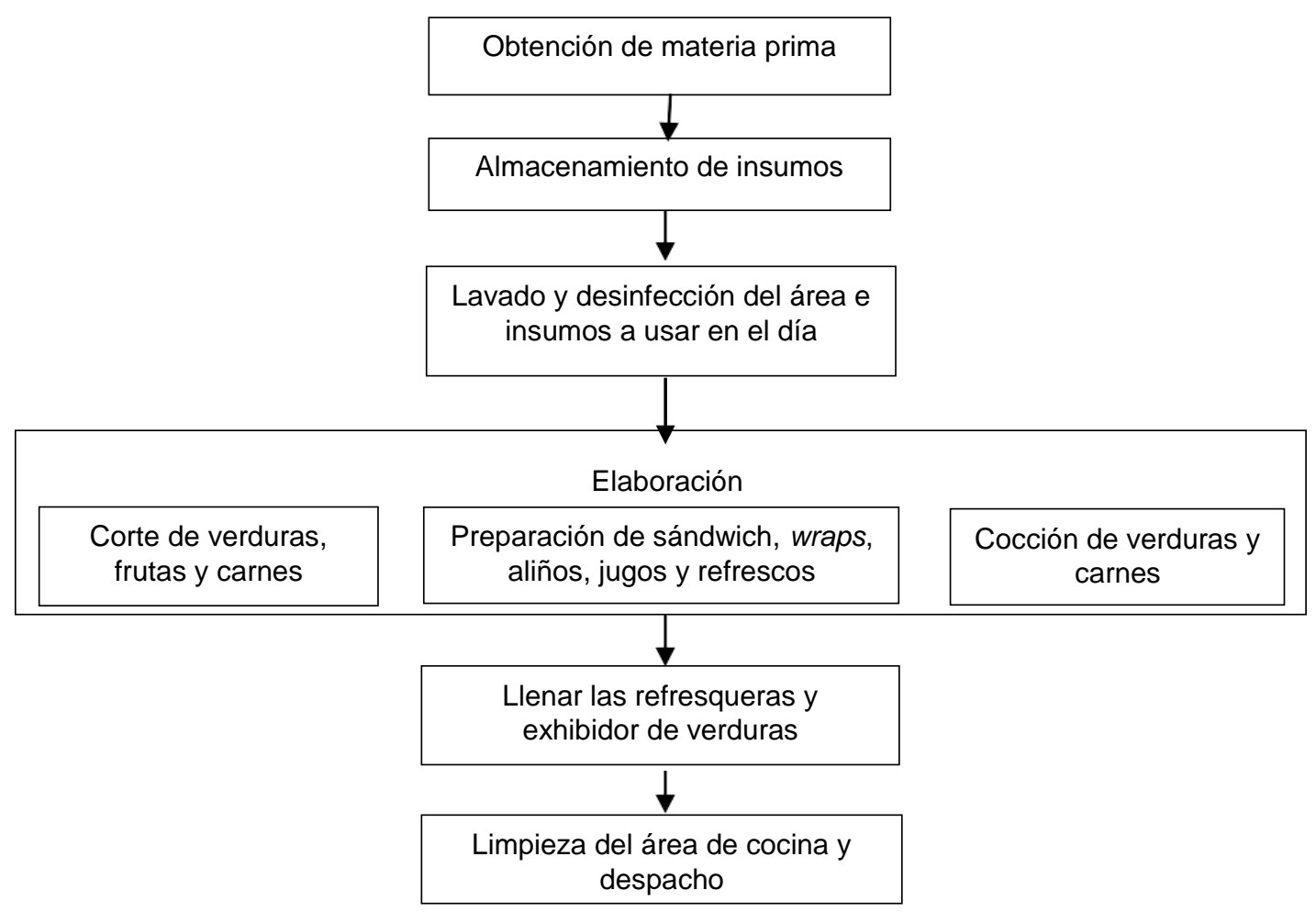

Gráfico 2: Proceso productivo del servicio del fast food Healthy Corner. Elaboración propia 
Al inicio de un día de labores, la supervisora de calidad hace el check list al personal (aseo personal y estar correctamente uniformados). A continuación, se detallará el proceso productivo de cada preparación, teniendo en cuenta que este proceso productivo se realiza cada cambio de turno.

- Obtención de materia prima: Se realizará el pedido de los insumos no perecibles con frecuencia quincenal; las verduras y frutas, cada tres días; las carnes de pollo, pavo y res, semanalmente. En el caso particular de los postres de Vegánimo, el ingreso será diario. La supervisora de calidad hará el respectivo control de calidad de toda la materia prima ingresada.

- Almacenamiento de insumos: Una vez obtenidos los insumos se procederá a almacenarlos, contando con espacios definidos y específicos para cada tipo de insumo tanto perecibles como no perecibles.

Particularmente lácteos, verduras y frutas se encontrarán en la conservadora; las carnes en la congeladora; ya que estos alimentos al no ser conservados bajo las temperaturas adecuadas se deterioran.

La supervisora de calidad debe controlar el registro de las fichas de Puntos críticos de control de temperatura de congeladora, conservadora y exhibidora de las verduras.

- Lavado y desinfección del área de trabajo: Antes de empezar a trabajar en el proceso de lavado y desinfección de alimentos, se debe realizar el lavado y desinfección de las superficies (piso, paredes, mesas de trabajo, utensilios, cuchillos, tablas de picar, entre otros) utilizando amonio cuaternario de marca Ecolab; este proceso debe ser verificado por la supervisora de calidad. 
- $\quad$ Lavado y desinfección de insumos a usar en el día: El lavado y desinfección de frutas y verduras es obligatorio, para ese procedimiento se utilizará hipoclorito de sodio de la marca Ecolab; este proceso debe ser verificado por la supervisora de calidad.

- Elaboración: Se dividirá en tres procesos, el primero es el corte de verduras, frutas y carnes; en sus respectivas tablas de cortar, el cual servirá para las diferentes preparaciones que se ofrecen en el servicio. Seguido por el proceso de preparación de los refrescos y aliños para las ensaladas.

El proceso de cocción de verduras será para las preparaciones de combos, ensaladas y wraps. La cocción de carnes se realizará según la demanda de pedidos para lograr la preparación final del sándwich, wraps y combos.

La supervisora de calidad debe controlar el registro de las fichas de Puntos críticos de control de temperatura de cocción en cocina caliente.

- Llenar las refresqueras y el exhibidor de verduras: Este procedimiento lo realiza el colaborador que se encuentra en el área de despacho; se encarga de mantener las refresqueras llenas y las verduras que se exhiben en el mostrador. Así como abastecer los insumos de trabajo llámese vasos, sorbetes, servilletas, bandejas, cubiertos, etc.

El colaborador manipula directamente con los alimentos por ello debe realizar correctamente el lavado de manos y estar correctamente uniformado y mantener el área de despacho limpia.

- Limpieza del área de cocina y despacho: Es el último proceso que se realiza al finalizar la jornada laboral, se debe dejar limpio y bajo la solución desinfectante las tablas de picar, cuchillos y utensilios de cocina; eliminar los desechos del área de cocina y despacho; también se debe realizar la limpieza y desinfección de las 
superficies como mesas de trabajo, cocina, piso, paredes, entre otros materiales y/o equipos de ambas áreas con amonio cuaternario marca Ecolab, este proceso debe ser verificado por la supervisora de calidad.

Por otro lado, se detalla el procedimiento de Atención para consumo de producto en el local y para llevar (take out):

- El cliente se acerca a caja para ser atendido.

- El cajero saluda y le toma la orden, le hace el cobro del monto a consumir.

- El cliente se dirige a buscar mesa y esperar.

- Una vez terminada la producción, el colaborador llama al cliente al mostrador para que recoja su pedido (consumo en el local o para llevar).

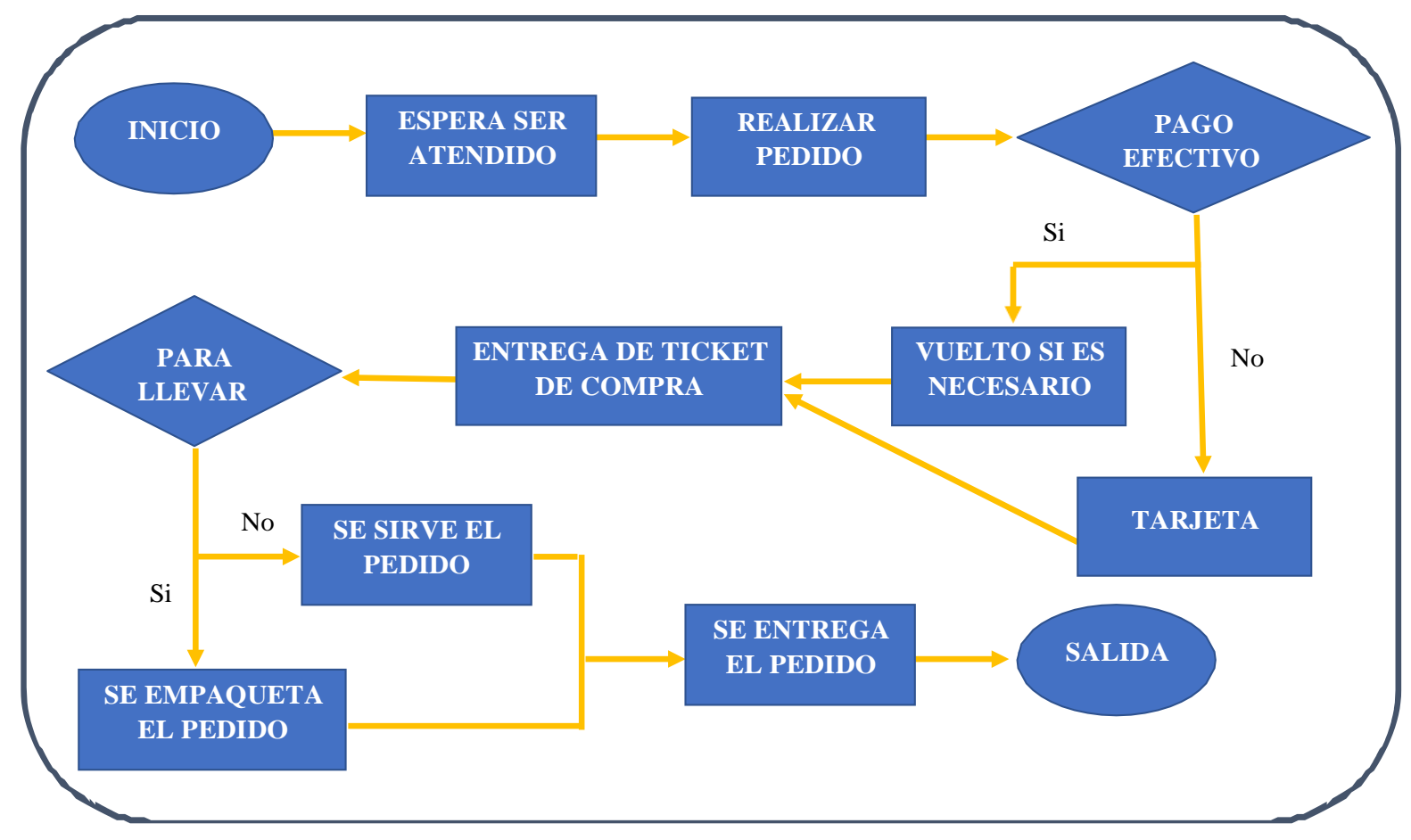

Gráfico 3: Flujograma fast food "Healthy Corner". Elaboración propia. 


\subsubsection{Selección del equipamiento}

El equipamiento para las áreas de cocina, despacho y oficina del administrador son indispensable para llevar a cabo los procesos productivos con eficacia y rapidez, con el fin de optimizar los recursos y por ende un servicio de calidad. (3)

Tabla 28

Artículos de equipamiento del área de cocina y despacho de Healthy Corner

\begin{tabular}{lc}
\hline Artículo & Unidades \\
\hline Refresquera & 1 \\
Congelador & 1 \\
Conservador & 1 \\
Campana extractora industrial & 1 \\
Licuadoras & 2 \\
Hervidores eléctricos & 2 \\
Caja registradora & 1 \\
Exprimidor de naranja industrial & 1 \\
Cocina Industrial con plancha y horno & 1 \\
Balanza gramera & 1 \\
Vaporera & 1 \\
Lavadero de acero inoxidable de dos pozas & 1 \\
Mostrador & 1 \\
Exhibidor de productos fríos & 1 \\
Vitrina para postres & 1 \\
Escurridero de acero inoxidable dos niveles & 1 \\
Mesa de acero inoxidable & 2 \\
Utensilios de cocina & 1 \\
Tablas de picar de plástico $\left(35^{*} 24\right)$ & 4 \\
Estantería vertical de acero inoxidable & 1 \\
Rallador mediano & 1 \\
Cuchillería Facusa & 1 \\
\hline
\end{tabular}

Fuente: Elaboración propia. 
Tabla 29

Artículos de equipamiento del área administrativa de Healthy Corner

\begin{tabular}{lc}
\hline Artículo & Unidades \\
\hline Escritorio de melanina & 1 \\
Silla giratoria & 1 \\
Teléfono inalámbrico & 1 \\
Computadora de mesa & 1 \\
Impresora HP & 1 \\
Útiles de oficina & 1 \\
Mueble para archivadores & 1 \\
\hline
\end{tabular}

Fuente: Elaboración propia.

Por otro lado, es importante mencionar la relación de los artículos de trabajo que se brindan en el servicio al cliente:

Tabla 30

Artículos descartables de Healthy Corner

\begin{tabular}{l}
\hline Artículo \\
Sorbete de plástico \\
Tenedor $\mathrm{N}^{\circ} 7$ \\
Cuchillo $\mathrm{N}^{\circ} 7$ \\
${\text { Cuchara } \mathrm{N}^{\circ} 7}{\text { Cucharita } \mathrm{N}^{\circ} 5}$ \\
Envase de plástico $500 \mathrm{ml}$ \\
Envase de plástico $250 \mathrm{ml}$ \\
Pote de plástico $30 \mathrm{ml}$ \\
Vaso de cartón 8 Onz. Con tapa \\
Servilletas
\end{tabular}

Fuente: Elaboración propia.

\subsubsection{Lay out}

El local se ubicará en el food courts del Centro Comercial Jockey Plaza, el área total es de $20 \mathrm{~m}^{2}$, distribuido en las áreas de almacenamiento de congelados y conservados, área de producción, oficina y el área de atención al cliente. A continuación, el diseño y la distribución de la planta se desarrollará empleando el Lay Out. 
Figura 7: Lay Out del fast food Healthy Corner.

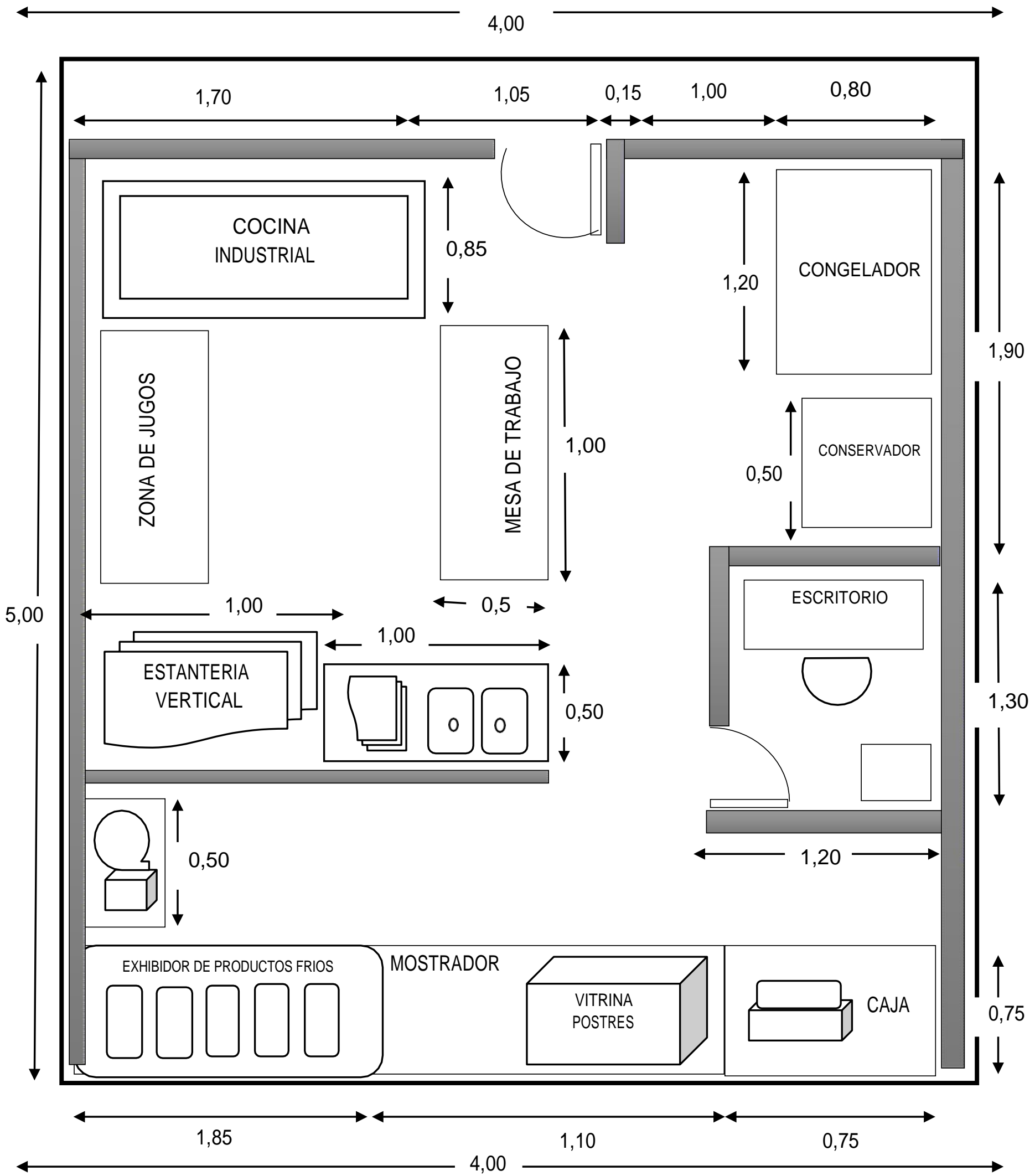

Fuente: Elaboración propia 


\subsubsection{Distribución de equipos y maquinarias}

El lay out se utiliza para nombrar al esquema de distribución de los elementos dentro un diseño. Según el lay out se puede visualizar la distribución de los equipos y maquinarias del área de almacén de alimentos no perecibles y perecibles, área de cocina, despacho, caja y administración.

\subsection{Determinación del Tamaño}

\subsubsection{Proyección de crecimiento}

La proyección de crecimiento de Healthy Corner se verá en función al tamaño de la demanda a satisfacer a partir del año 2017 , se planea que sea $0,5 \%$ cada año.

\subsubsection{Recursos}

Cabe resaltar que posterior al 2021 se aperturará nuevas locales de Healthy Corner, en donde se necesitará: Recurso humanos y financieros.

Recurso humano: Se necesitará la misma cantidad de colaboradores por sede.

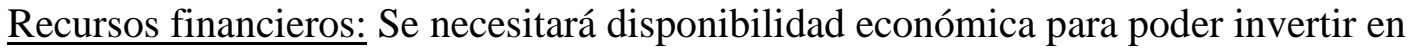
las próximas sedes. Vale recalcar que la inversión será similar al local ubicado en el Jockey Plaza ya que cada sede es independiente.

\subsubsection{Tecnología}

La tecnología ha tomado importancia en todos los ámbitos, en el negocio de fast food se aprecia que hay equipos y maquinarias especializadas y de última tecnología y que se hace indispensable para una mejor y rápida producción de las preparaciones.

\subsubsection{Flexibilidad}

La prioridad es que el cliente se sienta satisfecho del servicio, por ello se hace una atención personalizada, considerando que el cliente pida la orden según su preferencia. 


\subsubsection{Selección del tamaño ideal}

El tamaño de planta está diseñado para cubrir la demanda de clientes (mercado objetivo), cuya área comprende de 20 metros cuadrados, con dimensiones de 5 metros de largo por 4 metros de ancho.

La altura del local tiene 3 metros de altura, piso y paredes con mayólica en el área de cocina, especialmente el piso tiene mayólica antideslizante.

Es importante señalar que estas medidas corresponden al espacio que ocuparemos dentro del patio de comidas del Centro Comercial Jockey Plaza en el Distrito de Santiago de Surco.

\subsection{Estudio de localización}

\subsubsection{Definición de factores locacionales}

A continuación, se describen las variables de localización:

- Venta anual: Este factor es importante, dado que el nivel de ventas considera la cantidad de productos que son adquiridos además de definir el éxito, nivel de magnitud e impacto del centro comercial en una zona geográfica.

- Público objetivo: Como se definió en el Capítulo anterior, el centro comercial escogido debe enfocarse al mismo segmento que se busca explotar. Dado quelos segmentos B y C1 poseen la cultura que cuidar su salud mediante la alimentación.

- Afluencia mensual: Estará ubicado en el centro comercial Jockey Plaza ya que brinda la posibilidad de captar la mayor cantidad de clientes, es decir, es conveniente un alto flujo de personas provenientes del distrito donde se ubica el centro comercial como de los adyacentes. 


\subsubsection{Consideraciones legales}

\subsubsection{Identificación del marco legal}

- Arts. 4, 51, 234 a 237 y 247 Ley General de Sociedades, Ley 26887.

- Norma sanitaria para el funcionamiento de restaurantes y servicios afines resolución ministerial $\mathrm{n}^{\mathrm{o}}$ 363-2005/MINSA.

\subsubsection{Ordenamiento jurídico de la empresa}

Los trámites a realizar son los siguientes:

- Búsqueda y verificación en Registros Públicos (SUNARP) que no exista en el mercado un nombre o razón social igual al de la empresa.

- Elaboración de la minuta, documento en el cual los miembros de la sociedad manifiestan su voluntad de constituir la empresa, y en donde se señalan todos los acuerdos respectivos. La minuta consta del pacto social y los estatutos, además de los insertos que se puedan adjuntar a esta. Los elementos fundamentales de una minuta son:

- Los generales de ley de cada socio (sus datos personales, nombres, edades, documentos de identificación, etc.).

- El giro de la sociedad.

- El tipo de empresa o sociedad (E.I.R.L, S.R.L, S.A, etc.).

- El tiempo de duración de la sociedad (plazo fijo oindeterminado).

- La fecha en la que se va a dar inicio a las actividades comerciales.

- Lugar de funcionamiento de la sociedad (domicilio comercial).

- La denominación o razón social de la sociedad.

- Representante de la sociedad. 
Los aportes de cada socio. Los cuales pueden ser:

- Bienes dinerarios: dinero y sus medios sustitutos tales como cheques, pagarés, letras de cambios, etc.

- Bienes no dinerarios: inmuebles o muebles tales como escritorios, mesas, sillas, etc.

Es recomendable elaborar la minuta con la ayuda de un abogado. Elevar minuta a escritura pública con los pasos para crear una empresa.

Una vez redactada la minuta, debe ser llevada a una Notaría para que un notario público la revise y la eleve a escritura pública.

Por lo general, los documentos que debe llevar junto con la minuta son:

1. La constancia o el comprobante de depósito del capital aportado en una cuenta bancaria a nombre de la empresa.

2. Un inventario detallado y valorizado de los bienes no dinerarios.

Una vez elevada la minuta, no se puede cambiar. Al final, se genera la Escritura Pública, Testimonio de Sociedad o Constitución Social, que es el documento que da fe de que la minuta es legal, la cual debe estar firmada y sellada por el notario.

- Inscribir a la Escritura Pública en Registros Públicos. La Persona Jurídica existe a partir de su inscripción en SUNARP.

- Acudir a la SUNAT para obtener el número de Registro Único de Contribuyentes (RUC) es lo que identifica a una persona o empresa ante la Superintendencia Nacional de Administración Tributaria (SUNAT) para el pago de los impuestos. (25) 
- Elegir régimen tributario para el pago de los impuestos, ya sea al Régimen Único Simplificado (RUS), al Régimen Especial de Impuesto a la Renta (RER), o al Régimen General.

- Comprar y legalizar libros contables dependiendo del régimen tributario al cual se haya acogido y, posteriormente, se lleva a una notaría para que sean legalizados por un notario público.

- Inscribir de los trabajadores en el Seguro Social de Salud EsSalud) a través de un formulario que podemos obtener en SUNAT.

- Solicitud de licencia municipal del Distrito de Santiago de Surco para el funcionamiento.

\subsection{Determinación de la localización óptima}

Healthy Corner estará ubicado en la capital del Perú, Lima, localidad que actualmente se encuentra en el apogeo de grandes centros comerciales que elevan el ritmo y calidad de vida de las personas. El centro comercial que hoy por hoy está creciendo dentro de la industria del retail y que además ha traído mayor capacidad de distracción a los limeños desde hace muchos años, es el Jockey Plaza ubicado en Av. Javier Prado Este 4200, Santiago de Surco.

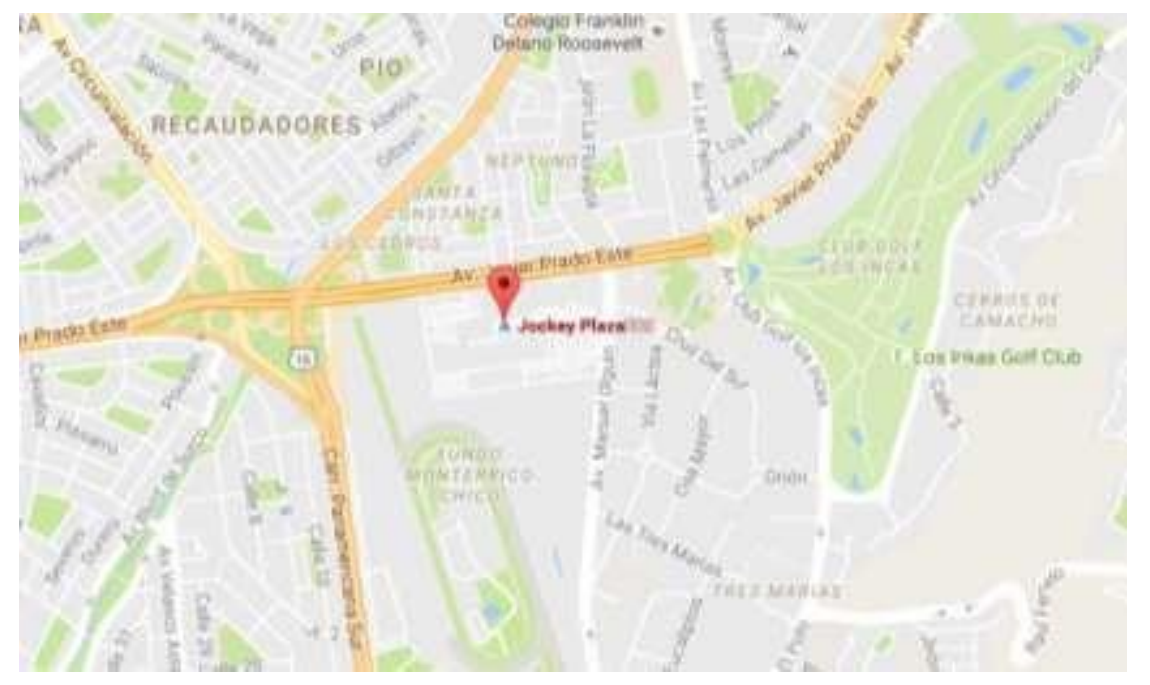

Figura 8: Mapa de ubicación del Centro Comercial Jockey Plaza 
El fast food de comida saludable estará ubicado en el interior del centro comercial Jockey Plaza, específicamente en el patio de comidas. Es una zona con regular afluencia de personas y más aún, se encuentra en un proceso de expansión y crecimiento.

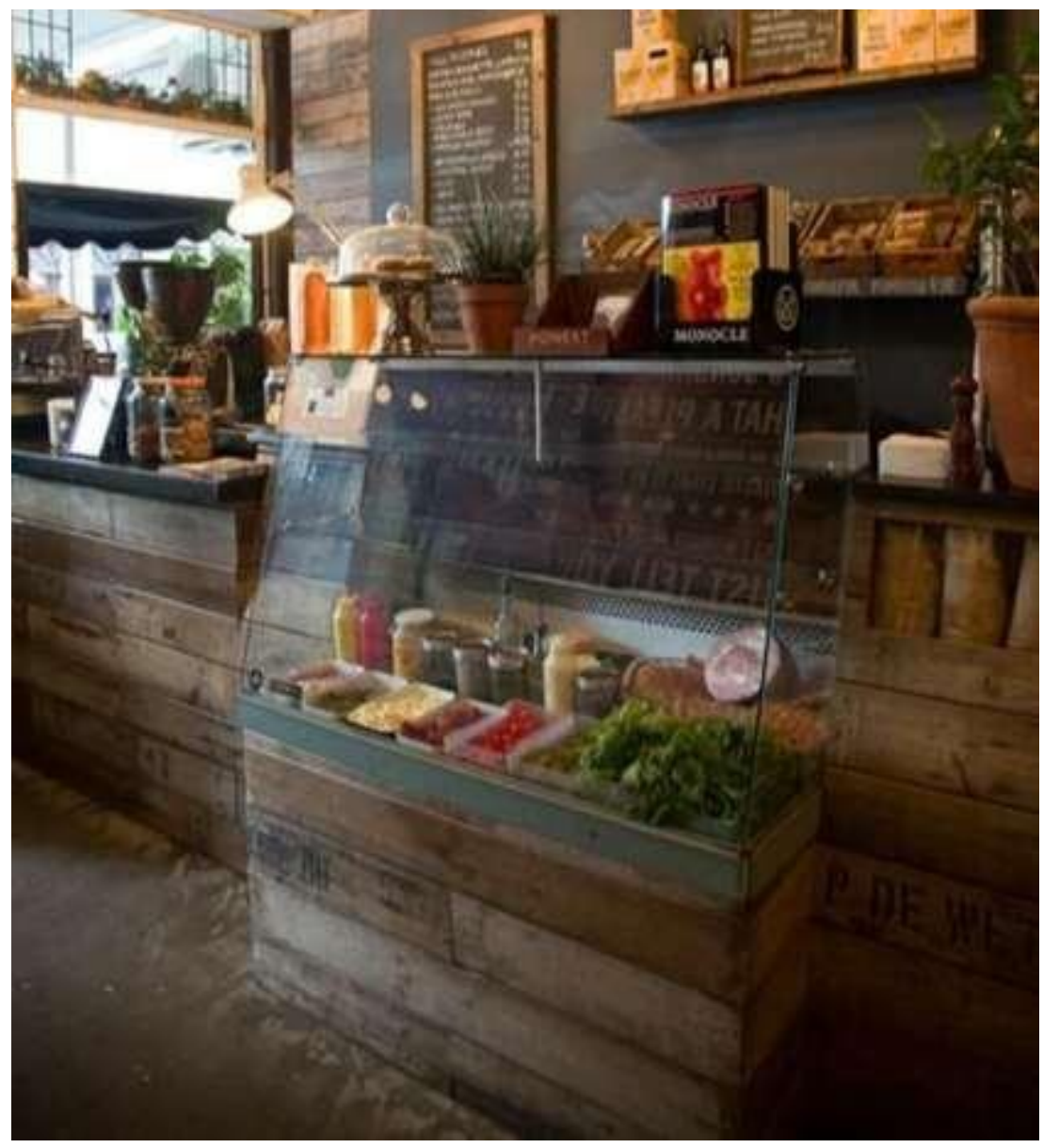

Figura 9: Interior del local. Imagen referencial 


\section{CAPÍTULO VI: ASPECTOS ORGANIZACIONALES}

\subsection{Caracterización de la cultura organizacional deseada}

\subsubsection{Visión}

"Ser una empresa prestigiosa y líder en el rubro de fast food reconocida por su filosofía "saludable" que aumenta la calidad de vida de sus clientes. En cinco años abrir nuevos locales en otros centros comerciales en los distritos de Lima Moderna, llevando nuestra cultura cada vez a más lugares, logrando ser una empresa innovadora, competitiva con el mercado y que pueda cumplir con todas las necesidades de nuestros clientes."

\subsubsection{Misión}

"Somos una empresa peruana con altos estándares de calidad, que aspiramos satisfacer las necesidades de nuestros clientes, con un servicio de comida rápida a base de alimentos saludables, pensando en un mejor estilo de vida."

\subsubsection{Principios}

- Nutrición: Es filosofía de Healthy Corner cuidar la salud de sus clientes, promoviendo un estilo de vida saludable, mediante los productos ofrecidos.

- Calidad: Es importante ofrecer a los clientes productos de primera calidad con una presentación atractiva.

- Respeto: A los clientes, colaboradores que componen el equipo Healthy Corner incluyendo el medio ambiente.

- Compromiso: Con el propósito de satisfacer al cliente, demostrando vocación de servicio y sentido de pertenencia.

- Trabajo en equipo: Cada aporte o idea por nuestro equipo de trabajo es importante para la empresa. 
- Servicio: El cliente es "complacido" en Healthy Corner con el fin de crear una satisfacción y fidelidad completa por el servicio ofrecido, el trato amable y personal.

- Transparencia: La información debe ser totalmente transparente para el consumidor: precios, ingredientes, valor nutricional.

- Mejora continua: El proceso de escucha de clientes y empleados es el mejor motor de mejora. El entorno es cambiante y la empresa debe anticiparse a esos cambios de forma proactiva.

\subsection{Determinación de las ventajas competitivas críticas}

Healthy Corner se caracteriza por lo siguiente:

- Rapidez en la atención personalizada y la variedad de platos saludables, de este modo el servicio será percibido como único y superior.

- Crear una identidad de marca que actuará como barrera protectora frente a la competencia obteniendo como resultado la menor sensibilidad al precio.

- La empresa deberá involucrarse en actividades como diseño del producto, materiales e insumos de alta calidad para conservar la diferenciación.

\subsection{Diseño de la estructura organizacional deseada}

La estructura organizacional que propone Healthy Corner es mixta. Teniendo en cuenta que es una empresa pequeña el organigrama permite involucrar a todos los colaboradores, optimizando el espacio del equipo de trabajo sólido.

Por ello el organigrama es encabezada por los socios, seguido por dos áreas (a) supervisor de tienda, el cual tiene a su cargo al (a.1) cajero; y (b) supervisor de calidad, que a su vez 
este tiene a cargo las siguientes áreas: (b.1) jefe de cocina, (b.2) ayudante de cocina y (b.3) atención al cliente.

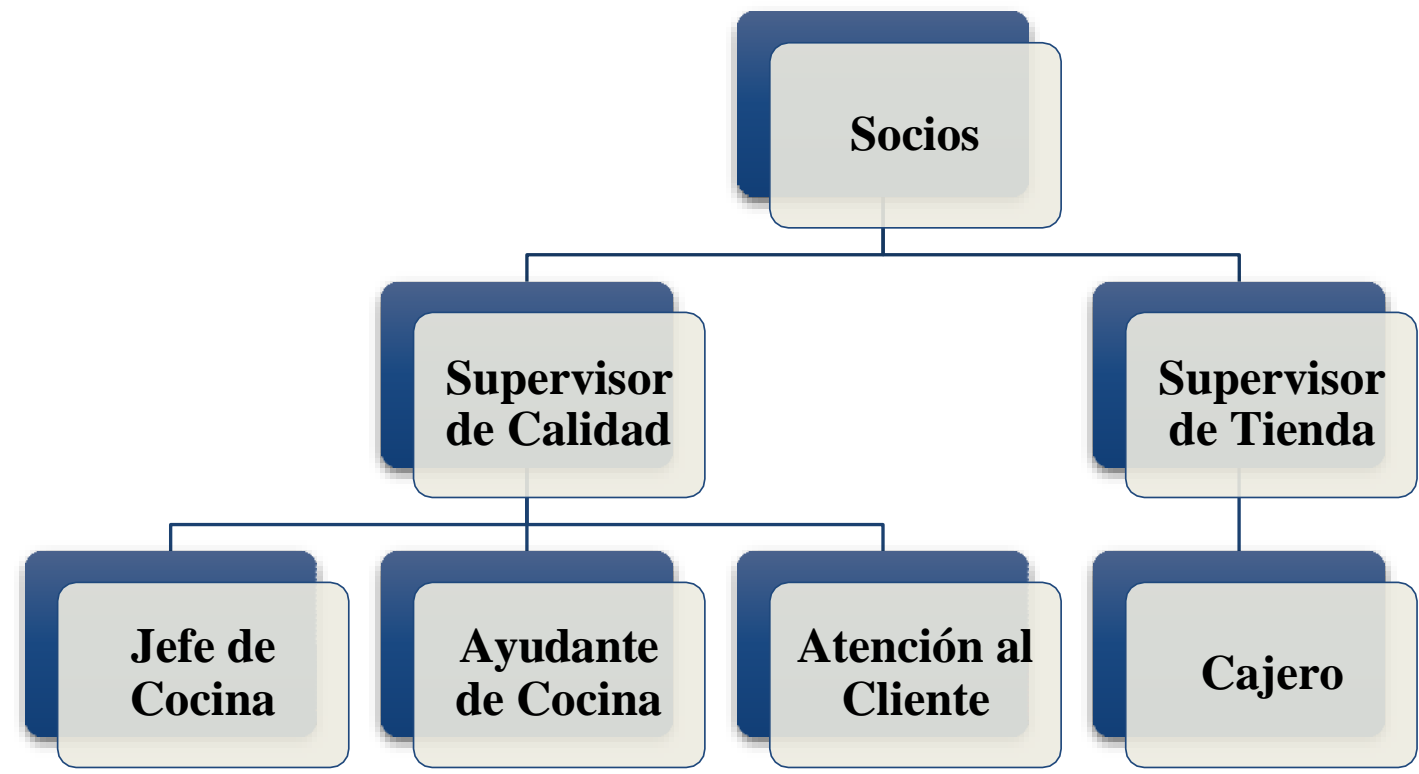

Gráfico 4: Estructura organizacional de Healthy Corner

\subsection{Diseño de los perfiles de puestos clave}

A continuación, se detalla los puestos claves que engrana el equipo de trabajo de Healthy Corner:

\section{a. Supervisor de tienda:}

Responsable de dirigir, controlar, planificar y desarrollar las actividades que aseguren el buen funcionamiento y abastecimiento del servicio, así como proporcionar la imagen y calidad profesional que requiere la empresa.

Funciones:

- Cumplir los objetivos con la máxima utilización de los recursos.

- Responsable del desempeño de los colaboradores a cargo.

- Responsable del cuadre de ingresos diarios del servicio.

- Controla el fondo fijo de la caja general. 
- Responsable de pagos a proveedores, reembolsos y sueldos a los colaboradores.

- Coordinar actividades de promoción y negociaciones.

- Responsable del manejo de redes sociales.

$\underline{\text { Requerimientos del puesto: }}$

- Egresado de la carrera de Administración de Empresas, Turismo y Hotelería, Ingeniería Industrial o carreras afines.

- Experiencia mínima de dos años en supervisión de restaurantes o fast food.

- Manejo de indicadores operacionales y estados financieros.

\section{b. Supervisor de calidad:}

Responsable de supervisar todos los aspectos de las operaciones del servicio de cocina, asegurándose que una excelente calidad de producto final.

\section{Funciones:}

- Realizar auditorías internas, inspecciones, pruebas o mediciones de los materiales, productos y/o instalaciones, a fin de comprobar el cumplimiento de las especificaciones según los manuales y protocolos de calidad.

- Responsable del desempeño de los colaboradores a su cargo.

- Supervisión diaria de los procesos productivos.

- Controlar y verificar el registro adecuado de los formatos de calidad y check list de personal.

- Capacitación diaria a los colaboradores sobre Buenas Prácticas de Manufactura (BPM) y temas relacionados a calidad.

\section{$\underline{\text { Requerimientos del puesto: }}$}

- Licenciada en nutrición, colegiada y habilitada. 
- Experiencia mínima de dos años de supervisión en servicios de alimentación y/o restaurantes.

- Conocimiento en Buenas Prácticas de Manipulación de Alimentos (BPM), Procedimiento Operativos Estandarizados de Saneamiento (POES), Sistema de Análisis de Peligros y Puntos de Control Críticos (HACCP) e International Organization for Standardization ISO 9000, ISO 14000 y ISO 22000.

\section{c. Jefe de cocina:}

Responsable del área de cocina, realizando sus labores según los estándares de calidad establecidos.

\section{Funciones:}

- Supervisión de todos los procesos que se realizan en el área de cocina, delegando funciones al asistente de cocina.

- Responsable último de la conservación de la materia prima.

\section{$\underline{\text { Requerimiento del puesto: }}$}

- Egresado de la Carrera de Gastronomía.

- Experiencia mínima de 1 año.

- Capacidad de liderazgo y trabajo en equipo.

\section{d. Ayudante de cocina:}

Encargado de asistir en los requerimientos necesarios por parte del jefe de cocina. Mantendrá funciones sobre el ordenamiento y limpieza del área de cocina.

\section{Funciones:}

- Asistir al jefe de cocina en las funciones de preparación.

- Realizar la limpieza requerida de los insumos a utilizar en el día. 
- Prepara higiénicamente y bajo las normas de calidad los alimentos que se sirven en el fast food.

- Verifica el funcionamiento de los equipos del área de trabajo y lo reporta.

- Registrar los formatos de temperatura de congelador, conservador, etc.

$\underline{\text { Requerimiento del puesto: }}$

- Estudiante de tercer año de Gastronomía.

- Capacidad de trabajo en equipo

\section{e. Cajero:}

Garantizar las operaciones de una unidad de caja, efectuando actividades de recepción, entrega y custodia de dinero, a fin de lograr la recaudación de ingresos a la empresa.

\section{Funciones:}

- Atención amable con el cliente, ofreciendo opciones según sus preferencias y realizando el cobro.

- Registra directamente los movimientos de entrada y salida de dinero.

\section{$\underline{\text { Requerimiento del puesto: }}$}

- Profesional técnico con experiencia comprobada mayor a un año en labores y funciones de caja (cobranza y liquidación) y que tenga manejo de caja chica. 


\section{f. Atención al cliente:}

Responsable de la atención amable y cortés hacia el público.

Funciones:

- Recepcionar de cocina el pedido de los clientes y entregarlo a los mismos.

- Reponer los insumos de las vitrinas de ensaladas y de postres.

- Buena atención y capacidad para resolver situaciones difíciles.

- Apoyar en mantener el orden y la limpieza del área de despacho.

$\underline{\text { Requerimiento del puesto: }}$

- Actitudes, habilidades y destrezas afines al puesto.

- Trabajo bajo presión y en equipo.

- Excelentes relaciones interpersonales, pulcritud, cooperación yempatía.

\subsection{Remuneraciones, compensaciones e incentivos}

Es importante mencionar que Healthy Corner cuenta con dos turnos de 8 - 10 horas cada uno. Por ello la planilla consta de 9 personas.

La remuneración de los colaboradores se ajusta al mercado según el puesto a considerar:

Tabla 31

Remuneración del personal

\begin{tabular}{clc}
\hline $\mathbf{N}^{\circ}$ & \multicolumn{1}{c}{ Personal } & Remuneración (S/.) \\
\hline 1 & Supervisor de tienda & 1500 \\
1 & Supervisor de calidad & 1500 \\
1 & Jefe de cocina & 1200 \\
2 & Ayudante de cocina & 850 \\
2 & Atención al cliente & 850 \\
2 & Cajero & 850 \\
\hline \multicolumn{2}{c}{ Total } \\
\end{tabular}

Fuente: Elaboración propia 


\subsection{Política de recursos humanos}

La propuesta de valor de Healthy Corner son:

- Brindar servicio de calidad

- Brindar preparaciones a base de alimentos orgánicos.

- Ofrecer productos para veganos

- Ofrecer productos libres de azúcar

- Personalización de productos

- Personal capacitado

El servicio al cliente es justamente un área en la cual el fast food saludable propuesto hará esfuerzos específicos para asegurar un servicio al cliente de mejor calidad que el promedio de la industria.

Healthy Corner tendrá colaboradores que tengan vocación de servicio; estos deberán cumplir con un perfil que denote responsabilidad, iniciativa, higiene personal y un interés por la alimentación saludable. Previamente deberán pasar por un programa de capacitación en servicio al cliente, manejo de alimentos, nutrición básica, preparación de los productos, plataforma tecnológica, promoción de ventas y solución de problemas.

Para medir la calidad del servicio se llevará a cabo investigaciones periódicas para medir la percepción de los clientes del servicio, así como podrán comunicar sus observaciones, sugerencias, quejas y recomendaciones. 


\section{CAPÍTULO VII: PLAN DE MARKETING}

\subsection{Estrategias de marketing}

La estrategia de marketing busca penetrar en el mercado, teniendo un reconocimiento de marca por el concepto que se ofrece, en principio se encontrará en el único local ubicado en el patio de comidas del Centro Comercial Jockey Plaza, lugar donde se encuentra la competencia directa Cottage, Design Your Salad y Cafefit.

\subsubsection{Estrategia de producto}

Healthy Corner ofrecerá jugos, infusiones y platos elaborados (sándwich, wraps, combos y postres).

La estrategia para utilizar es la diferenciación del producto en base a sus características, ya que incluyen platos ricos y nutritivos a precios accesibles que lo hace exclusivo y diferente a los de la competencia.

Nombre: Según el estudio de mercado competitivo, los nombres se encuentran en el idioma inglés, por otro lado, según el estudio cualitativo (Focus Group) los participantes refieren que el nombre debería estar relacionado a la palabra "saludable" y en el idioma inglés. Finalmente, en el estudio cuantitativo (encuesta estructurada) el 46,4\% de los encuestados optaron por escoger el nombre "Healthy Corner" como la opción de su preferencia; que significa rincón saludable.

\section{Logo y Eslogan:}

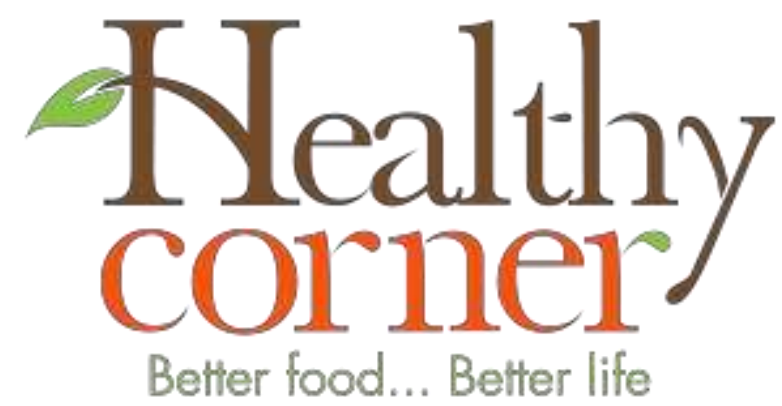

Figura 10: Imagen y slogan "Healthy Corner”. Elaboración propia 
La propuesta satisface las necesidades de consumo de los consumidores de Lima Moderna. Es de suma importancia destacar la lista que fue elaborada por el o la nutricionista y el o la chef, a continuación, se detallará:

Tabla 32

Lista de preparaciones del fast food saludable "Healthy Corner"

\section{Bebidas}

Jugo de Naranja (250ml u8oz)

Jugo de Piña (250ml u 8oz)

Jugo de Papaya (250ml u 8oz)

Jugo de Melón (250ml u 8oz)

Refresco de Maracuyá (250ml u 8oz)

Limonada $(250 \mathrm{ml} \mathrm{u} 8 \mathrm{oz})$

Chicha (250ml u 8oz)

Té Verde $(250 \mathrm{ml} \mathrm{u} 8 \mathrm{oz})$

Té de Menta (250ml u 8oz)

Té de frutos del bosque (mora, arándanos, frambuesa) $(250 \mathrm{ml} \mathrm{u} 8 \mathrm{oz})$

Té digestivo (Manzanilla, muña, boldo, anís, cedrón, menta) (250ml u 8oz)

Té Relax (valeriana, menta, romero, hierba luisa, manzanilla) (250ml u 8oz)

Té Dulces sueños (manzanilla, valeriana, naranja, menta, canela, cedrón) (250ml u 8oz)

\section{Sándwiches}

Filete de pechuga de pollo (70g en crudo)

Atún (60g escurrido)

Pavo (70g en crudo)

Hamburguesa vegana de lentejas

Wraps

Jamón de pavo $(100 \mathrm{~g})$

Vegetariano $(100 \mathrm{~g})$

Postres

Ensalada de fruta con yogur natural y kiwicha (250g)

2 opciones de postres dulces con edulcorante y sin leche $(100 \mathrm{~g})$

Combos

Combo Tuna Salad:

Ensalada + Filete de toyo $150 \mathrm{~g}$ en crudo + bebida $250 \mathrm{ml}+$ fruta entera

Combo Beef:

Ensalada + Asado de res $150 \mathrm{~g}$ en crudo + bebida $250 \mathrm{ml}+$ fruta entera

Combo Chicken Grill:

Ensalada + Filete de pechuga de pollo 150 en crudo + bebida $250 \mathrm{ml}+$ fruta entera

Combo Vegan:

Ensalada + Toffu $150 \mathrm{~g}$ en crudo + bebida $250 \mathrm{ml}+$ fruta entera

Fuente: Elaboración propia 


\subsubsection{Estrategia de Precio}

Healthy Corner ofrecerá un $15 \%$ de descuento en todas las variedades de wraps y combos por los primeros seis meses de apertura, como precio de introducción al mercado.

Se contará con las diversas formas de pago como: pago por tarjeta de crédito y débito con Visa y MasterCard. Pago en efectivo y en vales.

De acuerdo con el perfil del consumidor, está dispuesto a pagar hasta 20 soles por consumo personal. A continuación, se detalla Tabla de Precios de costo por plato.

Tabla 33

Lista de precios de venta de platos de fast food saludable "Healthy Corner"

\begin{tabular}{lccc}
\hline Productos & Valor venta & IGV & Precio (S/.) \\
\hline Jugos & 6,5 & 1,17 & 7,70 \\
Wrap/ Sándwich & 9 & 1,62 & 10,60 \\
Postres & 7 & 1,26 & 8,30 \\
Combos & 14 & 2.52 & 16,50 \\
\hline
\end{tabular}

Fuente: Elaboración propia 
Tabla 34

Lista de costos en soles de platos de fast food saludable "Healthy Corner"

\begin{tabular}{|c|c|c|c|}
\hline Bebidas & $\begin{array}{c}\text { Precio de } \\
\text { Ingredientes }\end{array}$ & $\begin{array}{l}\text { Precio de } \\
\text { Cubiertos }\end{array}$ & $\begin{array}{l}\text { Costo } \\
\text { Total }\end{array}$ \\
\hline Jugo de Naranja (250ml u8oz) & 0,50 & & 0,75 \\
\hline Jugo de Piña (250ml u 8oz) & 0,50 & 0,25 & 0,75 \\
\hline Jugo de Papaya (250ml u 8oz) & 0,50 & 0,25 & 0,75 \\
\hline Jugo de Melón (250ml u 8oz) & 0,50 & 0,25 & 0,75 \\
\hline Refresco de Maracuyá (250ml u 8oz) & 0,50 & 0,25 & 0,75 \\
\hline Limonada $(250 \mathrm{ml} \mathrm{u} 8 \mathrm{oz})$ & $\begin{array}{l}0,50 \\
0,20\end{array}$ & 0,25 & 0,45 \\
\hline Chicha $(250 \mathrm{ml} \mathrm{u} 8 \mathrm{oz})$ & 0,20 & 0,25 & 0,75 \\
\hline Té Verde $(250 \mathrm{ml} \mathrm{u} 8 \mathrm{oz})$ & $\begin{array}{l}0,50 \\
010\end{array}$ & 0,25 & 0,35 \\
\hline Té de Menta (250ml u 8oz) & $\begin{array}{l}0,10 \\
0.10\end{array}$ & 0,25 & 0,35 \\
\hline Té de frutos del bosque (mora, arándanos, & 0,15 & 0,25 & 0,40 \\
\hline frambuesa) $(250 \mathrm{ml} \mathrm{u} 8 \mathrm{oz})$ & & 0,25 & \\
\hline $\begin{array}{l}\text { Té digestivo } \\
\text { (Manzanilla, muña, boldo, anís, cedrón, menta) }(250 \mathrm{ml} \mathrm{u}\end{array}$ & 0,15 & 0,25 & 0,40 \\
\hline & 015 & & 0,40 \\
\hline Té Relax (valeriana, menta, romero, hierba luisa, & 0,15 & 0,25 & \\
\hline $\begin{array}{l}\text { manzanilla) }(250 \mathrm{ml} \text { u } 8 \mathrm{oz}) \\
\text { Té Dulces sueños (manzanilla, valeriana, naranja, } \\
\text { menta, canela, cedrón) ( } 250 \mathrm{ml} \text { u } 8 \mathrm{oz})\end{array}$ & 0,15 & 0,25 & 0,40 \\
\hline \multicolumn{4}{|l|}{ Sándwiches } \\
\hline Filete de pechuga de pollo (70g en crudo) & 1,09 & 0,20 & 1,29 \\
\hline Atún (60g escurrido) & 2,80 & 0,20 & 3,00 \\
\hline Pavo (70g en crudo) & 1,02 & 0,20 & 1,22 \\
\hline Hamburguesa vegana de lentejas ( $70 \mathrm{~g}$ en crudo) & 1,00 & 0,20 & 1,20 \\
\hline \multicolumn{4}{|l|}{ Wraps } \\
\hline Jamón de pavo (100g) & 1,30 & 0,18 & 1,48 \\
\hline Vegetariano $(100 \mathrm{~g})$ & 1,25 & 0,18 & 1,43 \\
\hline \multicolumn{4}{|l|}{ Postres } \\
\hline $\begin{array}{l}\text { Ensalada de fruta con yogur natural y kiwicha } \\
(250 \mathrm{~g})\end{array}$ & 2,00 & 0,22 & 2,22 \\
\hline $\begin{array}{l}2 \text { opciones de postres dulces con edulcorante y } \\
\text { sin leche }(100 \mathrm{~g})\end{array}$ & 2,50 & 0,22 & 2,75 \\
\hline \multicolumn{4}{|l|}{ Combos } \\
\hline $\begin{array}{l}\text { Combo Tuna Salad: Ensalada + Filete de toyo } 150 \mathrm{~g} \\
\text { en crudo + bebida } 250 \mathrm{ml}+\text { fruta entera }\end{array}$ & 5,10 & 1,67 & 6,77 \\
\hline $\begin{array}{l}\text { Combo Beef: Ensalada + Asado de res } 150 \mathrm{~g} \text { en crudo } \\
\text { + bebida } 250 \mathrm{ml}+\text { fruta entera }\end{array}$ & 7,50 & 1,67 & 9,17 \\
\hline $\begin{array}{l}\text { Combo Chicken Grill: Ensalada + Filete de pechuga } \\
\text { de pollo } 150 \text { en crudo + bebida } 250 \mathrm{ml}+\text { fruta entera }\end{array}$ & 6,30 & 1,67 & 7,97 \\
\hline $\begin{array}{l}\text { Combo Vegan: Ensalada + Toffu } 150 \mathrm{~g} \text { en crudo }+ \\
\text { bebida } 250 \mathrm{ml}+\text { fruta entera }\end{array}$ & 6,00 & 1,67 & 7,67 \\
\hline
\end{tabular}

Fuente: Elaboración propia 


\subsubsection{Estrategia de distribución}

La estrategia de distribución es directa, ya que Healthy Corner ofrece el servicio de alimentación para el público en el punto de venta.

La propuesta se ubicará en el patio de comidas del Centro Comercial Jockey Plaza, el criterio de ubicación se debe a la mayor demanda de público en centros comerciales de Lima Moderna y el mayor desarrollo comercial, ya que en el mismo patio de comidas se encuentra la competencia directa Cottage, Design your salad y Cafefit.

\subsubsection{Estrategia de promoción y publicidad}

Healthy Corner realiza una estrategia de promoción para difundir el servicio con ética y responsabilidad social, a continuación, se detallará las promociones:

- Descuentos por temporada baja o según cantidad de ventas.

- Convenios corporativos con la cadena de Farmacias Inkafarma y el Banco Continental; con el objetivo de ofrecer a sus clientes cupones y vales de consumo en Healthy Corner.

Tabla 35

Presupuesto para la estrategia de promoción

\begin{tabular}{cccccc}
\hline $\begin{array}{c}\text { Tipo de } \\
\text { Promoción }\end{array}$ & $\begin{array}{c}\text { Tipo de } \\
\text { Establecimiento }\end{array}$ & $\begin{array}{c}\text { Duración } \\
\text { Meses }\end{array}$ & Cantidad & $\begin{array}{c}\text { Costo } \\
\text { Unitario }\end{array}$ & $\begin{array}{c}\text { Costo } \\
\text { Total }\end{array}$ \\
\hline Cupones & C.C. Jockey Plaza & 6 & 360000 & 0,02 & 7200 \\
Vales de & Inkafarma & 3 & 200000 & 0,04 & 8000 \\
consumo & Banco continental & 3 & 200000 & 0,04 & 8000 \\
\hline & Monto Total de Plan de Promoción & & $\mathbf{S} / .23200$ \\
\hline
\end{tabular}

Fuente: Elaboración propia 


\section{CUPONES}

DESCUENTO

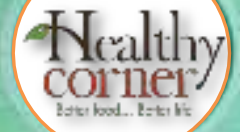

Figura 11: Imagen de cuponera de descuento. Elaboración propia

La estrategia de publicidad es de suma importancia para fidelizar al consumidor, se detallará las estrategias:

- La difusión en las redes sociales como Blog y Facebook serán los principales medios de publicidad, ya que el perfil del consumidor utiliza como fuente directa la tecnología. Se organizará sorteos mediante esta red para regalar paquetes de asesoría nutricional y cupones.

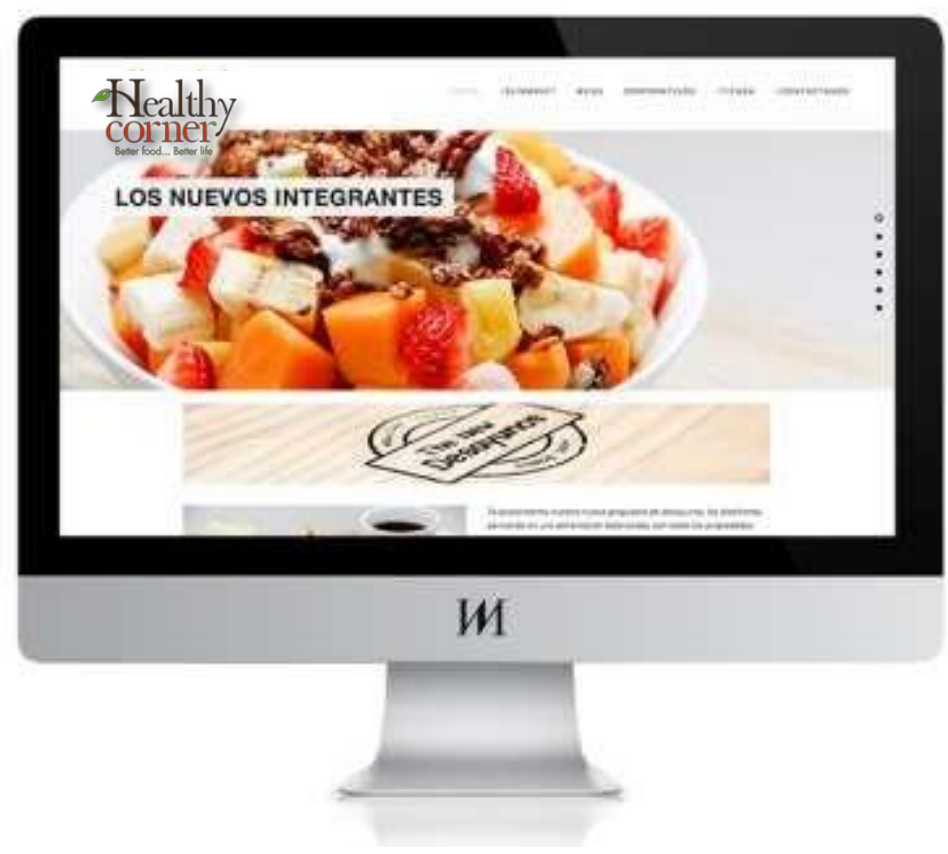

Figura 12: Medio de publicidad Blog y Facebook. Elaboración propia. 
- Difusión en paneles publicitarios el concepto de Healthy Corner.

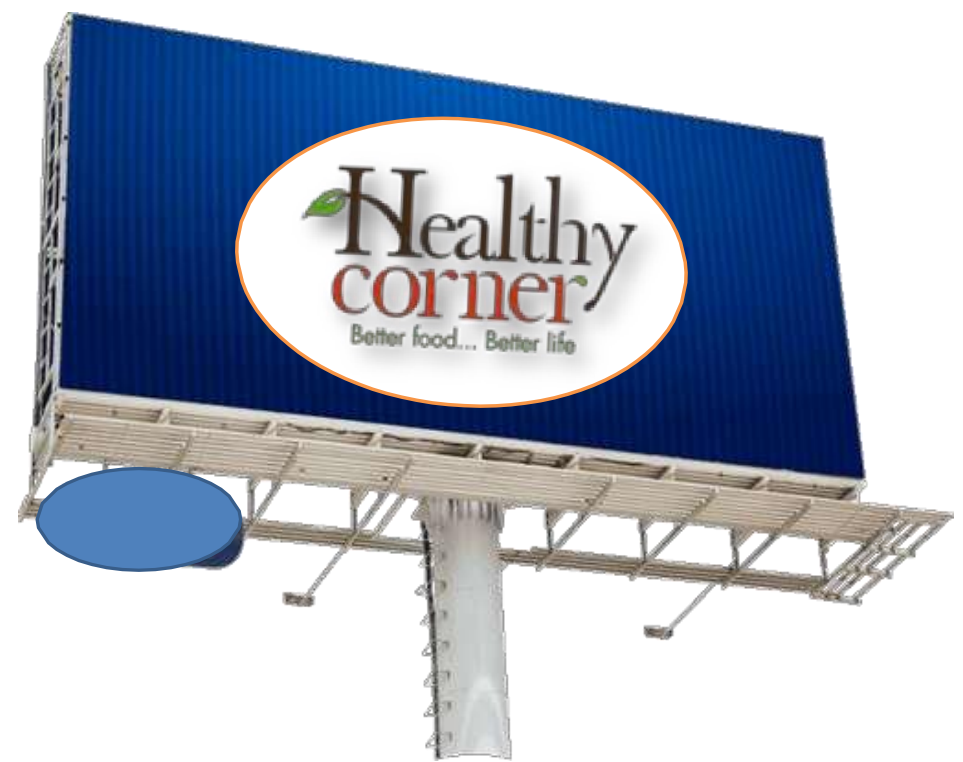

Figura 13: Panel publicitario. Imagen referencial

- Presencia y difusión en medio de comunicación radial, mediante entrevistas abordando temas de salud y alimentación saludable y promocionando el fast food saludable.

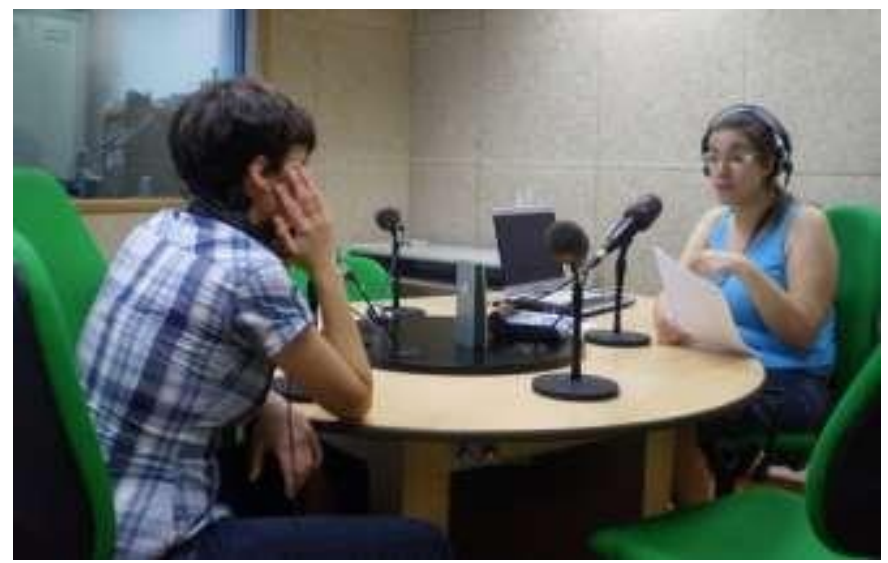

Figura 14: Medio de difusión radial. Imagen referencial 
Tabla 36

Presupuesto para la estrategia de publicidad

\begin{tabular}{|c|c|c|c|c|}
\hline Tipo de Publicidad & Descripción & $\begin{array}{c}\text { Duración } \\
\text { Meses }\end{array}$ & Ubicación & $\begin{array}{c}\text { Costo } \\
\text { Total }\end{array}$ \\
\hline \multirow{2}{*}{ Redes sociales } & Facebook & 12 & Internet & 6000 \\
\hline & $\mathrm{B} \log$ & 12 & Internet & 0 \\
\hline Panel publicitario & $1 \mathrm{~m} \times 1,7 \mathrm{~m}$ & 12 & Av. Javier Prado & 72000 \\
\hline Radio & Entrevistas & Permanente & $\begin{array}{c}\text { Radio Capital y } \\
\text { RPP }\end{array}$ & 0 \\
\hline \multicolumn{4}{|c|}{ Monto Total de Plan de Publicidad } & $\mathrm{S} / .78000$ \\
\hline
\end{tabular}

Fuente: Elaboración propia

\subsection{Estrategia de ventas}

Healthy Corner plantea una estrategia de ventas, para ello se hará descuentos de consumo futuro mediante el comprobante de pago.

Luego del primer año del establecimiento se pretende tener en cuenta las siguientes estrategias de ventas:

- Incrementar y renovar la lista de platos a ofrecer, con el fin mejorar la carta para nuestros clientes y captar nuevos.

- Implementar el servicio delivery, para los clientes que se encuentran en los distritos aledaños al Centro comercial Jockey Plaza, ubicados en el distrito de Santiago de Surco.

- Incrementar el número de locales en otros centros comerciales de mayor concurrencia ubicados en Lima Moderna. 


\subsubsection{Plan de ventas}

La estrategia de ventas se planteará anualmente y se adaptará según el movimiento de mercado. Para ello se realiza un cronograma con las actividades.

Tabla 37

Cronograma de actividades de publicidad

\begin{tabular}{|c|c|c|c|c|c|c|c|c|c|c|c|c|}
\hline \multirow[b]{2}{*}{ Actividad } & \multicolumn{12}{|c|}{ Meses } \\
\hline & $\mathbf{E}$ & $\mathbf{F}$ & $\mathbf{M}$ & $\mathbf{A}$ & $\mathbf{M}$ & $\mathbf{J}$ & $\mathbf{J}$ & $\mathbf{A}$ & $\mathbf{S}$ & $\mathbf{O}$ & $\mathbf{N}$ & D \\
\hline \multicolumn{13}{|l|}{ Cupones de introducción } \\
\hline \multicolumn{13}{|l|}{ Convenio corporativo } \\
\hline \multicolumn{13}{|l|}{ Redes sociales } \\
\hline \multicolumn{13}{|l|}{ Paneles publicitarios } \\
\hline \multicolumn{13}{|l|}{ Radio } \\
\hline \multicolumn{13}{|l|}{$\begin{array}{l}\text { Sorteo de paquetes de } \\
\text { asesoría nutricional }\end{array}$} \\
\hline \multicolumn{13}{|l|}{$\begin{array}{l}\text { Sorteo de vales de } \\
\text { consumo }\end{array}$} \\
\hline $\begin{array}{l}\text { Descuento de consumo } \\
\text { futuro }\end{array}$ & & & & & & & & & & & & \\
\hline
\end{tabular}

Fuente: Elaboración propia.

\subsubsection{Políticas de servicios y garantías}

En la política de servicios y garantías, se considera el "servicio añadido", este consiste en darle un valor agregado al servicio de fast food saludable, brindando paquetes de asesoría nutricional y otras actividades promocionales de la salud. Estas actividades tendrán presencia en todos los distritos de Lima Moderna. 


\section{CAPÍTULO VIII: PLANIFICACIÓN FINANCIERA.}

\subsection{La inversión}

\subsubsection{Inversión preoperativa}

La inversión preoperativa es aquel monto de dinero que se necesita antes del inicio de las actividades. La inversión pre operativa es de 101458 soles.

Tabla 38

Inversión preoperativa

Preoperativa

\begin{tabular}{l}
\hline \multicolumn{1}{c}{ Ingresos (S/.) } \\
\hline \multicolumn{1}{c}{ Total de ingresos de caja } \\
\hline Egresos (S/.) \\
\hline Compra de mercadería \\
Compra de suministros \\
Sueldos y aportaciones \\
Gratificaciones \\
Vacaciones \\
CTS \\
Servicios de contabilidad \\
Electricidad \\
Agua \\
Teléfono, internet \\
Alquiler de local \\
Materiales y útiles de oficina \\
Equipos y maquinarias \\
Muebles y enseres \\
Equipos de oficina \\
Compras mandadas al gasto \\
Otros gastos mandados al gasto \\
Pago de IGV \\
Pago a cuenta IR3era \\
Pago anual de IR \\
\hline \multicolumn{1}{c}{ Flujo de caja económico } \\
\\
\hline
\end{tabular}

Fuente: Elaboración propia 


\subsubsection{Inversión en capital de trabajo}

La inversión de capital de trabajo es el dinero en efectivo que se dispone, siendo aproximadamente el 35,6 \% de la inversión total, $\mathbf{5 6} \mathbf{1 7 4 , 8 0}$ soles.

Tabla 39

Inversión en capital de trabajo

\begin{tabular}{|c|c|}
\hline & Preoperativa \\
\hline Ingresos (S/.) & \\
\hline Ingresos por ventas & \\
\hline Total de ingresos de caja & \\
\hline Egresos (S/.) & \\
\hline Compra de mercadería & \\
\hline Compra de suministros & \\
\hline Sueldos y aportaciones & \\
\hline Gratificaciones & \\
\hline Vacaciones & \\
\hline CTS & \\
\hline Servicios de contabilidad & \\
\hline Electricidad & \\
\hline Agua & \\
\hline Teléfono, internet & 51840 \\
\hline Alquiler de local & 13804 \\
\hline Materiales y útiles de oficina & 18237 \\
\hline Equipos y maquinarias & 10577 \\
\hline Muebles y enseres & 5000 \\
\hline Equipos de oficina & 900 \\
\hline Compras mandados al gasto & 1100 \\
\hline Otros gastos mandados al gasto & \\
\hline Pago de IGV & \\
\hline Pago a cuenta IR3era & \\
\hline Pago anual de IR & \\
\hline $\begin{array}{l}\text { Flujo de caja económico } \\
\text { (operativo) }\end{array}$ & 101458 \\
\hline Ingresos $(\mathrm{S} /)$. & \\
\hline Adquisición de préstamo & 45283,20 \\
\hline Total de ingresos de caja & 45283,20 \\
\hline Egresos $(\mathrm{S} /)$. & \\
\hline Amortizaciones de préstamo & \\
\hline Pago de interés & \\
\hline Total de egresos de caja & \\
\hline $\begin{array}{l}\text { Flujo de caja financiero } \\
\end{array}$ & 56174,80 \\
\hline Saldo inicial de caja & 56174,80 \\
\hline
\end{tabular}

Fuente: Elaboración propia 


\subsubsection{Costo del proyecto}

El costo del proyecto será $157 \mathbf{6 3 2 , 8 0}$ soles; el cual consiste en la suma de los conceptos: equipo y maquinarias, muebles y enseres, uniformes, útiles y equipos de oficina y, gastos preliminares. Detallado en la Tabla 40.

Tabla 40

Costo de proyecto

\begin{tabular}{|c|c|c|c|}
\hline Concepto & Unidades & Artículo & $\begin{array}{l}\text { Precio Total } \\
\quad \text { (soles) }\end{array}$ \\
\hline \multirow{4}{*}{$\begin{array}{l}\text { Equipo y } \\
\text { Maquinaria }\end{array}$} & 2 & Licuadoras y hervidores eléctricos & 816 \\
\hline & 1 & $\begin{array}{l}\text { Refresquera, congelador, conservador, } \\
\text { extractor }\end{array}$ & 7650 \\
\hline & 1 & $\begin{array}{l}\text { Caja registradora, exprimir de cítricos, } \\
\text { cocina industrial }\end{array}$ & 9849 \\
\hline & 1 & Balanza gramera, vaporera, lavadero & 1980 \\
\hline \multirow{3}{*}{$\begin{array}{l}\text { Muebles y } \\
\text { enseres }\end{array}$} & 4 & Tablas de cocina $(35 * 24)$ & 260,80 \\
\hline & 1 & Mostrador, exhibidor, escurridero, mesa & 7499 \\
\hline & 1 & $\begin{array}{l}\text { Utensilios de cocina, alacena, rallador } \\
\text { mediano, cuchillería Facusa }\end{array}$ & 5998 \\
\hline Uniformes & 9 & Uniformes & 1500 \\
\hline \multirow{6}{*}{$\begin{array}{c}\text { Útiles y } \\
\text { Equipos de } \\
\text { oficina }\end{array}$} & 2 & Sillas & 700 \\
\hline & 1 & Escritorio, teléfono & 3500 \\
\hline & 1 & Computadora, impresora & 7900 \\
\hline & 1 & Útiles de oficina & 1631 \\
\hline & 1 & Mueble para archivadores & 2500 \\
\hline & 1 & Útiles de aseo & 7653 \\
\hline \multirow[t]{2}{*}{$\begin{array}{c}\text { Gastos } \\
\text { preliminares }\end{array}$} & 1 & $\begin{array}{l}\text { Diseño de tienda, constitución de la } \\
\text { empresa, alquiler en Jockey Plaza, } \\
\text { extintor, señalización, software para } \\
\text { pedidos, web, sueldos }\end{array}$ & 97,676 \\
\hline & 2 & $\begin{array}{l}\text { Servicios de pagos (VISA, } \\
\text { MASTERCARD) }\end{array}$ & 520 \\
\hline & & Total (S/.) & 157632,80 \\
\hline
\end{tabular}

Fuente: Elaboración propia 


\subsubsection{Inversiones futuras}

No hayinversiones futuras en los cinco años, ya que se mantendrá un único local del Centro Comercial Jockey Plaza.

\subsection{Financiamiento}

\subsubsection{Endeudamiento y condiciones}

El financiamiento del proyecto es el 35,6\% de la inversión preoperativa, siendo

$\mathbf{5 6} \mathbf{1 7 4 , 8 0}$ soles, en 24 cuotas de 2814 soles.

Tabla 41

Financiamiento

\begin{tabular}{lc}
\hline Monto (S/.) & $\mathbf{5 6 ~ 1 7 4 , 8 0}$ \\
\hline Tasa anual & $20 \%$ \\
Tasa mensual & $1,53 \%$ \\
Plazo (meses) & 24 \\
\hline
\end{tabular}

Fuente: Elaboración propia

\subsubsection{Capital y costo de oportunidad}

El capital propio para el proyecto será de 101458 soles.

El Costo de Oportunidad del Capital es el rendimiento esperado de la mejor alternativa de inversión con igual riesgo. No es un indicador de rentabilidad y sirve para evaluar el aporte propio. El COK nos ayuda a saber si existe alguna mejor alternativa, con igual riesgo, en la que podríamos invertir. Nos indica, entonces, cuál es la alternativa equivalente. Siendo nuestro costo de oportunidad del capital 27,25. 


\subsubsection{Costo de capital promedio ponderado}

También conocido como WACC (Weighted Average Cost of Capital), es una tasa de descuento que mide el costo promedio que han tenido nuestros activos operativos, en función de la forma en que han sido financiados, ya sea a través de capital propio (Patrimonio) o recursos de terceros (Deuda).En el actual proyecto el WACC es de $\mathbf{1 1 , 5 \% . ~}$

\subsection{Presupuestos base}

El presupuesto base consiste en el (a) presupuesto de ventas, (b) presupuesto de gastos de ventas, (c) presupuesto de compras, (d) presupuesto de costo de ventas, (e) presupuesto de gastos administrativos, (f) presupuesto de marketing y ventas y (g) presupuesto de gastos financieros. Se detalla en las siguientes tablas.

\subsubsection{Presupuesto de ventas}

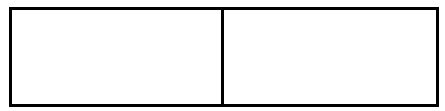

\begin{tabular}{|c|c|c|c|c|c|}
\hline \multicolumn{6}{|c|}{ Presupuesto de Ventas (en soles) } \\
\hline Conceptos & 2017 & 2018 & 2019 & 2020 & 2021 \\
\hline Cantidad de productos & 125823 & 133583 & 141822 & 150700 & 159856 \\
\hline $\begin{array}{l}\text { Valor de venta unitario } \\
\text { promedio }\end{array}$ & 114 & 114 & 114 & 114 & 114 \\
\hline Valor de venta total & 1192170 & 1265701 & 1343767 & 1426647 & 1514640 \\
\hline IGV & 214591 & 227826 & 241878 & 256796 & 272635 \\
\hline Total de Ingresos (S/.) & 1406761 & 1493527 & 1585645 & 1683444 & 1787275 \\
\hline
\end{tabular}

Fuente: Elaboración propia 
8.3.2. Presupuesto de costos de producción

Tabla 43

Presupuesto de gastos de ventas

\begin{tabular}{|c|c|c|c|c|c|}
\hline \multicolumn{6}{|c|}{ Presupuesto de Gasto de Ventas (en soles) } \\
\hline Conceptos & 2017 & 2018 & 2019 & 2020 & 2021 \\
\hline $\begin{array}{l}\text { Costo de } \\
\text { personal }\end{array}$ & 109788 & 109788 & 109788 & 109788 & 109788 \\
\hline Electricidad & 10677,966 & 10677,966 & 10677,966 & 10677,966 & 10677,966 \\
\hline Agua & 136677,966 & 136677,966 & 136677,966 & 136677,966 & 136677,966 \\
\hline $\begin{array}{l}\text { Teléfono, } \\
\text { internet }\end{array}$ & 6874,57 & 6874,57 & 6874,57 & 6874,57 & 6874,57 \\
\hline Alquiles de local & 210874,576 & 210874,576 & 210874,576 & 210874,576 & 210874,576 \\
\hline Útiles de oficina & 1220,338 & 1220,338 & 1220,338 & 1220,338 & 1220,338 \\
\hline Depreciación & 0 & 0 & 0 & 0 & 0 \\
\hline Total (S/.) & 469926,305 & 469926,305 & 469926,305 & 469926,305 & 469926,305 \\
\hline
\end{tabular}

Fuente: Elaboración propia

\subsubsection{Presupuesto de compras}

Tabla 44

Presupuesto de compras

\begin{tabular}{lccccc}
\hline \multicolumn{5}{c}{ Presupuesto de Compras (en unidades y en soles) } \\
\hline Conceptos & $\mathbf{2 0 1 7}$ & $\mathbf{2 0 1 8}$ & $\mathbf{2 0 1 9}$ & $\mathbf{2 0 2 0}$ & $\mathbf{2 0 2 1}$ \\
\hline $\begin{array}{l}\text { Ventas en unidades } \\
\text { Inventario final de } \\
\text { mercaderías }\end{array}$ & 1078 & 1144 & 1215 & 1289 & 1369 \\
$\begin{array}{l}\text { Total necesidades } \\
\text { Inventario inicial de } \\
\text { mercaderías }\end{array}$ & 138463 & 147003 & 156069 & 165695 & 175915 \\
\hline $\begin{array}{l}\text { Total a Comprar } \\
\text { (Unidades) }\end{array}$ & $\mathbf{1 2 6} \mathbf{9 0 0}$ & $\mathbf{1 3 3 6 5 0}$ & $\mathbf{1 4 1 ~ 8 9 3}$ & $\mathbf{1 5 0 6 4 5}$ & $\mathbf{1 5 9} \mathbf{1 5 3 6}$ \\
\hline
\end{tabular}

Fuente: Elaboración propia 


\subsubsection{Presupuesto de costo de ventas}

Tabla 45

Presupuesto de costo de ventas

\begin{tabular}{lccccc}
\hline \multicolumn{5}{c}{ Presupuesto de Costo de Ventas (en soles) } \\
\hline Conceptos (46\%) & $\mathbf{2 0 1 7}$ & $\mathbf{2 0 1 8}$ & $\mathbf{2 0 1 9}$ & $\mathbf{2 0 2 0}$ & $\mathbf{2 0 2 1}$ \\
\hline Costos de ventas bebidas & 7553 & 8019 & 8513 & 9038 & 9596 \\
Costo de ventas & 10130 & 10755 & 11418 & 12122 & 12870 \\
sándwiches/wraps & 5331 & 5660 & 6009 & 6380 & 8467 \\
Costos de ventas postres & 30070 & 31924 & 33924 & 35984 & 38203 \\
Costos de ventas combos & 2034 & 2034 & 2034 & 2034 & 2034 \\
Suministros & $\mathbf{5 5 1 1 8}$ & $\mathbf{5 8 3 9 2}$ & $\mathbf{6 1 ~ 3 9 2}$ & $\mathbf{6 5 5 5 8}$ & $\mathbf{7 1 ~ 1 7 0}$ \\
\hline Costo del Servicio (S/.) & & & & & \\
\hline
\end{tabular}

Fuente: Elaboración propia

\subsubsection{Presupuesto de gastos administrativos}

Tabla 46

Presupuesto de gastos administrativos

\begin{tabular}{lccccc}
\hline \multicolumn{7}{c}{ Presupuesto de Gastos Administrativos (en soles) } \\
Conceptos & $\mathbf{2 0 1 7}$ & $\mathbf{2 0 1 8}$ & $\mathbf{2 0 1 9}$ & $\mathbf{2 0 2 0}$ & $\mathbf{2 0 2 1}$ \\
\hline $\begin{array}{l}\text { Costo personal } \\
\text { Servicio de }\end{array}$ & 111600 & 111600 & 111600 & 111600 & 111600 \\
contabilidad & 6000 & 6000 & 6000 & 6000 & 6000 \\
Electricidad & 10677,966 & 10677,966 & 10677,966 & 10677,966 & 10677,966 \\
Agua & 136677,966 & 136677,966 & 136677,966 & 136677,966 & 136677,966 \\
Teléfono, internet & 6874,57 & 6874,57 & 6874,57 & 6874,57 & 6874,57 \\
Alquiler de local & 210874,576 & 210874,576 & 210874,576 & 210874,576 & 210874,576 \\
Útiles de oficina & 1220,338 & 1220,338 & 1220,338 & 1220,338 & 1220,338 \\
Depreciación & 0 & 0 & 0 & 0 & 0 \\
\hline Total (S/.) & $\mathbf{4 8 3 ~ 9 2 5 , 4 1 6}$ & $\mathbf{4 8 3} \mathbf{9 2 5 , 4 1 6}$ & $\mathbf{4 8 3} \mathbf{9 2 5 , 4 1 6}$ & $\mathbf{4 8 3} \mathbf{9 2 5 , 4 1 6}$ & $\mathbf{4 8 3 ~ 9 2 5 , 4 1 6}$
\end{tabular}

Fuente: Elaboración propia 
8.3.6. Presupuesto de marketing y ventas

Tabla 47

Presupuesto de marketing y ventas

\begin{tabular}{lccc}
\hline Gastos & Valor de Venta & IGV & Precio de Venta \\
\hline Publicidad & 16025 & 2884 & 18090 \\
Materiales publicitarios & 3616 & 651 & 4266,60 \\
\hline Total (S/.) & $\mathbf{1 9 6 4 0}$ & $\mathbf{3 5 3 5}$ & $\mathbf{2 3 ~ 1 7 6}$ \\
\hline
\end{tabular}

Fuente: Elaboración propia

\subsubsection{Presupuesto de gastos financieros}

Ingresos (Soles)

Adquisición de préstamo

\section{4,80 soles}

\subsection{Presupuestos de Resultados}

El presupuesto de resultados consiste en el (a) estado de ganancia y pérdidas proyectadas,

(b) balance proyectado y (c) flujo de caja proyectado. Se detalla en las siguientes tablas. 
8.4.1. Estado de ganancias y pérdidas proyectado

Tabla 48

Estado de ganancias y pérdidas proyectado

\begin{tabular}{|c|c|c|c|c|c|}
\hline Conceptos & 2017 & 2018 & 2019 & 2020 & 2021 \\
\hline Ventas & 1192170,42 & 1265700,88 & 1343766,55 & 1426647,11 & 1514639,60 \\
\hline Costo de servicio & 55117,58 & 58391,67 & 61867,69 & 65558,11 & 71169,54 \\
\hline Utilidad Bruta & 1137052,83 & 1207309,21 & 1281898,85 & 1361089,01 & 1443470,06 \\
\hline \multicolumn{6}{|l|}{ Gastos de Ventas } \\
\hline Costo de personal & 109788 & 109788 & 109788 & 109788 & 109788 \\
\hline Electricidad & 10677,966 & 10677,966 & 10677,966 & 10677,966 & 10677,966 \\
\hline Agua & 136677,966 & 136677,966 & 136677,966 & 136677,966 & 136677,966 \\
\hline Teléfono, internet & 6874,57 & 6874,57 & 6874,57 & 6874,57 & 6874,57 \\
\hline Alquiles de local & 210874,576 & 210874,576 & 210874,576 & 210874,576 & 210874,576 \\
\hline Útiles de oficina & 1220,338 & 1220,338 & 1220,338 & 1220,338 & 1220,338 \\
\hline Depreciación & 0 & 0 & 0 & 0 & 0 \\
\hline \multicolumn{6}{|c|}{ Gastos Administrativos } \\
\hline Costo personal & 111600 & 111600 & 111600 & 111600 & 111600 \\
\hline $\begin{array}{l}\text { Servicio de } \\
\text { contabilidad }\end{array}$ & 6000 & 6000 & 6000 & 6000 & 6000 \\
\hline Electricidad & 10677,966 & 10677,966 & 10677,966 & 10677,966 & 10677,966 \\
\hline Agua & 136677,966 & 136677,966 & 136677,966 & 136677,966 & 136677,966 \\
\hline Teléfono, internet & 6874,57 & 6874,57 & 6874,57 & 6874,57 & 6874,57 \\
\hline Alquiler de local & 210874,576 & 210874,576 & 210874,576 & 210874,576 & 210874,576 \\
\hline Útiles de oficina & 1220,338 & 1220,338 & 1220,338 & 1220,338 & 1220,338 \\
\hline Depreciación & 0 & 0 & 0 & 0 & 0 \\
\hline $\begin{array}{l}\text { Utilidad (pérdida) } \\
\text { Operativa }\end{array}$ & 493062,80 & 563319,18 & 637908,81 & 717098,698 & 799480,02 \\
\hline Gastos financieros & 6638,76 & 2524,62 & 0 & 0 & 0 \\
\hline $\begin{array}{l}\text { Utilidad } \\
\text { (pérdida) antes } \\
\text { de impuestos }\end{array}$ & 486424,04 & 560794,56 & 637 908,81 & 717098,98 & 799480,02 \\
\hline $\begin{array}{l}\text { Impuestos } \\
\text { a la renta }\end{array}$ & 145927,21 & 168238,36 & 191372,646 & 215129,685 & 239844,008 \\
\hline Utilidad Neta & 340496,82 & 392556,19 & 446536,17 & 501969,87 & 559636,01 \\
\hline
\end{tabular}

Fuente: Elaboración propia 


\subsubsection{Balance proyectado}

Tabla 49

Balance proyectado

\begin{tabular}{|c|c|c|c|c|c|c|}
\hline \multicolumn{7}{|c|}{ Estado de Situación Financiera (en soles) } \\
\hline Conceptos & Preoperativo & 2017 & 2018 & 2019 & 2020 & 2021 \\
\hline \multicolumn{7}{|l|}{ Activos } \\
\hline $\begin{array}{l}\text { Efectivo y equivalente } \\
\text { de efectivo }\end{array}$ & 56174,8 & 426632,51 & 838394,82 & 1310429,64 & 1838589,43 & 2425420,45 \\
\hline Mercadería & & 454,59 & 482,63 & 512,40 & 544,01 & 577,56 \\
\hline $\begin{array}{l}\text { Inmuebles, maquinarias } \\
\text { y equipos }\end{array}$ & 28216,10 & 28216,10 & 28216,10 & 28216,10 & 28216,10 & 28216,10 \\
\hline $\begin{array}{l}\text { Depreciación } \\
\text { acumulada }\end{array}$ & & 4147,82 & 8295,65 & 12443,47 & 16591,30 & 20739,13 \\
\hline Impuesto a la renta & & 19294,32 & 0 & 0 & 0 & 0 \\
\hline $\begin{array}{l}\text { Total de Activos } \\
\text { (S/.) }\end{array}$ & 27958,69 & 470449,71 & 858797,91 & 1326714,67 & 1850758,24 & 2433474,78 \\
\hline Pasivos & & 0 & & & & \\
\hline $\begin{array}{l}\text { Impuesto general a las } \\
\text { ventas }\end{array}$ & 15308,84 & 10299,54 & 11382,54 & 12532,33 & 13753,04 & 15022,93 \\
\hline Impuestos a la renta & & 144682,86 & 166994,02 & 190128,29 & 213885,34 & 238599,66 \\
\hline $\begin{array}{l}\text { Remuneraciones } \\
\text { por pagar }\end{array}$ & & 9300 & 9300 & 9300 & 9300 & 9300 \\
\hline $\begin{array}{l}\text { Beneficios sociales de } \\
\text { los trabajadores } \\
\text { por pagar }\end{array}$ & & 1808,33 & 1808,33 & 1808,33 & 1808,33 & 1808,33 \\
\hline $\begin{array}{l}\text { Obligaciones } \\
\text { financieras }\end{array}$ & 45283,2 & 24698,67 & 0 & 0 & 0 & 0 \\
\hline Total Pasivos (S/.) & 29974,35 & 190789,41 & 189484,89 & 213768,96 & 238746,72 & 264730,92 \\
\hline Patrimonio Neto & 0 & 0 & & & & \\
\hline Capital social & 0 & 0 & 0 & 0 & 0 & 0 \\
\hline Utilidades retenidas & 80448,59 & 256544,75 & 646197,47 & 1089830,16 & 1588895,97 & 2145628,51 \\
\hline Reserva legal & 0 & 600 & 600 & 600 & 600 & 600 \\
\hline $\begin{array}{c}\text { Total Patrimonio } \\
\text { Neto }(\mathrm{S} / .)\end{array}$ & 80448,59 & 257144,75 & 646797,47 & 1090430,16 & 1589495,97 & 2146228,51 \\
\hline $\begin{array}{c}\text { Total Pasivos y } \\
\text { Patrimonio Neto } \\
\text { (S/.) }\end{array}$ & 50474,24 & 447934,17 & 836282,36 & 1304 199,13 & 1828242,69 & 2410959,44 \\
\hline
\end{tabular}

Fuente: Elaboración propia 


\subsubsection{Flujo de caja proyectado}

Tabla 50

Valoración del proyecto

\begin{tabular}{|c|c|c|c|c|c|c|}
\hline \multicolumn{7}{|c|}{ Valoración del Proyecto } \\
\hline Conceptos & Preoperativo & 2017 & 2018 & 2019 & 2020 & 2021 \\
\hline $\begin{array}{l}\text { Flujo de caja económico } \\
\text { (operativo) }\end{array}$ & - $\quad 101458$ & 438985,6 & \multicolumn{4}{|c|}{$472034,82510030,61528159,79586831,02$} \\
\hline Flujo de caja financiero & 56174,8 & 411762,31 & \multicolumn{4}{|c|}{$412034,82482807,32528159,79586831,02$} \\
\hline \multicolumn{7}{|c|}{ VAN: Flujo de caja operativo (en soles) } \\
\hline $\mathrm{COK}$ & 22,51 & & & & & \\
\hline Resumen & Preoperativo & 2017 & 2018 & 2019 & 2020 & 2021 \\
\hline $\begin{array}{l}\text { Flujo de caja } \\
\text { económico } \\
\text { (operativo) }\end{array}$ & 101458 & 438985,60 & 472034,82 & 510030,60 & 528159,82 & 586831,02 \\
\hline VAN & 2434583,83 & & & & & \\
\hline TIR & 492 & & & & & \\
\hline
\end{tabular}

VAN: Flujo de caja financiero (en soles)

COK 36,32

Resumen Preoperativo 2017 2018 2019 2020 2021

Flujo de caja financiero $56174,80 \quad 411762,30 \quad 472$ 034,82 $482807,31528159,78586831,02$

VAN 2425420,45

TIR 847

Fuente: Elaboración propia 


\section{CAPÍTULO IX: EVALUACIÓN ECONÓMICO FINANCIERA}

\subsection{Evaluación financiera}

La evaluación financiera mide los niveles de rentabilidad de Healthy Corner.

\subsubsection{TIR (Tasa Interna de Retorno)}

La tasa interna de retorno del proyecto, obtenido del flujo de caja operativo es de $492 \%$ y el financiero es de $847 \%$. Lo cual indica que el retorno de la inversión realizada resulta ser bastante propicio para el desarrollo de nuestro proyecto y que el negocio puede ser rentable casi de inmediato. Una de las razones es la acogida que tuvo el servicio al ser explicado a las personas entrevistadas, así como el aumento por la elección de comidas cada vez más saludables y reconfortantes para el organismo.

\subsubsection{VAN (Valor Actual Neto)}

El método del valor actual neto es una de las medidas de evaluación de la rentabilidad de un proyecto. Se analiza teniendo en cuenta los flujos de caja proyectados, para lo cual utilizaremos el flujo de caja financiero.

El valor actual neto obtenido en el flujo de caja operativo es de S/. 2434 583,83 soles, bajo una tasa de descuento (COK) de $22.51 \%$ y el flujo de caja financiero es de 2425 420,45 trabajado bajo una tasa de descuento (COK) de 36,32\%. Este resultado nos indica que el proyecto presentado es bueno, ya que obtenemos un VAN mayor a cero.

\subsubsection{ROE (Return On Equity)}

Beneficio después de impuestos/fondos propios. Nuestra utilidad neta del primer año del 2017 es de 340 496,82 soles. 
Tabla 51

Rentabilidad financiera

\begin{tabular}{lccccc}
\hline $\begin{array}{l}\text { Utilidad (pérdida) } \\
\text { operativa }\end{array}$ & 493062,80 & 563319,18 & 637908,81 & 717098,98 & 799480,02 \\
\hline Gastos financieros & 6638,76 & 2524,62 & 0 & 0 & 0 \\
\hline $\begin{array}{l}\text { Utilidad (pérdida) } \\
\text { antes de impuestos }\end{array}$ & 486424,04 & 560794,56 & 637908,81 & 717098,98 & 799480,02 \\
\hline $\begin{array}{l}\text { Impuesto a la } \\
\text { renta }\end{array}$ & $\mathbf{1 4 5} \mathbf{9 2 7 , 2 1}$ & $\mathbf{1 6 8} \mathbf{2 3 8 , 3 6}$ & $\mathbf{1 9 1} \mathbf{3 7 2 , 6 4 6}$ & $\mathbf{2 1 5} \mathbf{1 2 9 , 6 9 5}$ & $\mathbf{2 3 9} \mathbf{8 4 4 , 0 0 8}$ \\
\hline Utilidad neta & 340496,82 & 392556,19 & 446536,17 & 501969,87 & 559636,01 \\
\hline
\end{tabular}

Fuente: Elaboración propia

\subsubsection{Ratios}

Tabla 52

Ratio de rentabilidad: Utilidad neta / costo de producción

\begin{tabular}{cccccc}
\hline Año & $\mathbf{2 0 1 7}$ & $\mathbf{2 0 1 8}$ & $\mathbf{2 0 1 9}$ & $\mathbf{2 0 2 0}$ & $\mathbf{2 0 2 1}$ \\
\hline \% Ratio Rentabilidad & 29 & 26 & 27 & 29 & 29
\end{tabular}

Fuente: Elaboración propia

Tabla 53

Ratio de endeudamiento: Pasivo total / Activo total

\begin{tabular}{|c|c|c|c|c|c|}
\hline Año & 2017 & 2018 & 2019 & 2020 & 2021 \\
\hline \% Ratio Endeudamiento & 461 & 462 & 462 & 462 & 409 \\
\hline
\end{tabular}

Fuente: Elaboración propia

\subsection{Análisis de riesgo}

\subsubsection{Análisis de punto de equilibrio}

Para calcular el punto de equilibrio, se tomaron todos los gastos en los cuales se incurrirá, descritos anteriormente. Para determinar los costos fijos y los costos variables, se tomaron los resultados del prorrateo realizado. Los costos variables 
corresponden a los gastos indirectos de fabricación o gastos operativos pues estos pueden variar de acuerdo con el nivel de producción. En los costos fijos, se consideraron todos los gastos de nómina, los gastos de administración y otros gastos generales.

\subsubsection{Análisis de sensibilidad}

Tabla 54

Estado de resultados integrales (en soles)

\begin{tabular}{|c|c|c|c|c|c|}
\hline Conceptos & 2017 & 2018 & 2019 & 2020 & 2021 \\
\hline Ventas & 1192170,42 & 1265700,88 & 1343766,55 & 1426647,11 & 1514639,60 \\
\hline Costo de servicio & 55117,58 & 58391,67 & 61867,69 & 65558,11 & 71169,54 \\
\hline Utilidad Bruta & 1137052,83 & 1207309,21 & 1281898,85 & 1361089,01 & 1443470,06 \\
\hline \multicolumn{6}{|l|}{ Gastos de Ventas } \\
\hline Costo de personal & 109788 & 109788 & 109788 & 109788 & 109788 \\
\hline Electricidad & 10677,966 & 10677,966 & 10677,966 & 10677,966 & 10677,966 \\
\hline Agua & 136677,966 & 136677,966 & 136677,966 & 136677,966 & 136677,966 \\
\hline Teléfono, internet & 6874,57 & 6874,57 & 6874,57 & 6874,57 & 6874,57 \\
\hline Alquiles de local & 210874,576 & 210874,576 & 210874,576 & 210874,576 & 210874,576 \\
\hline Útiles de oficina & 1220,338 & 1220,338 & 1220,338 & 1220,338 & 1220,338 \\
\hline Depreciación & 0 & 0 & 0 & 0 & 0 \\
\hline \multicolumn{6}{|l|}{ Gastos Administrativos } \\
\hline Costo personal & 111600 & 111600 & 111600 & 111600 & 111600 \\
\hline Servicio de contabilidad & 6000 & 6000 & 6000 & 6000 & 6000 \\
\hline Electricidad & 10677,966 & 10677,966 & 10677,966 & 10677,966 & 10677,966 \\
\hline Agua & 136677,966 & 136677,966 & 136677,966 & 136677,966 & 136677,966 \\
\hline Teléfono, internet & 6874,57 & 6874,57 & 6874,57 & 6874,57 & 6874,57 \\
\hline Alquiler de local & 210874,576 & 210874,576 & 210874,576 & 210874,576 & 210874,576 \\
\hline Útiles de oficina & 1220,338 & 1220,338 & 1220,338 & 1220,338 & 1220,338 \\
\hline Depreciación & 0 & 0 & 0 & 0 & 0 \\
\hline $\begin{array}{l}\text { Utilidad (pérdida) } \\
\text { Operativa }\end{array}$ & 493062,80 & 563319,18 & 637908,81 & 717098,698 & 799480,02 \\
\hline Gastos financieros & 6638,76 & 2524,62 & 0 & 0 & 0 \\
\hline $\begin{array}{l}\text { Utilidad (pérdida) antes de } \\
\text { Impuestos }\end{array}$ & 486424,04 & 560794,56 & 637908,81 & 717098,98 & 799480,02 \\
\hline Impuestos a la Renta & 145927,21 & 168238,36 & 191372,646 & 215129,685 & 239844,008 \\
\hline Utilidad Neta & 340496,82 & 392556,19 & 446536,17 & 501969,87 & 559636,01 \\
\hline
\end{tabular}

Fuente: Elaboración propia 


\subsubsection{Análisis de escenarios}

El análisis de escenario permite evaluar la situación de riesgo en la toma de decisiones en la inversión. Por ello se evalúa dos escenarios: pesimista y optimista, tablas 55y 56 respectivamente.

a) Escenario pesimista: Comprende el $20 \%$ menos de los visitantes al mes a Healthy Corner (8160 visitas).

Tabla 55

Escenario pesimista - con $20 \%$ menos de clientes al mes

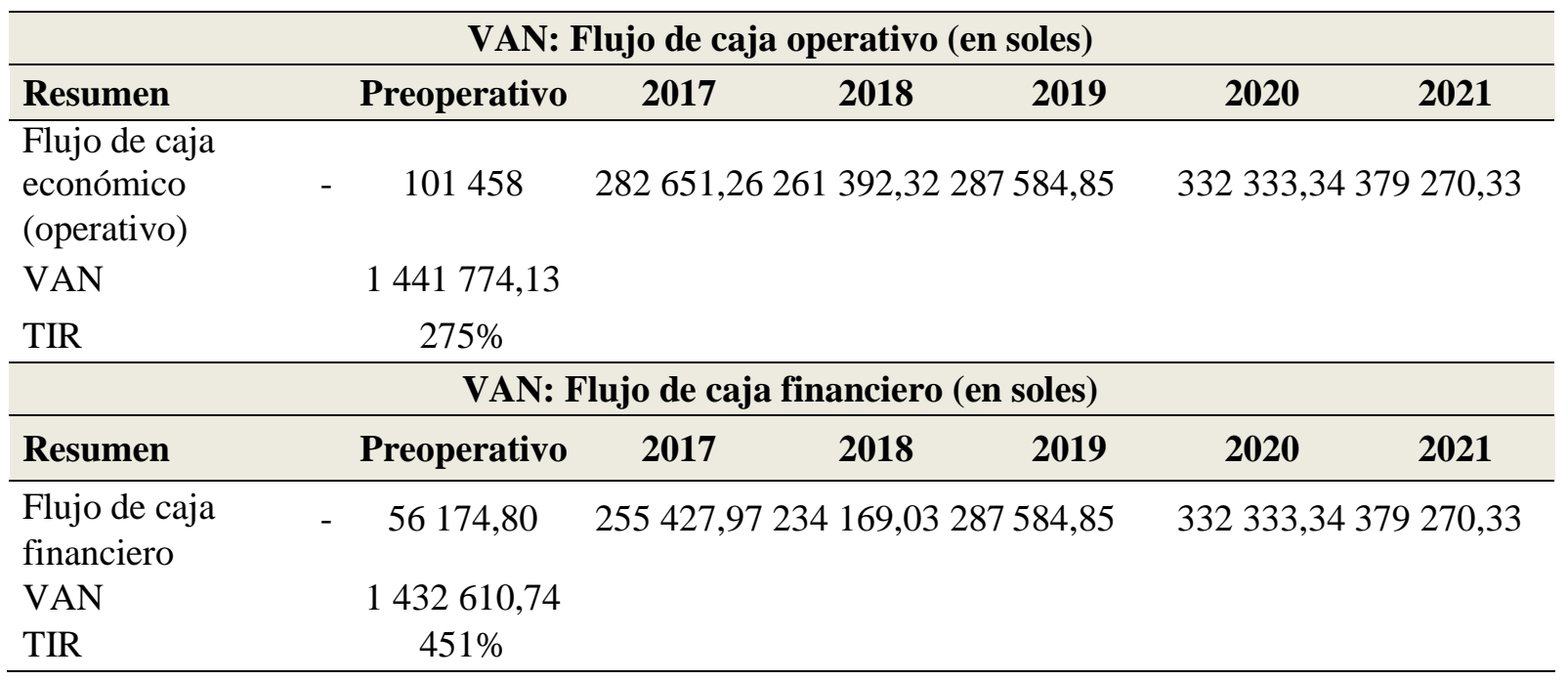


Estado de resultados integrales (en soles)

\begin{tabular}{|c|c|c|c|c|c|}
\hline Conceptos & 2017 & 2018 & 2019 & 2020 & 2021 \\
\hline Ventas & 953736,34 & 1012560,71 & 1075013,24 & 1141317,70 & 1211711,68 \\
\hline Costo de servicio & 44500,84 & 47120,11 & 49900,93 & 52853,27 & 57342,41 \\
\hline Utilidad (pérdida) Bruta & 909235,49 & 965440,59 & 1025112,30 & 188464,43 & 1154369,26 \\
\hline \multicolumn{6}{|l|}{ Gastos de Ventas } \\
\hline Costo de personal & 109788 & 109788 & 109788 & 109788 & 109788 \\
\hline Electricidad & 10677,966 & 10677,966 & 10677,966 & 10677,966 & 10677,966 \\
\hline Agua & 136677,966 & 136677,966 & 136677,966 & 136677,966 & 136677,966 \\
\hline Teléfono, internet & 6874,57 & 6874,57 & 6874,57 & 6874,57 & 6874,57 \\
\hline Alquiles de local & 210874,576 & 210874,576 & 210874,576 & 210874,576 & 210874,576 \\
\hline Útiles de oficina & 1220,338 & 1220,338 & 1220,338 & 1220,338 & 1220,338 \\
\hline Depreciación & 2759,21 & 2759,21 & 2759,21 & 2759,21 & 2759,21 \\
\hline \multicolumn{6}{|l|}{ Gastos Administrativos } \\
\hline Costo personal & 52280 & 52280 & 52280 & 52280 & 52280 \\
\hline Servicio de contabilidad & 2033,89 & 2033,89 & 2033,89 & 2033,89 & 2033,89 \\
\hline Electricidad & 4576,27 & 4576,27 & 4576,27 & 4576,27 & 4576,27 \\
\hline Agua & 58576,27 & 58576,27 & 58576,27 & 58576,27 & 58576,27 \\
\hline Teléfono, internet & 1031.18 & 1031.18 & 1031.18 & 1031.18 & 1031.18 \\
\hline Alquiler de local & 52718,64 & 52718,64 & 52718,64 & 52718,64 & 52718,64 \\
\hline Útiles de oficina & 2847,45 & 2847,45 & 2847,45 & 2847,45 & 2847,45 \\
\hline Depreciación & 1388,61 & 1388,61 & 1388,61 & 1388,61 & 1388,61 \\
\hline $\begin{array}{l}\text { Utilidad (pérdida) } \\
\text { Operativa }\end{array}$ & 261097,63 & 317302,73 & 376974,44 & 440326,57 & 506231,40 \\
\hline Gastos Financieros & 6638,76 & 2524,62 & 0 & 0 & 0 \\
\hline $\begin{array}{l}\text { Utilidad (pérdida) antes } \\
\text { de Impuestos }\end{array}$ & 254 458,86 & 314778,11 & 376974,44 & 440326,57 & 506231,40 \\
\hline Impuestos a la Renta & 76337,66 & 94433,43 & 113092,33 & 132097,97 & 151869,42 \\
\hline Utilidad Neta & 178121,20 & 220344,67 & 263882,11 & 308228,60 & 354361,98 \\
\hline
\end{tabular}

Fuente: Elaboración propia 
b) Escenario optimista: Comprende del número de visitas al mes según la proyección del mercado efectivo (26 198 visitas).

Tabla 56

Escenario optimista, con el mercado efectivo

\begin{tabular}{lcccccc}
\hline \multicolumn{7}{c}{ VAN: Flujo de caja operativo (en soles) } \\
\hline Resumen & Preoperativo & $\mathbf{2 0 1 7}$ & $\mathbf{2 0 1 8}$ & $\mathbf{2 0 1 9}$ & $\mathbf{2 0 2 0}$ & $\mathbf{2 0 2 1}$ \\
\hline $\begin{array}{l}\text { Flujo de caja } \\
\text { económico } \\
\text { (operativo) }\end{array}$ & 101458 & 2293175,05 & 1831699,92 & $1918,520,40$ & 2063861,43 & 2214554,47 \\
VAN & 10220 & & & & & \\
TIR & 353,29 & & & & \\
\hline \multicolumn{7}{c}{ VAN: Flujo de caja financiero (en soles) } \\
\hline Resumen & $2241 \%$ & $\mathbf{2 0 1 8}$ & $\mathbf{2 0 1 9}$ & $\mathbf{2 0 2 0}$ & $\mathbf{2 0 2 1}$ \\
\hline $\begin{array}{l}\text { Flujo de caja } \\
\text { financiero }\end{array}$ & $-56174,80$ & 2293175,05 & 1831699,92 & 1918520,40 & 2063861,43 & 2214554,47 \\
V $\mathbf{\Delta} \mathbf{N}$ & 10220 & & & & & \\
TIR & 353,29 & & & & & \\
\hline
\end{tabular}


Estado de resultados integrales (en soles)

\begin{tabular}{|c|c|c|c|c|c|}
\hline Conceptos & 2017 & 2018 & 2019 & 2020 & 2021 \\
\hline Ventas & 3062007,92 & 3250865,87 & 3451372,16 & 3664245,24 & 3890246,87 \\
\hline Costo de servicio & 138375,70 & 146784,97 & 155712,90 & 165191,48 & 179604,05 \\
\hline Utilidad (pérdida) Bruta & 2923632,21 & 3104080,89 & 3295659,26 & 3499053,76 & 3710643,81 \\
\hline \multicolumn{6}{|l|}{ Gastos de Ventas } \\
\hline Costo de personal & 109788 & 109788 & 109788 & 109788 & 109788 \\
\hline Electricidad & 10677,966 & 10677,966 & 10677,966 & 10677,966 & 10677,966 \\
\hline Agua & 136677,966 & 136677,966 & 136677,966 & 136677,966 & 136677,966 \\
\hline Teléfono, internet & 6874,57 & 6874,57 & 6874,57 & 6874,57 & 6874,57 \\
\hline Alquiles de local & 210874,576 & 210874,576 & 210874,576 & 210874,576 & 210874,576 \\
\hline Útiles de oficina & 1220,338 & 1220,338 & 1220,338 & 1220,338 & 1220,338 \\
\hline Depreciación & 2759,21 & 2759,21 & 2759,21 & 2759,21 & 2759,21 \\
\hline \multicolumn{6}{|l|}{ Gastos Administrativos } \\
\hline Costo personal & 52280 & 52280 & 52280 & 52280 & 52280 \\
\hline Servicio de contabilidad & 2033,89 & 2033,89 & 2033,89 & 2033,89 & 2033,89 \\
\hline Electricidad & 4576,27 & 4576,27 & 4576,27 & 4576,27 & 4576,27 \\
\hline Agua & 58576,27 & 58576,27 & 58576,27 & 58576,27 & 58576,27 \\
\hline Teléfono, internet & 1031.18 & 1031.18 & 1031.18 & 1031.18 & 1031.18 \\
\hline Alquiler de local & 52718,64 & 52718,64 & 52718,64 & 52718,64 & 52718,64 \\
\hline Útiles de oficina & 2847,45 & 2847,45 & 2847,45 & 2847,45 & 2847,45 \\
\hline Depreciación & 1388,61 & 1388,61 & 1388,61 & 1388,61 & 1388,61 \\
\hline $\begin{array}{l}\text { Utilidad (pérdida) } \\
\text { Operativa }\end{array}$ & 2275494,35 & 2455943,03 & 2647521,40 & 2850915,89 & 3062505,95 \\
\hline Gastos Financieros & 6638,76 & 2524,62 & 0 & 0 & 0 \\
\hline $\begin{array}{l}\text { Utilidad (pérdida) antes } \\
\text { de Impuestos }\end{array}$ & 2268855,59 & 2453418,41 & 2647521,40 & 2850915,89 & 3062505,95 \\
\hline Impuestos a la Renta & 680656,67 & 736025,52 & 794256,42 & 855274,76 & 918751,78 \\
\hline Utilidad Neta & 1588198,93 & 1717392,89 & 1853264,98 & 1995641,12 & 2143754,17 \\
\hline
\end{tabular}

Fuente: Elaboración propia 


\section{CAPÍTULO X: MODELO DE NEGOCIOS CANVAS}

\subsection{Definición del modelo de negocio CANVAS}

El modelo de negocio CANVAS, es la herramienta que va a ayudar a simplificar los pasos para generar un modelo de negocio rentable, sustentando la propuesta de valor para los clientes de Healthy Corner.

\subsection{Componentes del modelo de negocio CANVAS}

\subsubsection{Segmentos de clientes}

Hombres y mujeres entre los 21 a 59 años del NSE B y C de Lima Moderna. Por otro lado, se enfoca para personas que tengan la necesidad de alimentación saludable.

\subsubsection{Propuesta de valor}

Ofrece un servicio de calidad, preparaciones a base de productos orgánicos, productos para veganos y libres de azúcar, personalización de productos y personal calificado.

\subsubsection{Canales}

El punto de venta es directo, en el único local que se atiende en Centro Comercial Jockey Plaza.

\subsubsection{Relaciones con el cliente}

La relación con el cliente es atención en el local y atención take out (para llevar)

\subsubsection{Fuentes de ingresos}

La estructura de ingresos, principalmente se debe a la venta de los productos del fast food saludable. 


\subsubsection{Recursos clave}

El principal recurso es el talento humano, que tiene vocación de servicio y filosofía de vida saludable, adicional a equipos de última tecnología, paquetes de asesoría nutricional gratuitos e información a través de las redes sociales.

\subsubsection{Actividades clave}

Las actividades claves serán la atención a los clientes por ello es importante tener un personal capacitado, carta elaborada por el o la chef y la o el nutricionista y nutricionista experta en control de calidad.

\subsubsection{Socios clave}

Los principales aliados que Healthy Corner tiene es el proveedor del local alquilado que es Jockey Plaza, todos los proveedores de insumos perecibles y no perecibles, Inkafarma y Banco Continental.

\subsubsection{Estructura de costos}

Remuneración del personal, gastos administrativos, alquiler de local, publicidad y marketing. 
2. Paquete de asesoría nutricional gratuito

3. Información a través de las redes sociales

4. Talento humano con vocación de servicio y filosofía de vida saludable

ESTRUCTURA DE COSTOS

1. Remuneración del personal

2. Gastos administrativos

3. Alquiler de local

4. Publicidad y marketing

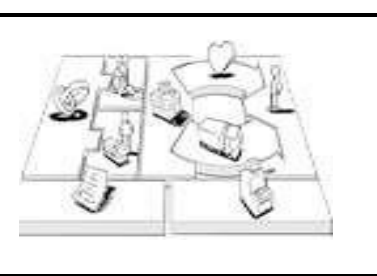

INGRESOS

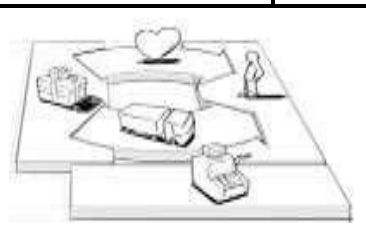

Servicio de comida rápida saludable

Gráfico 5: Modelo de negocio CANVAS.

Elaboración propia 


\section{CONCLUSIONES}

- Healthy Corner muestra viabilidad financiera, teniendo en cuenta que la inversión preoperativa es de 157632,80 soles, donde los 56 174,80 soles será financiado en 24 cuotas de 2814 soles mensuales.

El plan de negocios a nivel económico: el VAN es positivo, por lo que el proyecto sería viable si se invierte sólo con recursos propios, además el TIR (492\%) es mayor que el $\operatorname{COK}(22,51 \%)$ lo que generaría rentabilidad.

El plan de negocio a nivel financiero: el VAN es positivo incluso mayor al VAN económico, lo que significa que conviene financiar el proyecto con recursos de terceros.

- Según los resultados de la Encuesta el 100\% de los encuestados visitaban un fast food dos veces al mes como mínimo a pesar de que lo definen como "no saludable".

- Del 100\% de los encuestados; el 42,7\% acuden a un fast food por falta de tiempo y consideran el concepto de fast food saludable como una alternativa interesante; el $30,6 \%$ acudiría 2 a 3 veces a la semana y el 40,7\% acudiría una vez a la semana; prefiriendo acudir en el horario del almuerzo y pagar 20 soles por ración personal.

- La intención de compra del concepto fast food saludable es de 95,6\% de los Encuestados donde el $63.7 \%$ probablemente compraría nuestros productos, y el $31.9 \%$ definitivamente lo compraría. 


\section{RECOMENDACIONES}

- El $100 \%$ de los encuestados recomiendan implementar el servicio delivery e implementar un local / restaurante para disfrutar de un ambiente más tranquilo y acogedor. Por otro lado, recomiendan renovar los platos de la carta con alimentos novedosos y en tendencia.

- Es importante analizar la oportunidad de negocio para la expansión a otros distritos de Lima y posteriormente a provincias del Perú, manteniendo la innovación para que "Healthy Corner" sea sostenible.

- Es recomendable implementar un plan de contingencia asignando un presupuesto adecuado, que será un aporte a la seguridad del negocio. 
ANEXO 1: VALOR NUTRICIONAL DE PRODUCTOS FAST FOOD

\begin{tabular}{|c|c|c|}
\hline \multicolumn{3}{|c|}{ Raciones típicas de fast food y su valor calórico } \\
\hline Raciones & $\begin{array}{c}\text { Energía } \\
\text { (kcal) }\end{array}$ & $\begin{array}{c}\text { Grasas } \\
\text { (g) }\end{array}$ \\
\hline Porción de pizza (180 g) & 352 & 22,7 \\
\hline Hamburguesa doble con queso (190 g) & 480 & 26,6 \\
\hline Alitas de pollo fritas $(125 \mathrm{~g})$ & 280 & 11,4 \\
\hline Croquetas (150 g) & 183 & 11 \\
\hline Bocadillo (120 g) de Frankfurt (90 g) & 520 & 18,8 \\
\hline Papas fritas medianas (115 g) & 353 & 17,5 \\
\hline Pastel de manzana (115 g) & 320 & 14 \\
\hline Tarina de helado mediano (115 g) & 235 & 11,6 \\
\hline Refresco mediano (350 ml) & 145 & 0 \\
\hline Zumo de fruta $(225 \mathrm{ml})$ & 101 & 0 \\
\hline Bolsita de kétchup (15 g) & 15 & 0 \\
\hline Bolsita de mayonesa (12 g) & 86 & 9,5 \\
\hline Pasta, salsa de tomate y carne picada (50 g) & 331 & 7,1 \\
\hline
\end{tabular}

Fuente: Adaptado de Molíni (2007). Repercusiones de la comida rápida en la sociedad. 
ANEXO 2: LEY DE ALIMENTACIÓN SALUDABLE ( N $\left.^{\circ} 30021\right)$

GPeruanc

Viernea 17 de mayo de 2013

EORMAS LEGALES

494937

R.A. N* 117. Aprueban Manual de Operaciones del - Programa de Defensa Municipal de Victimas y Accidentes de Tránsito"

495000

RR. N's. 3512 y 3523-2013-MML/GTU-SRT.- Autorizan implementación de paraderos de transporte regular en los distritos de San Juan de Lurigancho y Santiago de Surco Res. N* 3530-2013-MML/GTU-SRT.- Autorizan implementación de paraderos de transporte regular en las cuadras 26 y 27 de la Av. Arenales, antes del cruce con la Av. Javier Prado

495002

\section{7\%}

Ordenanza $\mathrm{N}^{*}$ 216-2010-MDA.-Establecencompensación de deudas tributarias por concepto de arbitrios municipales contra los créditos jaborales devengados y créditos de dietas devengadas de la Municipalidad 495004 Ordenanza $N^{\circ}$ 265-2013-MDA- Incorporan articulos a la Ordenanza $N^{*}$ 253-2012-MDA, que aprueba el Reglamento de Aplicación de Sanciones y Cuadro de Infracciones y Sanciones (RASCIS) de la Municipalidad 495005

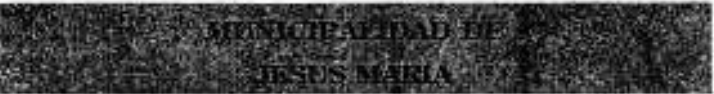

Acuerdo N* 020-2013-MDJM.- Autorizan viaje de Alcalde a Portugal y España, en comisión de servicios

495006

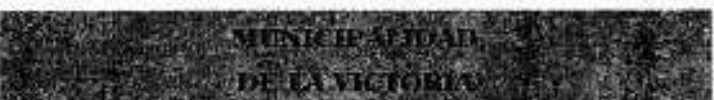

Ordenanza $\mathrm{N}^{\circ}$ 166-2013/MLV.- Aprueban celebración de Matrimonio Civil Comunitario en el distrito 495006

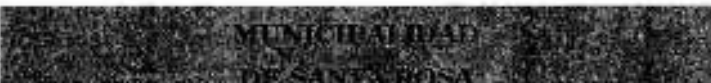

Ordenanza N* 369-2013-MDSR.- Aprueban Reglamento de Altas Bajas y Enajenaciones de los Bienes Muebles e Inmuebles de la Municialidad Distrital de Santa Rosa e Inmuebles de la Municialidad Distrital de Santa Rosa
495007

\section{PODER LEGISLATIVO}

\section{CONGRESO DE IA REPUBUCA}

\section{LEY N² 30021}

EL PRESIDENTE DE LA REPÚBLICA

POR CUANTO:

El Congreso de la República

Ha dado la Ley siguiente:

EL CONGRESO DE LA REPÚBLICA;

Ha dado la Ley siguiente:

\section{LEY DE PROMOCIÓN DE LA ALIMENTACIÓN SALUDABLE PARA NIÑOS, NIÑAS Y ADOLESCENTES}

Articulo 1. Objeto de la Ley

La presente Ley tiene por objeto la promoción y protección efectiva del derecho a la salud pública, al crecimiento y desarrollo adecuado de las personas, a través de las acciones de educación, el fortalecimiento y fomento de kioscos y comedores saludables en las instituciones de educación basica regular y la supervisión de la
D.A. N* 002-2013-MDSR.- Aprueban Normas Complementarias para la Venta de Bienes Inmuebles

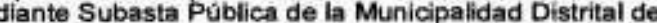
Santa Rosa 495007

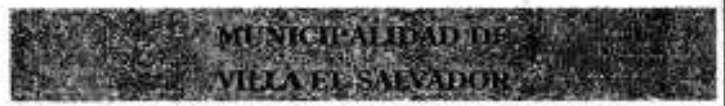

D.A. N* 011-2013-ALC/MVES.- Aprueban tabla de puntuación para la calificación de los proyectos que se presenten en el Marco del Presupuesto Participativo 2014. Basado en Resultados de la Municipalidad

495008

PROVINCLAS

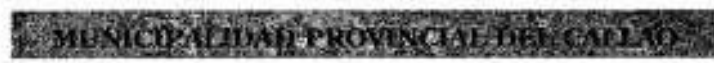

D.A. N* 07-2013-MPC-AL.- Aprueban Reglamento de Convenio de Acogimiento al Régimen de Fraccionamiento de Deudas Tributarias y Multas Administrativas 495008

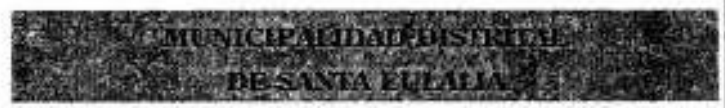

Ordenanza N* 022-2012-MDSE,- Aprueban beneficios tributarios excepcionales sobre predios ubicados en zona del distrito 495009

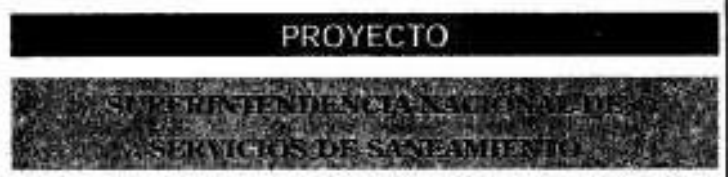

Res. $N^{\circ}$ 012-2013-SUNASS-CD. Disponen publicar proyecto de resolución que aprueba Formula Tarifaria, Estructura Tarifaria y Metas de Gestión aplicables a SEDACUSCO S.A en el quinquenio 2013-2018 y costos máximos de unidades de medida de actividades requeridas para establecer precios de servicios colaterales 495010

publicidad la información y otras prácticas relacionadas con los alimentos y bebidas no alcoholicas dirigidas a los nifíos, niffas y adolescentes para reducir y éliminar las enfermedades vinculadas con el sobrepeso, la obesidad y las enfermedades crónicas conocidas como no transmisibles.

Articulo 2. Ámbito de aplicación

Las disposiciones contenidas en la presente Ley son de aplicación a todas las personas naturales y jurfdicas que comercialicen, importen, suministren y fabriquen alimentos procesados, asi como al anunciante de dichos productos.

Están excluidos de lo sehlalado en el párrafo anterior los alimentos y las bebidas no alcohólicas en estado natural, no sometidas a proceso de industrialización.

Articulo 3. Glosario por:

Para la aplicación de la presente Ley, se entiende

Alimentación saludable. Es una alimentación variada, preferentemente en estado natural o con procesamiento minimo, que aporta energía y todos los nutrientes esenciales que cada persona necesita para mantenerse sana, permitiéndole tener una mejor calidad de vida en todas las edades.

Bonificación, regalo o premio. Todo bien, producto, servicio o beneficio ofrecido de forma gratuita $u$ onerosa por adquirir el a limento o la bebida no alcohólica.

Promoción de ventas. Toda aquella acción destinada - incentivar la transacción de bienes o servicios en condiciones de oferta excepcionales y temporales, que aparecen como más ventajosas respecto de las 
condiciones de la oferta ordinaria o estándar. Puede consistir en la reducción de precios, incremento de cantidad, concursos, sorteos, canjes u otros similares.

Publicidad. Toda forma de comunicación difundida a través de cualquier medio o soporte, y objetivamente apta o dirigida a promover, directa o indirectamente, la imagen, marcas, productos o servicios de una persona, empresa - entidad en el ejercicio de su actividad comercial industrial o profesional, en el marco de una actividad de concurrencia, promoviendo la contratación o la realización de transacciones para satisfacer sus intereses empresariales.

Publicidad dirigida a niños, niñas y adolescentes. Es aquella que, por su contenido, argumentos, gráficos, música, personajes, simbolos y tipo de programa en el que se difunde, es atractiva y está dirigida preferentemente a menores de 16 aȟos.

Anunciante. Persona, natural ojuridica, que desarrolla actos cuyo efecto o finalidad directa 0 indirecta sea concurrir en el mercado y que, por medio de la difusión de publicidad, se propone: i) ilustrar al público, entre otros, acerca de la naturaleza, las caracteristicas, propiedades - los atributos de los bienes o servicios cuya producción, intermediación o prestación constituye el objeto de su actividad; o ii) motivar transacciones para satisfacer sus intereses empresariales.

Publicidad testimonial. Toda publicidad que puede ser percibida por el consumidor como una manifestación de las opiniones, las creencias, los descubrimientos o las experiencias de un testigo, a causa de que se identifique el nombre de la persona que realiza el testimonial o esta sea identificable por su fama o notoriedad pública

Publicidad en producto. Toda publicidad fijada en el empaque, en el envase o en el cuerpo del producto.

Articulo 4. Promoción de la educación nutricional

4.1 El Ministerio de Educación promueve la enseñanza de la alimentación saludable, incorpora en el diseño curricular nacional de la educación básica regular y de la educación no escolarizada, programas de promoción de hábitos alimentarios que contribuyan a mejorar los niveles de nutrición.

4.2 El Ministerio de Salud, en coordinación con el Ministerio de Educación, realiza campañas y charlas informativas para promover la alimentación saludable y mejorar los habitos alimentarios de la población, dirigidas especialmente a los alumnos y padres de familia.

4.3 El Ministerio de Educación y el Ministerio de Salud difunden y promocionan a nivel nacional, en los medios de comunicación masiva, las ventajas de la alimentación saludable y el
consumo de alimentos naturales con alto contenido nutricional.

Articulo 5. Observatorio de Nutrición y de Estudio del Sobrepeso y de Obesidad

5,1 Declárase de interés la creación del Observatorio de Nutrición y de Estudio del Sobrepeso y Obesidad, a cargo del Ministerio de Salud, como herramienta de monitoreo que permita suministrar información y hacer el análisis períódico de la situación nutricional de la población infantil y de la evolución de la tasa de sobrepeso y obesidad en nifios, nif̌as y adolescentes y cuantificar sus efectos.

5.2 El Observatorio de Nutrición y de Estudio del Sobrepeso y Obesidad, tiene las siguientes funciones:

a) Recaba información sobre el ambiente obesogénico, los hábitos alimentarics y la actividad fisica, considerando el género y los diversos grupos socioecononómicos a nivel nacional.

b) Suministra información a todas las entidades que lo soliciten de la incidencia y prevalencia del sobrepeso y obesidad y de sus factores determinantes.

c) Realiza el seguimiento y la evaluación de la efectividad e impacto en la salud pública de las medidas adoptadas e implementadas en las políticas públicas para mejorar los niveles de nutrición y promover la actividad fisica.

d) Elabora un informe anual sobre el seguimiento y la evaluación de las estrategias adoptadas como politicas públicas y lo remite, en el primer trimestre del año siguiente, a la Comisión de Salud y Población y a la Comisión de Defensa del y Poblacion y a la Comisión de Defensa de los Servicios Publicos del Congreso de la República.

e) Difunde un resumen del informe anual a través de los medios de comunicación masiva a nivel nacional.

Articulo 6. Los ambientes y la promoción de una alimentación saludable

6.1 Las instituciones de educación básica regular pública y privada en todos sus niveles y en todo el territorio nacional, promueven los "kioscos y comedores escolares saludables", conforme a las normas que, para este efecto, dicta el Ministerio de Educación, en coordinación con el Ministerio de Salud, el Ministerio de Agricultura, los gobiernos locales y los gobiernos regionales.

6.2 Los kioscos y los comedores escolares brindan exclusivamente alimentos y bebidas saludables conforme a los estándares que establece Ministerio de Salud, a través de un listado de alimentos adecuados para cada edad, basado en el reglamento.

6.3 Los establecimientos de salud públicos y privados promueven kioscos y comedores saludables",

Articule 7. La promoción del deporte y de la actividad fisica

7.1 Las instituciones de educación básiça regular, en todos sus niveles, promueven la práctica de la actividad física de los alumnos en la cantidad minima diaria establecida para cada edad.

7.2 Los gobiemos locales, en el marco de sus competencias, fomentan la implementación de juegos infantiles en parques $\mathbf{y}$ espacios públicos.

Articule 8. Publicidad de alimentos y bebidas no alcohblicas

La publicidad que esté dingida a niños, niñas y adolescentes menores de 16 años y que se difunda por cualquier soporte o medio de comunicación social debe estar acorde a las politicas de promoción de la salud, no debiendo:

a) Incentivar el consumo inmoderado de alimentos y bebidas no alcoholicas, con grasas trans, alto contenido de azúcar, sodio y grasas saturadas, conforme a lo establecido en la presente Ley.

b) Mostrar porciones no apropiadas a la situación presentada ni a la edad del público al cual está dingida.

c) Usar argumentos o técnicas que exploten la ingenuidad de los niños, niñas y adolescentes, de manera tal que puedan confundirlos o inducirlos a error respecto de los beneficios nutricionales del producto anunciado.

d) Generar expectativas referidas a que su ingesta proporcione sensación de superioridad o que su falta de ingesta se perciba como una situación de inferioridad.

e) Indicar. como beneficios de su ingesta la obtención de fuerza, ganancia o pérdida de peso, adquisición de estatus o popularidad.

f) Representarestereotipos sociales o que originen prejuicios o cualquier tipo de discriminación, vinculados con su ingesta.

g) Crear una sensación de urgencia o dependencia por adquirir el alimento o la bebida no alcohólica, nl generar un sentimiento de inmediatez 0 exclusividad. 
ËPercians

Viernes 17 de mayo do 2013

\$ NORMAS LEGALES

494939

h) Sugerir que un padre o un adulto es más inteligente o más generoso por adquirir el alimento o bebida que el que no lo hace: tampoco hacer referencia a los sentimientos de afecto de los padres hacia sus hijos por la adquisición o no del producto.

i) Promover la entrega de regalo, premio o cualquier otro beneficio destinado a fomentar la adquisición 0 el consumo de alimentos bebidas no alcohólicas.

j) Utilizar testimonios de personajes reales o ficticios conocidos o admirados por los niños y adolescentes para inducir a su consumo.

k) Establecer sugerencias referidas a que se puede sustituir el régimen de alimentación o nutrición diaria de comidas principales, como el desayuno, el almuerzo o la cena.

I) Alentar ni justificar el comer o beber de forma inmoderada, excesiva o compulsiva.

m) Mostrar imágenes de productos naturales si estos no lo son.

Las afimaciones y terminologia referidas a la salud o a la nutrición deben estar sustentadas en evidencia cientifica y pueden ser requeridas en cualquier momento por la autoridad, de oficio o a pedido de cualquier ciudadano.

Articulo 9. Principio de veracidad publicitaria

Los mensajes publicitarios deben ser claros, objetivos y pertinentes, teniendo en cuenta que el público infantil y adolescente no tiene la capacidad ni la experiencia suficiente para valorar 0 interpretar debidamente la naturaleza de dichos mensajes.

Las imágenes, dílogos y sonidos que se utilicen en la publicidad de los alimentos y bebidas deben ser precisos en cuanto a las caracteristicas del producto y a cualquier atributo que se pretenda destacar, asi como su sabor, color, taman̂o, contenido, peso, sus propiedades nutricionales, de salud u otros.

Articulo 10. Advertencias publicitarias

En la publicidad, incluida la que se consigna en el producto, de los alimentos y bebidas no alcohólicas con grasas trans y alto contenido de azúcar, sodio y grasas saturadas, se debe consignar en forma clara, legible. destacada y comprensible las siguientes frases, según el caso:

"Alto en (Sodio-azúcar-grasas saturadas): Evitar su consumo excesivo"

"Contiene grasas trans: Evitar su consumo"

Dicha advertencia publicitaria será aplicable a los alimentos y las bebidas no alcohólicas que superen los parametros técnicos establecidos en el reglamento.

Articulo 11. Fiscalización y sanción

La autoridad encargada del cumplimiento de lo establecido en los artículos 8 y 10 de la presente Ley, en cuanto a publicidad es la Comisión de Fiscalización de la Competencla Desteal del instituto Nacional de Defensa de la Competencia y de la Protección de la Propiedad Intelectual (Indecopi) y las respectivas comisiones de las oficinas regionales, en las que se hubieran desconcentrado sus funciones, aplicando para el efecto lo establecido en el Decreto Legislativo 1044, Ley de Represión de la Competencia Desleal.

La autoridad encargáda de fiscalizar el cumplimiento de las normas de promoción de la educación en alimentación saludable, ambientes escolares libres de alimentos no saludables y la promoción del deporte y de ia actividad fisica en los centros educativos en el pais es el Ministerio de Educación los gobiernos regionales y las Unidades de Gestión Educativa Local (UGEL) en
sus respectivas jurisdicciones. El Ministerio de Educación emite las nomas especificas para el cumplimiento de la fiscalización a cargo de los órganos regionalizados, con la participación de los gobiernos locales.

\section{DISPOSICIONES COMPLEMENTARIAS TRANSITORIAS}

PRIMERA. Reglamentación de los parámetros técnicos

Los parámetros técnicos sobre los alimentos y las bebidas no alcohólicas referentes al alto contenido de

azúcar, sodio y grasas saturadas son elaborados por el Ministerio de Salud via reglamento en un plazo no mayor de sesenta $(60)$ dias calendario, contado a partir de la vigencia de la presente Ley y estarán basados en el conjunto de recomendaciones emitidas por el organismo intergubernamental en salud: Organización Mundial de la Salud-Organización Panamericana de la Salud OMSOPS.

En cuanto a los alimentos con contenido de grasas trans, el reglamento establecerá un proceso gradual de reducción hasta su eliminación, conforme a los parametros técricos y plazos que establezca.

SEGUNDA. Plazo de implementación

Los proveedores, propietarios o administradores de kioscos y comedores escolares, asi como las empresas de alimentos se adecúan a lo dispuesto en la presente Ley en un plazo no mayor de sesenta (60) dias calendario. contado a partir del dia siguiente de la entrada en vigencia del reglamento, con excepción de los articulos 8 , inciso a), y 10, que entran en vigencia a los ciento veinte (120) dias calendario, contados a partir de la vigencia del reglamento.

Comuniquese al señor Presidente Constitucional de la República para su promulgación. rece.

En Lima, a los diez días del mes de mayo de dos mil

VICTOR ISLA ROJAS

Presidente del Congreso de la República

MARCO TULIO FALCONI PICARDO

Primer Vicepresidente del

Congreso de la República

\section{AL SENNOR PRESIDENTE CONSTITUCIONAL DE LAREPUBBLICA}

POR TANTO:

Mando se publique y cumpla.

Dado en la Casa de Gobierno, en Lima, a los dieciséis dias del mes de mayo del afio dos mil trece.

OLLANTA HUMALA TASSO

Presidente Constitucional de la República

JUAN F. JIMÉNEZ MAYOR

Presidente del Consejo de Ministros

938532-1

PODER EJECUTIVO

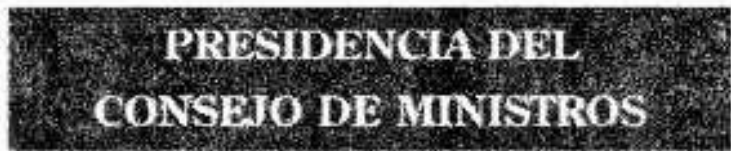

Autorizan viaje del Ministro de Defensa a Colombia y encargan su despacho al Ministro de Agricultura

\section{RESOLUCIÓN SUPREMA \\ $N^{*}$ 158-2013-PCM}

Lima, 16 de mayo de 2013

\section{CONSIDERANDO:}

Que, en el Acta de la XV Reunión de Comandos Nayales Fronterizos Perú-Colombia, se acordó desarrollar un programa de actividades operacionales conjuntas, entre las cuales se consideró una Acción Cívica Binacional PerúColombia y Control Fluvial Binacional en los rios Putumayo y Amazonas, curya inauguración se realizará el dia 18 de mayo de 2013 en Puerto Leguizamo, República de Colombia. cúdad ubicada en la frontera con la República del Perú: 


\section{ANEXO 3: TRANSCRIPCIÓN DE FOCUS GROUP Nº1}

\section{GUÍA DE INDAGACIÓN \\ FOCUS GROUP N$^{\circ} 01$ "Personas del NSE B"}

\section{a. Introducción:}

Buenos días, mi nombre es Gianina Cabrera y mi compañera Ivanna Pisfil. La finalidad de esta reunión es para tratar algunos temas de interés en la cual cada uno puede expresar libremente sus opiniones. Les informo que serán grabados sólo para la facilidad del recojo de información, y recuerden que ninguna de sus respuestas estará equivocada sino al contrario todas sus opiniones serán válidas y de gran ayuda para el propósito de la investigación. A continuación, me gustaría que se presente, brindando su nombre y ocupación.

P1: Mi nombre es Percy y soy administrador

P2: Mi nombre es Deanira y soy estudiante de contabilidad

P3: Mi nombre es Joanie y soy contadora

P4: Mi nombre es Joe y soy ingeniero civil

P5: Mi nombre es Violeta y soy Psicóloga

P6: Mi nombre es Jenny y soy licenciada en enfermería

P7: Mi nombre es Mariella y soy empresaria

P8: Mi nombre es Rosario y soy administradora

\section{b. Calentamiento:}

Empecemos hablando de las tres comidas diarias, desayuno, almuerzo y cena:

1. ¿Suele consumir las tres comidas?
P1: Si
P2: Si
P3: Si
P4: Si

P5: Si

P6: No

P7: No, dos

P8: No, dos 
2. ¿En dónde suele consumir sus comidas, en casa o fuera de casa?

P1: En casa P2: En casa $\quad$ P3: Fuera de casa P4: Fuera de casa

P5: Fuera de casa y a veces en casa P6: En casa y a veces fuera de casa

P7: Mayormente fuera de casa $\quad$ P8: En casa

3. Si es en casa ¿Qué suele consumir?

P1: Comida de casa, comida criolla P2: Si comida de casa, comida criolla

P3: Comida casera P4: Comida criolla

P5: Comida casera P6: Comida casera, vegetariana

P7: Comida de casa $\quad$ P8: Comida de casa

4. Si es fuera de casa ¿A qué sitios suele acudir? ¿Qué ordena? ¿Con qué frecuencia?

P1: Suelo acudir a Burger King y pido un combo, cada 15 días o una vez al mes

P2: Burger King o a Popeyes una vez al mes

P3: Pollerías o restaurantes, pido comida criolla si no hay pollo, dos veces a la semana

P4: Otto Grill y comida criolla y una vez a la semana un fin de semana

P5: Pollería o KFC y dos veces a la semana

P6: KFC y siempre pido pollo con mi ensalada al mes

P7: Pollo a la brasa, KFC y a veces dos veces al mes

P8: Pollería y pizza dos veces al mes

5. ¿Ha acudido a algún fast food en los últimos 30 días?

$\begin{array}{llll}\mathrm{P} 1: \mathrm{Si} & \mathrm{P} 2: \mathrm{Si} & \mathrm{P} \text { : } \mathrm{Si} & \mathrm{P} 4: \mathrm{Si}\end{array}$

$\begin{array}{llll}\text { P5: } \mathrm{Si} & \text { P6: } \mathrm{Si} & \text { P7: } \mathrm{Si} & \text { P8: } \mathrm{Si}\end{array}$

c. Preguntas de profundidad:

1. ¿Qué entiende por fast food o comida rápida?

P1: Es un exprés de comida que no es saludable en un $100 \%$ pero agradable

P2: Lugar donde ganas tiempo para alimentarse y no es saludable 
P3: Lugar donde venden comida procesada

P4: Lugar donde hay atención rápida

P5: Lugar donde obtienes la comida de forma inmediata

P6: Lugar donde la atención es rápida

P7: Lugar donde se acude por ganar tiempo

P8: Lugar donde venden frituras y se puede llevar comida para casa

2. ¿Cuál es su opinión con respecto a la comida rápida o fast food?

$\mathrm{P} 1$ : Es rica pero poco saludable $\quad \mathrm{P} 2$ : Es rica

P3: Es poco saludable $\quad$ P4: Es poco saludable

P5: No nutritiva y llena P6: Contiene grasa saturada

P7: Es rica y no saludable $\quad$ P8: Rica y no saludable

3. ¿Qué fast food conoce?

P1: Burger King, KFC P2: KFC, Burger King, Bembos, Popeye’s

P3: KFC, Pizza Hut P4: KFC, Burger King, Otto Grill, Pizza Hut

P5: KFC, Burger King, Bembos P6: KFC, Bembos, Pizza Hut

P7: Bembos, pollería, Pizza P8: Pizza Hut, Popeye’s

4. ¿Cuál es su preferido o a cuál acude la mayoría de las veces? ¿Por qué? ¿Influye el precio?

P1: Burger King, por la variedad de productos de venta y precio si influye

P2: Burger king, porque conozco la marca, a veces Popeyes y el precio influye

P3: Pollería, por la atención rápida y el precio influye

P4: KFC, porque es rico y tiene precios económicos

P5: KFC, influye el precio

P6: KFC, porque tiene ensalada y si influye el precio

P7: Bembos, si influye el precio 
P8: Pizza Hut, porque tiene menos condimentos y el precio es económico

5. ¿En qué momento del día acude a un fast food?
P1: Cena
P2: Almuerzo y cena
P3: Almuerzo
P4: Almuerzo
P5: Cena
P6: Almuerzo
P7: Cena
P8: Cena

6. ¿Con quiénes suele acudir a estos centros de comida rápida, solos, con la familia, con los amigos?
P1: Los tres grupos
P2: Amigos
P3: Solo y amigos
P4: Familia y amigos
P5: Amigos
P6: Familia
P7: Familia y amigos
P8: Familia y amigos

7. ¿Entre comer en casa e ir a un fast food, cuál prefiere? ¿Qué diferencias encuentra? ¿Cree que la comida rápida puede afectar su salud? ¿Por qué?

P1: Prefiere comida de casa es más saludable y el fast food afecta a la salud

P2: Prefiere comida de casa es más rica y saludable y el fast food afecta a la salud

P3: Prefiere comida de casa es casera, al gusto y el fast food afecta a la salud

P4: Prefiere comida de casa, el fast food no sabes cómo lo preparan

P5: Prefiere comida de casa es rica y saludable y el fast food genera enfermedades

P6: Prefiere comida de casa, el fast food afecta a la salud

P7: Prefiere comida de casa es saludable y lo preparas a tu gusto, el fast food hace daño a la salud y genera sobrepeso

P8: Prefiere comida de casa el aderezo es natural y el fast food contiene preservantes

\section{8. ¿Qué entiende usted por "comida saludable"?}

P1: Comida sin colesterol, que es buena y no cause un mal

P2: Comida con poca grasa y condimentos

P3: Que tenga los nutrientes necesarios como proteínas

P4: Comida balanceada con poca grasa 
P5: Alimentación balanceada y en raciones justas

P6: Lo más natural, fresco y no afecta a la salud

P7: Que no tenga mucho aderezo, frituras, y que tenga verduras y carnes magras

P8: Lo más natural posible, que no tenga muchos preservantes

\section{d. Prueba de concepto:}

A continuación, les explicaré un concepto para que me den su opinión.

La propuesta de fast food saludable, ofrece al consumidor en Lima Moderna una alternativa de tener rápido acceso a consumir bebidas y platos agradables teniendo conocimiento del valor calórico y nutricional que estos aportan y a un precio acorde al mercado, favoreciendo la salud y necesidades del consumidor.

El único local estará estratégicamente ubicado en el patio de comidas del Centro Comercial Jockey Plaza en el distrito de Santiago de Surco. El horario de atención al público será de lunes a domingo desde las 10:00 horas hasta las 23:00 horas.

Se ofrecerá una carta elaborada por la o el nutricionista y la o el chef, la cual tiene una variedad y nuevas opciones de bebidas y platos agradables, atractivos y sobre todo saludables, ya que son productos a base de alimentos $100 \%$ naturales, orgánicos y productos elaborados libres de gluten y/o azúcares refinados como las verduras, hortalizas, frutas frescas, zumos, alimentos de origen animal y/o vegetal, entre otros. Adicional a la carta, se ofrecerá postres veganos, integrales y orgánicos, de Vegánimo, empresa socia y comprometida con la salud y el medio ambiente.

\section{1. ¿Qué opina/piensa de este concepto que les acabo de describir?}
P1: Muy bueno
P2: Interesante
P3: Muy bueno
P4: Buena idea
P5: Buena opción
P6: Interesante y hace falta
P7: Interesante
P8: Interesante y al alcance 
2. ¿Es bueno, malo?
P1: Bueno
P2: Bueno
P3: Bueno
P4: Bueno
P5: Muy bueno
P6: Buenísimo
P7: Bueno
P8: Bueno

3. ¿Qué le gusta, qué no le gusta? ¿Por qué?

P1: Me gusta el concepto, la carta es elaborada por chef y nutricionista y han pensado en preparaciones para personas con enfermedades.

P2: Me parece muy bueno, la carta está elaborada por profesionales

P3: Bueno, la carta presenta platos saludables elaborados por nutricionista y chef

P4: Bueno, la carta es de comida saludable y está elaborada por chef y nutricionista

P5: Buena opción

P6: Muy bueno, los profesionales van a elaborar una carta con su aporte nutricional P7: Muy buena opción, la carta de comida saludable es natural y buena para la salud P8: Muy buena opción, encuentras comida saludable y al paso

\section{4. ¿Ha escuchado algún concepto como éste?}

P1: Parecido

P2: Parecido

P3: He escuchado de alguno, en el cual hay pura verdura

P4: He escuchado

P5: Sé que hay, pero no como fast food

P6: He escuchado, pero no hay variedad de estas tiendas

P7: Si he escuchado pero la opción que presentas es muy buena

P8: Si he escuchado este concepto, pero no como stand alone

5. ¿Usted asistiría a un sitio como éste? ¿Por qué?

P1: Si, porque es opción distinta

$\mathrm{P} 2$ : Si, porque quiero algo distinto 
P3: Si, es una opción más saludable

P4: Si, por la comida que es saludable

P5: Si, porque es saludable

P6: Si, porque es natural, saludable para uno

P7: Si, porque es comida rica, nutritiva y está al alcance

P8: Si, porque es natural

6. ¿Con quiénes asistiría?

P1: Familia y amigos

P4: Amigos

P7: Familia o sola
P2: Familia y amigos

P5: Familia
P3: Sola o con amigos

P6: Familia, amigos o sola

7. ¿En qué horario asistiría, desayuno, almuerzo o cena?
P1: Almuerzo
P2: Almuerzo
P3: Desayuno y almuerzo
P4: Almuerzo
P5: Almuerzo cena
P6: Desayuno y almuerzo
P7: Almuerzo
P8: Desayuno y cena

8. ¿Le gustaría que en este servicio que les acabo de describir, hubiese servicio de delivery?
$\mathrm{P} 1: \mathrm{Si}$
$\mathrm{P} 2$ : Si
P3: Si
P4: Si

P5: Si

P6: Si

$\mathrm{P7}: \mathrm{Si}$

P8: Si

9. ¿Usted lo tomaría como una opción entre sus alternativas de fast food?
$\mathrm{P} 1: \mathrm{Si}$
$\mathrm{P} 2: \mathrm{Si}$
P3: Si
P4: Si

P5: Si

P6: Si

P7: Si

P8: Si

10. ¿Cuánto pagaría por una ración personal?
P1: 15 y 20 soles
P2: 15 soles
P3: 15 soles
$\mathrm{P} 4: 13$ soles
P5:15 soles
P6:12, 13 o 14 soles por tamaño
P7:15 soles

P8: 12 soles (desayuno) y 15 a 20 soles (almuerzo) 
11. ¿Con qué frecuencia asistiría?
P1: Dos veces a la semana
P2: Una vez a la semana
P3: Tres veces a la semana
P4: Dos veces a la semana
P5: Cinco veces a la semana
P6: Diario
P7: Diario
P8: Diario

12. ¿Le gusta el nombre HEALTHY CORNER o preferiría otro nombre para el establecimiento? ¿Preferiría que el nombre sea en inglés o en español?

P1: Si me gusta, prefiero el nombre en español

P2: Si me gusta, prefiero el nombre en español

P3: No me gusta, prefiero el nombre en español

P4: No me gusta, prefiero el nombre en inglés

P5: No me gusta, prefiero el nombre en español

P6: Si me gusta, prefiero el nombre en quechua

P7: Si me gusta, prefiero el nombre en español o quechua

P8: No me gusta, prefiero el nombre en inglés

13. ¿Dónde le gustaría que se promocione el concepto?

P1: Redes sociales, periódico o panel publicitario

P2: Panel publicitario, televisión y redes sociales

P3: Redes sociales

P4: Redes sociales y folletos (menú)

P5: Redes sociales y paneles publicitarios

P6: Redes sociales, paneles publicitarios y boletines

P7: Redes sociales y paneles publicitarios

P8: Redes sociales y paneles publicitarios cerca de universidades, gimnasios u oficinas 


\section{ANEXO 4: TRANSCRIPCIÓN DE FOCUS GROUP N²}

\section{GUÍA DE INDAGACIÓN \\ FOCUS GROUP Nº2 "Personas del NSE C"}

\section{b. Introducción}

Buenos días, mi nombre es Gianina Cabrera y mi compañera Ivanna Pisfil. La finalidad de esta reunión es para tratar algunos temas de interés en la cual cada uno puede expresar libremente sus opiniones. Les informo que serán grabados sólo para la facilidad del recojo de información, y recuerden que ninguna de sus respuestas estará equivocada sino al contrario todas sus opiniones serán válidas y de gran ayuda para el propósito de la investigación. A continuación, me gustaría que se presente, brindando su nombre y ocupación.

P1: Mi nombre es Carmen y soy ama de casa

P2: Mi nombre es Patricia y soy ama de casa

P3: Mi nombre es Cynthia y soy ama de casa

P4: Mi nombre es Wilber y soy militar en retiro

P5: Mi nombre es Julio y soy empleado

P6: Mi nombre es Endira y soy ama de casa

P7: Mi nombre es Doris y soy ama de casa

P8: Mi nombre es Luis y soy militar en retiro

\section{c. Calentamiento:}

Empecemos hablando de las tres comidas diarias, desayuno, almuerzo y cena:

1. ¿Suele consumir las tres comidas?
$\mathrm{P} 1: \mathrm{Si}$
P2: No
P3: Si
P4: Si

P5: No

P6: Si

P7: No

P8: Si 
2. ¿En dónde suele consumir sus comidas, en casa o fuera de casa?
P1: En casa
P2: En casa
P3: En casa
P4: En casa
P5: En casa
P6: En casa
P7: En casa
P8: En casa, a veces fuera

3. Si es en casa ¿Qué suele consumir?

P1: Comida de casa

P2: Comida criolla

P3: Comida casera

P4: Comida de casa a base de pollo y pescado

P5: Comida casera

P6: Comida casera

P7: Comida de casa

P8: Comida casera

4. Si es fuera de casa ¿A qué sitios suele acudir? ¿Qué ordena? ¿Con qué frecuencia?

P1: Chifa, tallarines o chaufa dos veces al mes

P2: Pollería o chifa, pollo al abrasa o chaufa dos veces al mes

P3: KFC, elige combo una vez a la semana

P4: Popeye's, elige un combo una vez a la semana

P5: Chifa, una vez a la semana

P6: Popeye's o KFC, dos veces a la semana

P7: KFC, una vez al mes

P8: Pollería, KFC, pizza, tres veces a la semana

5. ¿Ha acudido a algún fast food en los últimos 30 días?
$\mathrm{P} 1: \mathrm{Si}$
$\mathrm{P} 2$ : Si
P3: Si
P4: Si
P5: Si
P6: Si
P7: Si
P8: Si

c. Preguntas de profundidad:

\section{1. ¿Qué entiende por fast food o comida rápida?}

P1: Lugar donde se acude para consumir comida al paso

P2: Lugar donde encuentras comida rica en grasa

P3: Lugar donde hay comida poco saludable

P4: Lugar donde hay comida no saludable 
P5: Lugar donde puedes comer de manera rápida

P6: Lugar donde venden comida al paso

P7: Lugar donde venden comida al paso

P8: Lugar donde venden comida poco saludable

2. ¿Cuál es su opinión con respecto a la comida rápida o fast food?
P1: Rica y poco saludable
P2: Mucha grasa
P3: Es poco saludable
P4: Mucha fritura
P5: Grasa
P6: Contiene grasa saturada
P7: Mucha grasa
P8: Mucha fritura

3. ¿Qué fast food conoce?
P1: KFC, pizza, chifa
P2: Popeye's, Bembos, chifa, pizza
P3: Chifa, Bembos
P4: Popeye’s, KFC, pollerías
P5: Chifa, Burger King
P6: Popeyes, chifa, KFC
P7: Pizza Hut, KFC
P8: Pizza Hut, Bembos, Burger King, pollerías, chifa

4. ¿Cuál es su preferido o a cuál acude la mayoría de las veces? ¿Por qué? ¿Influye el precio?

P1: KFC, porque sirven gran cantidad de comida y si influye el precio

P2: Popeye's, porque tiene buenas promociones y si influye el precio

P3: Bembos, porque a mis hijos les gusta y si influye el precio

P4: Popeye's, porque hay promociones y si influye el precio

P5: Burger King, porque hay promociones y si influye el precio

P6: Pizza Hut, porque es agradable y si influye el precio

P7: Pizza Hut, porque nos gusta a toda la familia y si influye el precio

P8: Pizza Hut, porque es lo menos condimentado y si influye el precio 
5. ¿En qué momento del día acude a un fast food?

P1: Cena

P2: Almuerzo y cena

P3: Almuerzo y cena

P4: Almuerzo

P5: Almuerzo y cena

P6: Almuerzo y cena

P7: Almuerzo y cena P8: Almuerzo

6. ¿Con quiénes suele acudir a estos centros de comida rápida, solos, con la familia, con los amigos?

P1: Familia y amigos $\quad$ P2: Familia y amigos $\quad$ P3: Familia y amigos

P4: Familia P5: Solo P6: Familia

P7: Familia $\quad$ P8: Familia

7. ¿Entre comer en casa e ir a un fast food, cuál prefiere? ¿Qué diferencias encuentra? ¿Cree que la comida rápida puede afectar su salud? ¿Por qué?

P1: Prefiere comida de casa es más saludable y el fast food no es saludable

P2: Prefiere comida de casa es más agradable y el fast food es grasoso

P3: Prefiere comida de casa es mejor y el fast food tiene mucha grasa P4:

Prefiere comida de casa es saludable y el fast food afecta a la salud P5:

Prefiere comida de casa es saludable y el fast food trae enfermedades P6:

Prefiere comida de casa es mejor y el fast food tiene mucha grasa

P7: Prefiere comida de casa es saludable y sabroso y el fast food es rico, pero afecta a la salud

P8: Prefiere comida de casa es saludable y el fast food contiene muchas grasas

8. ¿Qué entiende usted por “comida saludable”?

P1: Es alimentación balanceada

P2: Contiene nutrientes y se encuentra en las verduras, menestras, etc.

P3: Es comida saludable y no tiene mucha grasa

P4: Es comida baja en grasa 
P5: Es comida con bajo aderezo

P6: Es comida con bajos aderezos

P7: Es comida balanceada y se encuentra en las verduras frescas y pescados

P8: Es comida balanceada

\section{d. Prueba de concepto:}

A continuación, les explicaré un concepto para que me den su opinión.

La propuesta de fast food saludable, ofrece al consumidor en Lima Moderna una alternativa de tener rápido acceso a consumir bebidas y platos agradables teniendo conocimiento del valor calórico y nutricional que estos aportan y a un precio acorde al mercado, favoreciendo la salud y necesidades del consumidor.

El único local estará estratégicamente ubicado en el patio de comidas del Centro Comercial Jockey Plaza en el distrito de Santiago de Surco. El horario de atención al público será de lunes a domingo desde las 10:00 horas hasta las 23:00 horas.

Se ofrecerá una carta elaborada por la o el nutricionista y la o el chef, la cual tiene una variedad y nuevas opciones de bebidas y platos agradables, atractivos y sobre todo saludables, ya que son productos a base de alimentos $100 \%$ naturales, orgánicos y productos elaborados libres de gluten y/o azúcares refinados como las verduras, hortalizas, frutas frescas, zumos, alimentos de origen animal y/o vegetal, entre otros. Adicional a la carta, se ofrecerá postres veganos, integrales y orgánicos, de Vegánimo, empresa socia y comprometida con la salud y el medio ambiente.

1. ¿Qué opina/piensa de este concepto que les acabo de describir?
P1: Bueno
P2: Buena opción
P3: Excelente
P4: Buen proyecto
P5: Bueno
P6: Buen proyecto
P7: Bien
P8: Buena opción

2. ¿Es bueno, malo?
P1: Bueno
P2: Muy Bueno
P3: Bueno
P4: Bueno 

P5: Bueno
P6: Bueno
P7: Bueno
P8: Bueno

3. ¿Qué le gusta, que no le gusta? ¿Por qué?

P1: Si me gusta, es una buena opción de comida rápida saludable

P2: Si me gusta, podemos comer comida saludable

P3: Me gusta, es saludable

P4: Si me gusta, es saludable y evitamos enfermedades

P5: Me gusta, es comida sana

P6: Me gusta, es una alternativa sana

P7: Me gusta, es una opción de comida sana

P8: Es una buena opción de comida

4. ¿Ha escuchado algún concepto como éste?
P1: No
P2: No
P3: No
P4: No
P5: No
P6: No
P7: No
P8: No

5. ¿Usted asistiría a un sitio como éste? ¿Por qué?

$\mathrm{P} 1$ : $\mathrm{Si}$, porque no cocino y es comida sana $\quad \mathrm{P} 2$ : $\mathrm{Si}$, porque es rápido y sano

P3: Si, es una opción más saludable

P4: Si, por la comida que es saludable P5:

$\mathrm{Si}$, porque es saludable

P6: $\mathrm{Si}$, porque es sana, rápido y no cocino

P7: Si, porque es comida sana y rápida

P8: Si, porque es saludable

6. ¿Con quiénes asistiría?
P1: Familia
P2: Familia
P3: Amigos
P4: Familia
P5: Solo
P6: Familia
P7: Familia
P8: Familia

7. ¿En qué horario asistiría, desayuno, almuerzo o cena?
P1: Almuerzo
P2: Almuerzo
P3: Desayuno y almuerzo
P4: Almuerzo
P5: Almuerzo cena
P6: Desayuno y almuerzo
P7: Almuerzo
P8: Almuerzo 
8. ¿Les gustaría que en este servicio que les acabo de describir, hubiese servicio de delivery?

$\begin{array}{llll}\mathrm{P} 1: \mathrm{Si} & \mathrm{P} 2: \mathrm{Si} & \mathrm{P} 3: \mathrm{Si} & \mathrm{P} 4: \mathrm{Si}\end{array}$

$\begin{array}{llll}\text { P5: } \mathrm{Si} & \text { P6: } \mathrm{Si} & \text { P7: } \mathrm{Si} & \text { P8: } \mathrm{Si}\end{array}$

9. ¿Usted lo tomaría como una opción entre sus alternativas de fast food?
$\mathrm{P} 1: \mathrm{Si}$
$\mathrm{P} 2: \mathrm{Si}$
P3: Si
P4: Si

P5: Si

P6: Si

P7: Si

P8: Si

10. ¿Cuánto pagaría por una ración personal?
P1: 10 soles
P2: 10 soles
P3: 12 a 15 soles
$\mathrm{P} 4: 10$ a 15 soles
P5: 15 soles
P6: 12 soles
$\mathrm{P} 7: 10$ a 15 soles
P8: 15 a 20 soles

11. ¿Con qué frecuencia asistiría?

P1: Tres veces a la semana

P2: Dos veces a la semana

P3: Diario

P4: Dos veces a la semana

P5: Dos veces a la semana

P6: Fin de semana

P7: Fin de semana

P8: Fin de semana

12. ¿Les gusta el nombre HEALTHY CORNER o preferiría otro nombre para el establecimiento? ¿Preferiría que el nombre sea en inglés o en español?

P1: Si me gusta, prefiero el nombre en inglés

P2: Si me gusta, prefiero el nombre en español

P3: Si me gusta, prefiero el nombre en español

P4: No me gusta, prefiero el nombre en quechua

P5: Si me gusta, prefiero el nombre en español

P6: Si me gusta, prefiero el nombre en español

P7: Si me gusta, prefiero el nombre en español

P8: Si me gusta, prefiero el nombre en español 
13. ¿Dónde le gustaría que se promocione el concepto?

P1: Centros Comerciales

P3: Redes sociales

P5: Supermercados

P7: Televisión
P2: Televisión y radio

P4: Televisión

P6: Hospitales

P8: Centros Comerciales

Muchas gracias por su tiempo. Se les pide que se acerquen al coffe break. 
ANEXO 5: EVIDENCIA FOTOGRÁFICA DE FOCUS GROUP
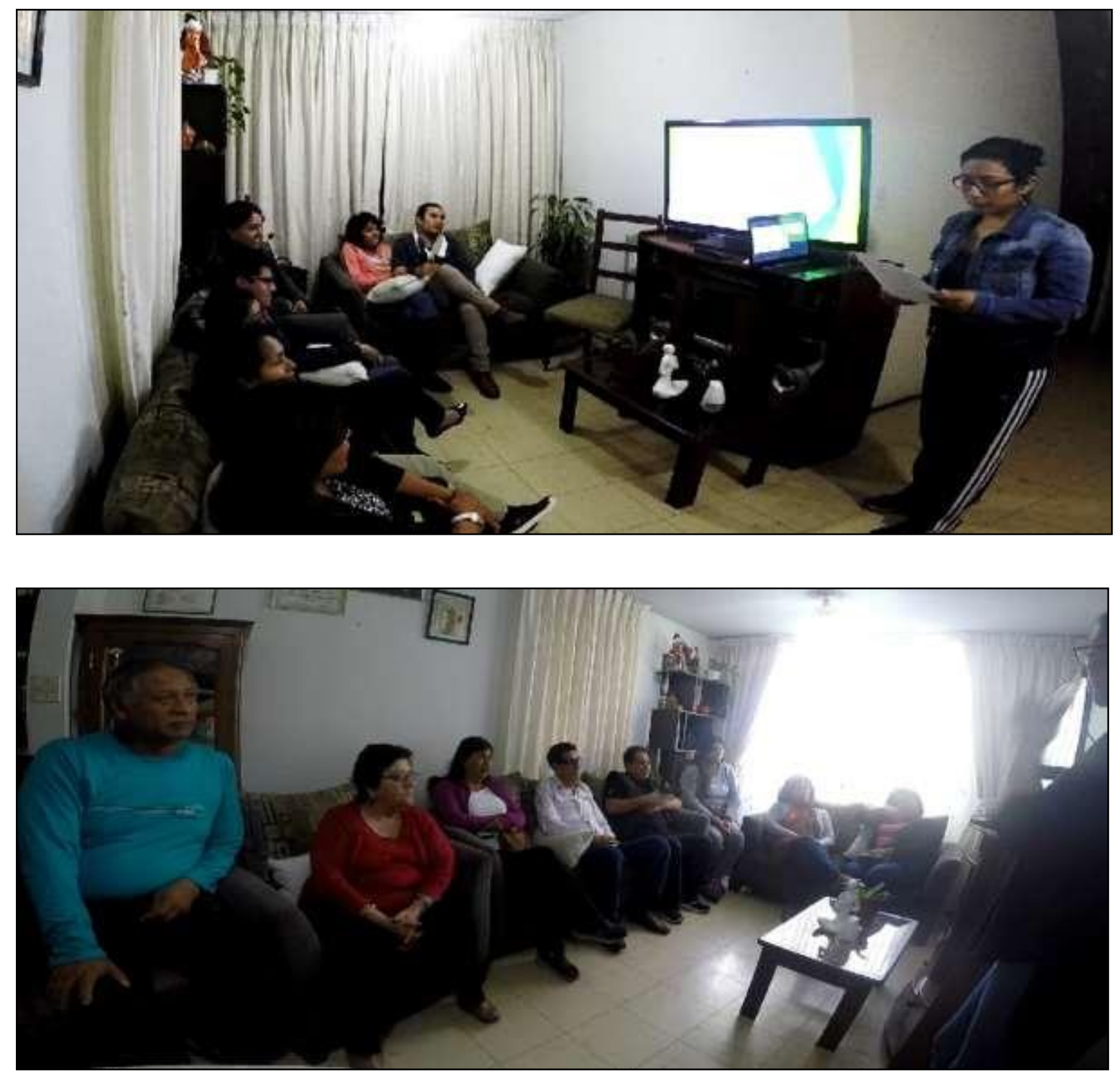


\section{ANEXO 6: FICHA NIVEL SOCIOECONÓMICO}

\section{DETERMINACIÓN DEL NSE}

Sr. / Sra. / Joven, Con la finalidad de agrupar sus respuestas con las de otras personas de similares características a las de usted, nos gustaría que responda a las siguientes preguntas.

1. ¿Quién es la persona que aporta MÁS al sostenimiento económico de su hogar? (E: 1. Si identifica a dos personas o más, preguntar por la de mayor edad. 2. Si la persona que más aporta no vive en el hogar, preguntar por la que administra los ingresos que recibe de la persona ausente.)

2. Las siguientes preguntas se refieren a... que es la persona que aporta MÁS al sostenimiento de su hogar (E:según pregunta 1)

3. ¿Cuál es el grado de instrucción alcanzado por...? (E: mencione a la persona que aporta más al sostenimiento de su hogar, según pregunta 1 , circular el grado de instrucción y puntaje)

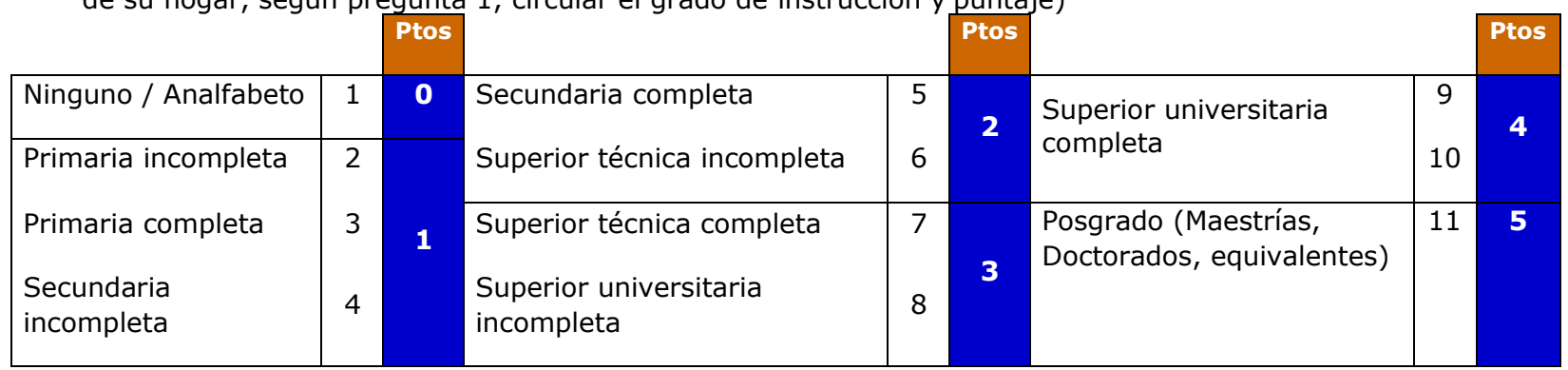

4. Ante una consulta médica, ¿en qué tipo de establecimiento de salud se atiende la persona que aporta más al sostenimiento económico de su hogar?

\begin{tabular}{|l|c|}
\hline Posta médica/ farmacia/ naturista & 1 \\
\hline Hospital del Ministerio de Salud/ Hospital de la Solidaridad & $\mathbf{1}$ \\
\hline Seguro Social/ Hospital FF.AA./ Hospital de Policía & $\mathbf{2}$ \\
\hline Médico particular en consultorio & $\mathbf{3}$ \\
\hline Médico particular en clínica privada & 4 \\
\hline
\end{tabular}

5. Tiene en su hogar... (LEER), o no?

\begin{tabular}{l|c|c|}
\hline Lavadora de ropa en buen estado, es decir que funcione & 1 & 2 \\
Refrigeradora en buen estado, es decir, que funcione & 1 & 2 \\
Cocina en buen estado, es decir, que funcione & 1 & 2 \\
Computadora & 1 & 2 \\
Teléfono fijo & 1 & 2 \\
\hline
\end{tabular}

\begin{tabular}{|l|c|}
\hline Bienes y servicios: & Ptos \\
\hline Cero & $\mathbf{0}$ \\
\hline Uno & $\mathbf{1}$ \\
\hline Dos & $\mathbf{2}$ \\
\hline Tres & $\mathbf{3}$ \\
\hline Cuatro & $\mathbf{4}$ \\
\hline Cinco & $\mathbf{5}$ \\
\hline
\end{tabular}

6. ¿Cuántas personas, incluyéndose usted pero sin incluir al personal de servicio, viven en su hogar?

\begin{tabular}{|l|r|}
\hline & 6 \\
\hline & 2 \\
\hline
\end{tabular}

\section{Coeficiente}

Nro. Dormitorios/ Nro. de personas

\begin{tabular}{|l|l|}
\hline 0 a 0,19 habitaciones por persona & 1 \\
\hline 0,2 a 0,32 habitaciones por persona & 2 \\
\hline
\end{tabular}


7. ¿Cuántas habitaciones/ dormitorios exclusivos para dormir tiene dentro de su hogar o no tiene ninguno? (MARCAR "CERO" SI NO TIENE)

\section{(E: PARA ASIGNAR EL PUNTAJE DEBE DIVIDIR EL NÚMERO DE HABITACIONES EXCLUSIVAS PA DORMIR/ EL NÚMERO DE PERSONAS QUE VIVEN EL HOGAR (NO SERVICIO DOMÉSTICO)}

8. De esta lista, ¿cuál es el material predominante en los pisos de su vivienda? (MOSTRAR TARJETA No. 2)

\begin{tabular}{|l|c|c|l|c|}
\cline { 2 - 5 } $\begin{array}{l}\text { Tierra/ arena/ tablones sin } \\
\text { pulir (selva) }\end{array}$ & 1 & $\mathbf{1}$ & Mayólica/ loseta/ mosaico/ vinílico y cerámicos & Ptos \\
\hline Cemento sin pulir. & 2 & $\mathbf{2}$ & & $\mathbf{4}$ \\
\hline $\begin{array}{l}\text { Cemento pulido/ tapizón/ } \\
\text { tablones (costa y sierra) }\end{array}$ & 3 & $\mathbf{3}$ & $\begin{array}{l}\text { Parquet/ madera pulida/ alfombra/ laminado tipo } \\
\text { madera/ mármol/ terrazo }\end{array}$ & 5 \\
\hline
\end{tabular}

\begin{tabular}{|c|c|c|c|c|c|c|c|c|c|c|c|c|c|}
\hline Puntaje & & NSE & Puntaje & & NSE & & Puntaje & & NSE & & Puntaje & NS & \\
\hline $25-24$ & $\mathrm{~A} 1$ & & $20-19$ & B1 & & & $15-14$ & C1 & & & 10- 6 & D & 04 \\
\hline $23-21$ & $\mathrm{~A} 2$ & & $18-16$ & B2 & & & $13-11$ & C2 & & & Hasta 5 & 틀 & 05 \\
\hline
\end{tabular}

Notas:

- Si el principal sostén económico no trabaja, la variable OCUPACIÓN deberá ser reemplazada por el puntaje correspondiente a la variable EDUCACIÓN restándole 1 punto, no considerar puntaje negativo, el menor puntaje es cero (0).

- La ocupación corresponde a aquella que el entrevistado declara espontáneamente y al mostrarle la tarjeta.

- Se considera tenencia de servicio doméstico, cuando por lo menos el personal trabaja 4 horas a la semana y 16 horas al mes, $\mathrm{n}$ o interesa el número de días.

- El número de baños corresponde al total de baños dentro de la vivienda, incluidos los baños de servicio.

- Cuando la vivienda corresponde a un cuarto alquilado en una casa, donde se comparte el baño, la cantidad de baños es igual a 1 (puntaje $=2$ ).

- Cuando la vivienda está ubicada en un callejón o solar, con baño afuera, el número de baños es igual a 0 (puntaje = 1 ).

- Si la vivienda es multihogar, considerar para la evaluación de pisos TODA la vivienda, así el hogar encuestado ocupe una parte.

Fuente: Perfiles Consultoría 
DATOS DE CONTROL

1) Género: 2) Distrito de procedencia:

3) Completar ficha de NSE

\section{ENCUESTA}

Buen día, Soy estudiante de la Maestría de Gestión de Negocios de Salud y Nutrición de la Universidad San Ignacio de Loyola y estoy realizando una encuesta para conocer su opinión sobre un nuevo proyecto. Podría concederme unos 10 minutos, la información es confidencial. Muchas gracias. Marcar con una "X”, siga las instrucciones.

\section{I.- PREGUNTAS FILTRO}

1. ¿Cuál es su rango de edad?
a) $\leq 20$ años (Fin de la Encuesta)
b) 21 a 35 años
c) 36 a 59 años
d) $>60$ años (Fin de la Encuesta)

2. ¿Ha comido fuera de casa en los últimos 30 días?
a) $\mathrm{Si}$
b) No (Fin de la Encuesta)

3. ¿Cuál es el motivo por el cual usted come en un fast food? (Marque una opción)
a) Por gusto
b) Por falta de tiempo

4. ¿A qué patio de comida acude con más frecuencia? (Marque una opción)
a) Open Plaza Angamos
b) Real Plaza Salaverry
c) Food Court - Begonias
d) Jockey Plaza
e) Plaza San Miguel
f) Real Plaza Primavera

5. ¿Cuáles son los principales atributos que usted busca en un fast food? (Puede marcar hasta tres opciones)
a) Buen sabor
b) Variedad de menú
c) Horario de atención
d) Rapidez en la entrega del producto
e) Facilidad en el tipo de pago (uso de tarjetas de crédito, cambio en efectivo)
f) Precios económicos
g) Que realicen promociones
h) Buen ambiente 
6. Marcar con un aspa en el cuadro correspondiente la frecuencia de consumo de los siguientes fast food:

\begin{tabular}{|l|c|c|c|l|}
\hline Fast food Frecuencia & $\begin{array}{c}\text { Muy } \\
\text { frecuente }\end{array}$ & $\begin{array}{c}\text { Poco } \\
\text { frecuente }\end{array}$ & $\begin{array}{c}\text { Pocas } \\
\text { veces }\end{array}$ & Nunca \\
\hline China wok & & & & \\
\hline Bembos & & & & \\
\hline Pizza Hut & & & & \\
\hline KFC & & & & \\
\hline Burger King & & & & \\
\hline Otto Grill & & & & \\
\hline McDonald & & & & \\
\hline Popeye's & & & & \\
\hline
\end{tabular}

\section{PREGUNTAS PRUEBA DE CONCEPTO}

Fast food de comida saludable, que ofrece al ciudadano limeño una alternativa rápida de platos ricos y nutritivos, que pueden incorporarse a una dieta balanceada, favoreciendo la salud del consumidor. La carta es elaborada por chef y nutricionista que ofrecen una gran variedad de platos atractivos y saludables en la modalidad de raciones individuales y por combos.

1. ¿Qué le parece la idea?
a) Muy Bueno
b) Bueno
c) Ni bueno ni malo
d) Malo
e) Muy malo

2. ¿Conoce o ha escuchado hablar de algún servicio similar al concepto presentado?
a) Sí, Menciónelo
b) No

3. ¿Cuál es la opción que más se ajusta a su intención de compra en este servicio?
a) Definitivamente compraría
b) Probablemente compraría
c) Puede ser que sí o no compraría
e) Probablemente no compraría
f) Definitivamente no compraría

4. ¿Con qué frecuencia acudiría a consumir a este servicio? (Marque una opción)
a) Casi diariamente
b) Dos o tres veces a la semana
c) Una vez a la semana
d) Una vez cada dos semanas
e) Una vez al mes

5. ¿A cuál de los dos principales horarios asistiría? (Marque una opción)
a) Almuerzo
b) Cena 
6. ¿Usted que preferiría
a) Comer en el local
b) Take out (para llevar)

7. ¿Qué modalidad de pago prefiere?
a) Efectivo
b) Tarjeta débito
c)Tarjeta de crédito
d) Vale o cupones

8. ¿Cuál es el monto personal tope de consumo?
a) Menor de 20 soles
b) $21 \mathrm{a} 35$ soles
c)35 a 50 años
d) Mayor de 50 soles

9. ¿Qué nombre le va bien al fast food saludable? (Marque una opción)
a) Healthy corner
b) Rincón saludable
c) K’Uchu Q’Umara

10. ¿Por qué medio le gustaría enterarse del fast food saludable? (Puede marcar varias opciones)
a) Redes sociales
b) Paneles publicitarios
c) Televisión
d) Radio
e) Periódicos
f) Revistas 


\section{BIBLIOGRAFÍA}

1) Arbaiza, Lydia; Cánepa, Marco; Cortéz, Oscar y Lévano, Gabriel (2014). Análisis prospectivo del sector de comida rápida en Lima: 2014-2030. Universidad ESAN, Lima, Perú.

2) Carrillo Carrillo, Luis M. (2014). Plan de negocios para una red de locales de comida rápida saludable en Guadalajara, Jalisco, México. (Tesis de maestría inédita). Universidad de Chile, Santiago de Chile, Chile.

3) Castillo Sandoval, Laura (2014). Plan de negocios para la puesta en marcha de un fast food saludable en la ciudad de Piura. Universidad de Piura, Piura, Perú.

4) Cepeda, Lorena y Javier, Carlos. (2006). Estudio de pre factibilidad para la implementación de una cadena de comidas rápidas en base a pollo en Lima Norte. Universidad Pontificia Católica del Perú, Lima, Perú.

5) Diez Canseco Terry, Raúl (2015). El Arte de Emprender. 6ta Edición. Editorial Universidad San Ignacio de Loyola, Lima, Perú.

6) Jeffery, Robert W; Baxter, Judy; McGuire, Maureen; Linde, Jennifer (2006). Are fast food restaurants an environmental risk factor of obesity? International Journal of Behavioral Nutrition \& Activit Físical.

7) Mahan, L.K., Escott- Stump, S. \& Raymond, J.L. (2013). Krause Dietoterapia. 13a Edición. Editorial Elsevier, España.

8) Molíni Cabrera, Ma. Dolores (2007). Repercusiones de la comida rápida en la sociedad. Sevilla, España.

9) Robinson, T.N., Dina, L. G., Borzekowski, EdD., Matheson, D.M. y Kraemer H.C. (2007). Effects of fast food branding on young children's taste preferences. Arch. Pediatric Adolescent Med. 


\section{REFERENCIAS ELECTRÓNICAS}

10) América Económica (2015). Nota de Análisis \& Opinión: Estabilidad política y económica en Perú. Recuperado de http://www.americaeconomia.com/economiamercados/comercio/estabilidad-politica-y-economica-en-peru

11) Diario de Economía y Negocios del Perú “Gestión” (2016). Nota de Radiografía de la vida sana: el perfil del peruano saludable. Recuperado de http://gestion.pe/tendencias/radiografia-vida-sana-perfil-peruano-saludable2160143

12) Diario de Economía y Negocios del Perú “Gestión” (2016). Nota de peruanos pagan más por productos saludables en la región. Recuperado de http://gestion.pe/noticia/1377316/peruanos-pagan-mas-productos-saludablesregion

13) Diario El Comercio (2016). Nota de Economía: Más de 6 millones de mujeres peruanas trabajan fuera del hogar. Recuperado de http://elcomercio.pe/economia/peru/mas-6-millones-mujeres-peruanas-trabajanfuera-hogar-noticia-1884608

14) Diario El Peruano (2013). Artículo sobre Ley de Promoción de la Alimentación Saludable. Recuperado de http://www.elperuano.com.pe/NormasElperuano/2015/04/18/1226479-6.html

15) Diario La República (2012), Articulo los tres centros comerciales con la mayor facturación anual en el Perú. Recuperado de http://larepublica.pe/12-102012/los-tres-centros-comerciales-con-la-mayor-facturacion-anual-en-el-peru

16) EAE Business School - USA (2011). Documento El consumo de comida rápida, Situación en el mundo y acercamiento autonómico. Recuperado de http://www.abc.es/gestordocumental/uploads/Sociedad/comida-rapida.pdf 
17) Instituto Nacional de Estadística e Informática (2014). Documento "Perú: Enfermedades No Trasmisibles y Trasmisibles, 2014”. Recuperado de https://www.inei.gob.pe/media/MenuRecursivo/publicaciones_digitales/Est/Lib 1212/Libro.pdf

18) Instituto Nacional de Estadística e Informática (2015). Documento "Perú:

Enfermedades No Trasmisibles y Trasmisibles, 2015”. Recuperado de https://www.inei.gob.pe/media/MenuRecursivo/publicaciones_digitales/Est/Lib 1357/index.html

19) Instituto Nacional de Estadística e Informática INEI. (2016). Informe Técnico de $\begin{array}{lll}\text { Producción Nacional. } & \text { Recuperado de }\end{array}$ https://www.inei.gob.pe/media/menurecursivo/boletines/informe-tecnicon04_produccion_feb2016.pdf

20) IPSOS APOYO (2015). Perfiles zonales de Lima Metropolitana. Recuperado de http://www.ipsos.pe/sites/default/files/marketing_data/Perfiles\%20LM\%20\%28 4\%29.pdf

21) IPSOS APOYO (2016). Perfiles zonales de Lima Metropolitana. Recuperado de http://www.ipsos.pe/Perfiles_Zonales_2016

22) IPSOS PERU (2016). Nota de Tendencias del Mercado. Recuperado de http://www.ipsos.pe/tendencias_mercado?page=2

23) National Geographic (2009). Artículo Restaurantes sin camareros. Recuperado de http://www.nationalgeographic.com.es/fotografia/flashback?_page=

24) Plan de gobierno de PPK (2016 - 2021). Recuperado de http://ppk.pe/documentos/plandegobierno.pdf 
25) Superintendencia Nacional de Aduanas y Administración Tributaria - SUNAT (2017). ¿Cómo me inscribo en el RUC? Recuperado de http://emprender.sunat.gob.pe/como-me-inscribo-en-el-ruc

26) Universidad de Piura - Escuela de Dirección. (2000). Perfil del consumidor peruano. Recuperado de https://es.scribd.com/doc/57344247/Perfil-consumidorperuano. 
$\overline{2}$ 